University of Louisville

ThinkIR: The University of Louisville's Institutional Repository

Electronic Theses and Dissertations

$12-2013$

\title{
Success on their own terms : youths' perspectives on what it means to be successful in foster care.
}

Justin Miller

University of Louisville

Follow this and additional works at: https://ir.library.louisville.edu/etd

\section{Recommended Citation}

Miller, Justin, "Success on their own terms : youths' perspectives on what it means to be successful in foster care." (2013). Electronic Theses and Dissertations. Paper 982.

https://doi.org/10.18297/etd/982

This Doctoral Dissertation is brought to you for free and open access by ThinkIR: The University of Louisville's Institutional Repository. It has been accepted for inclusion in Electronic Theses and Dissertations by an authorized administrator of ThinkIR: The University of Louisville's Institutional Repository. This title appears here courtesy of the author, who has retained all other copyrights. For more information, please contact thinkir@louisville.edu. 


\title{
SUCCESS ON THEIR OWN TERMS:
}

YOUTHS' PERSPECTIVES ON WHAT IT MEANS TO BE SUCCESSFUL IN

FOSTER CARE

\author{
By \\ Justin "Jay" Miller \\ B.S., Western Kentucky University, 2003 \\ M.S.W, Spalding University, 2007
}

\begin{abstract}
A Dissertation
Submitted to the Faculty of the in Partial Fulfillment of the Requirements

for the degree of

Doctor of Philosophy

Kent School of Social Work

University of Louisville

Louisville, KY
\end{abstract}

Raymond A. Kent School of Social Work of the University of Louisville

December 2013 

SUCCESS ON THEIR OWN TERMS:

YOUTHS' PERSPECTIVES ON WHAT IT MEANS TO BE SUCCESSFUL IN FOSTER CARE

By

Justin "Jay" Miller

B.S., Western Kentucky University, 2003

M.S.W, Spalding University, 2007

A Dissertation Approved on

October 8, 2013

by the following Dissertation Committee:

Crystal Collins-Camargo, PhD, Chair

Anna Faul, PhD

Tom Lawson, $\mathrm{PhD}$

Karla Washington, $\mathrm{PhD}$

Chris Flaherty, PhD 


\section{DEDICATION}

To Walter and Charlayne, for making this work possible.

To my lovely wife $\mathrm{M}$, for supporting the journey. 


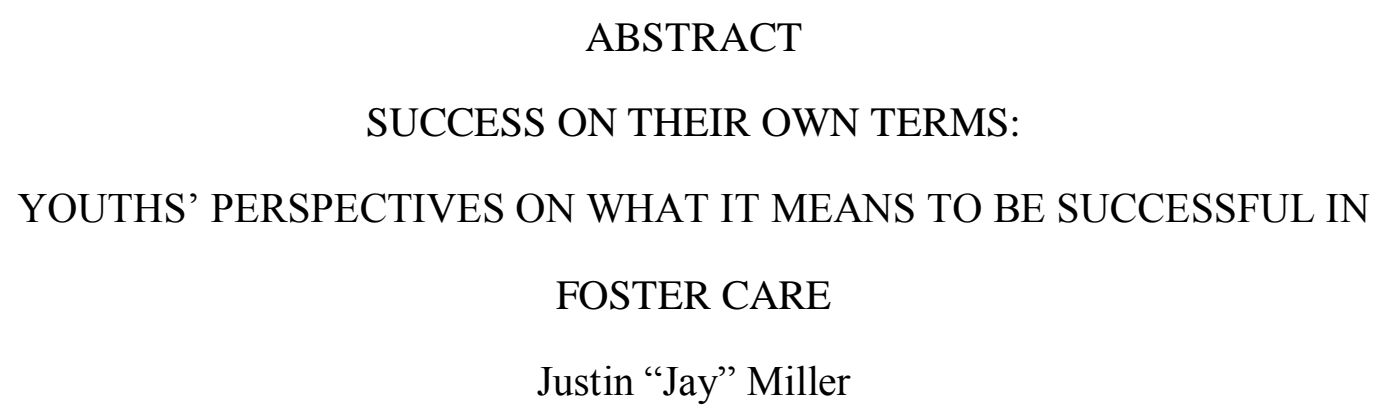

October 8, 2013

Foster care is a fundamental component of the child welfare system.

Traditionally, foster care has been viewed as the primary mechanism for caring for children placed outside of their home, and is considered one of the central intervention strategies for child welfare practitioners. Foster care services are regularly recommended for children who are abused and neglected. In 2011, there were an estimated 401,000 youths in foster care and approximately 646,000 youth were served by the foster care system.

Yet, despite the importance of foster care to child welfare, social work literature in general, and child welfare literature specifically, is devoid of a well-defined, conceptual framework for what success in foster care really means, from the perspective of those most impacted: foster youth. This study delineated a conceptual domain for successful foster care, from the perspective of teens in foster care, and explored differences in this conceptualization, based on maltreatment type. 
Method: This study utilized a sample of youth, currently in foster care in Kentucky and employed a mixed-method approach known as Concept Mapping (CM). CM combines multi-dimensional scaling with hierarchical cluster analyses to form factors relevant to an area of study. This method allowed for foster youth to actively be involved in the study, and is suited to delineate a conceptual framework for defining success in foster care.

Results: Data were analyzed utilizing The Concept Systems ${ }^{\mathrm{TM}}$ proprietary software. Results indicate that teens in foster care conceptualize success based on four distinct clusters: Social Work, Foster Parent(s), Foster Agency, and Foster Youth. Further, based on rating analyses, participants in foster care for abuse (to include physical and sexual), did not conceptualize success differently when compared to youth in foster care for neglect.

Conclusion: This study revealed that success is a complex, multi-faceted construct. Youth in this study conceptualized success based on a number of distinct deas. Stakeholders involved with foster care research, programming, and policy development must take into account this multi-dimensional conceptualization. Further, this study demonstrated that foster youth are able to take part in research studies, and should be involved in foster care research and programming endeavors. 


\section{TABLE OF CONTENTS}

\section{PAGE}

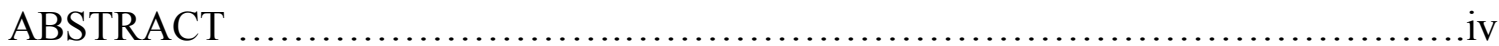

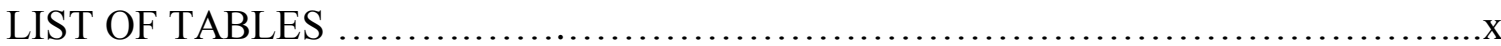

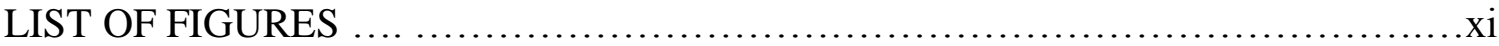

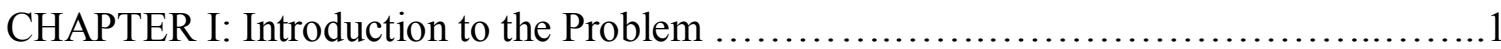

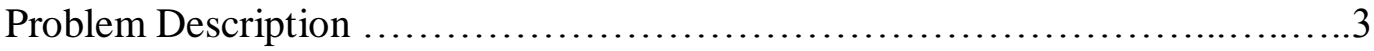

Conceptualizing Success: Defining A Construct ........................

Difficulties Defining Success in Foster Care ...........................4

Measuring Success in Foster Care ....................................8

Impact of Policy on Conceptualizing Success ........................10

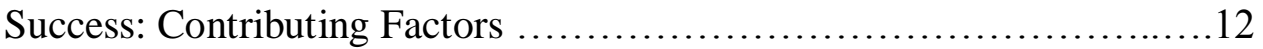

Abuse and Neglect: Pertinent Distinctions ..........................14

The Voice of Youth: A Missing Component .........................16

Significance of the Problem .............................................. 18

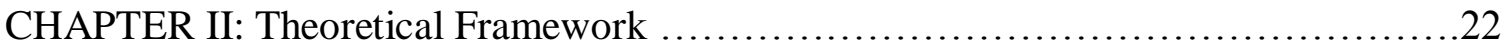

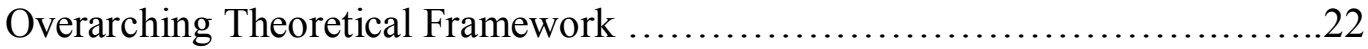

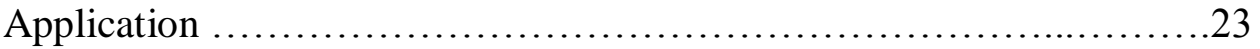

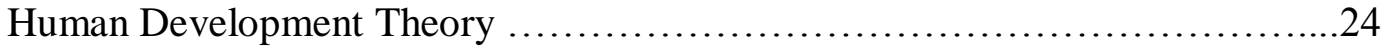

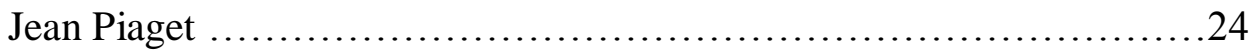

Piaget's Four Stages of Cognitive Development ......................25

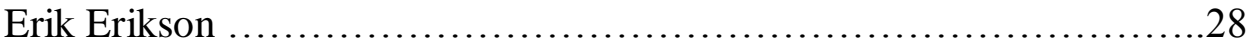


Erikson's Stages of Psychosocial Development .......................28

Human Development, Adolescence, and this Study ............................ 31

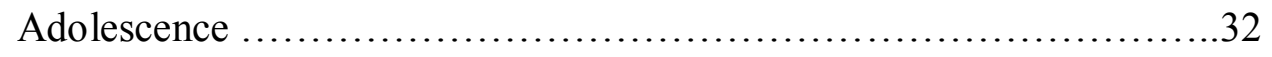

Applying Theory to the Current Study ...............................33

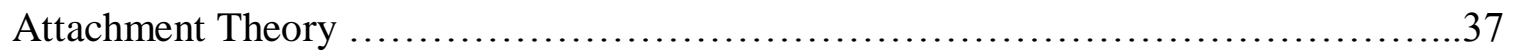

Attachment, Foster Care, and this Study .....................................

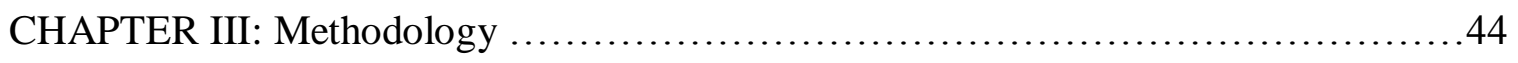

Research Goals .....................................................44

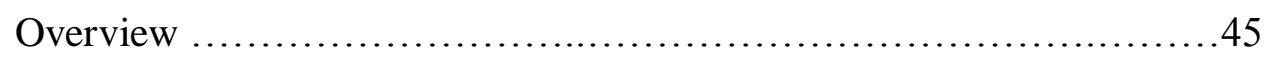

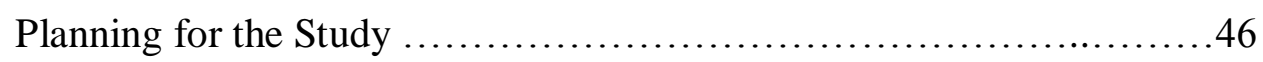

The Foster Care Alumni Advisors...........................47

Focus Prompt........................................47

Sampling and Participants................................48

Scheduling and Logistics................................50

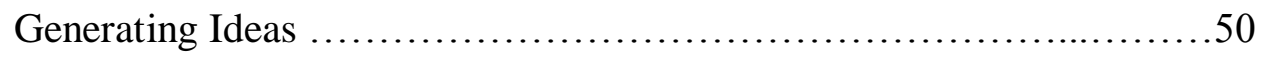

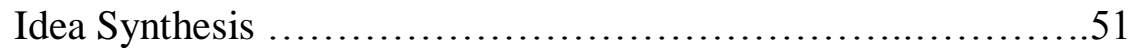

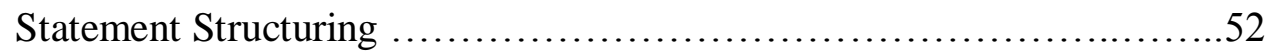

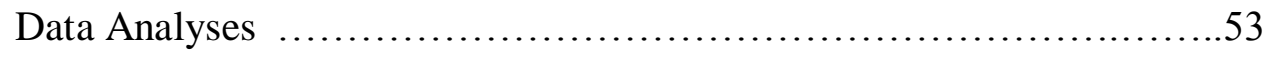

Multidimensional Scaling ................................54

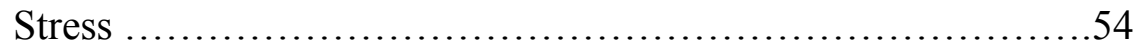

Hierarchical Cluster Analysis ..............................54

Bridging Analysis .....................................55

Finalizing the Cluster Solution .............................55

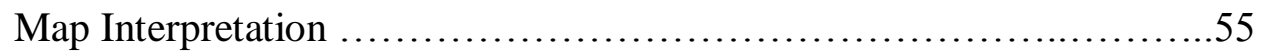

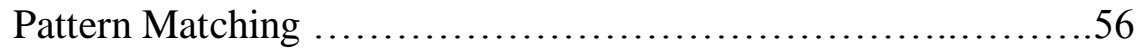

Go-Zone Graphs .........................................56 


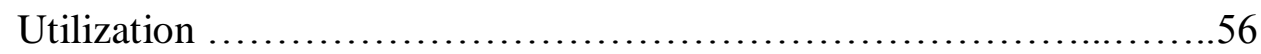

CHAPTER IV: Results .................................................. 58

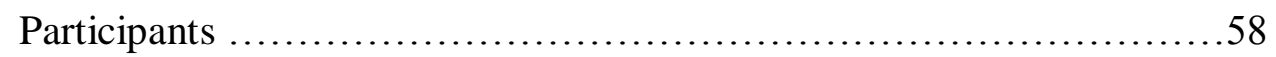

General Information ........................................59

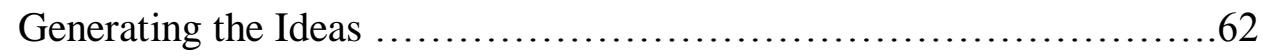

Structuring the Statements ...................................65

CM Analyses ................................................. 70

CM Item and Cluster Ratings Analyses ..........................78

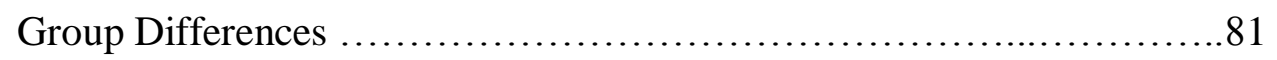

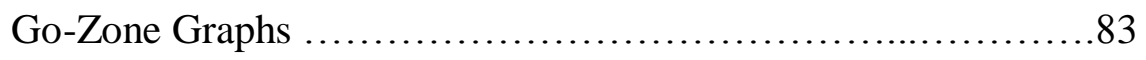

Finalizing the Results ........................................ 89

CHAPTER V: Discussion ..................................................90

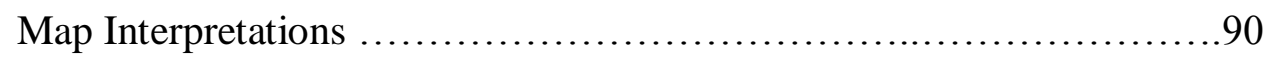

Interpreting Statements: Success .........................91

Interpreting Sorts: Responsibility .........................94

Why Responsibility? .......................................98

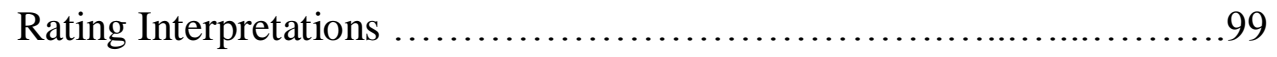

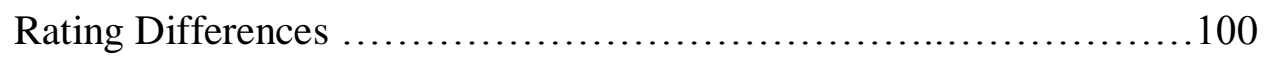

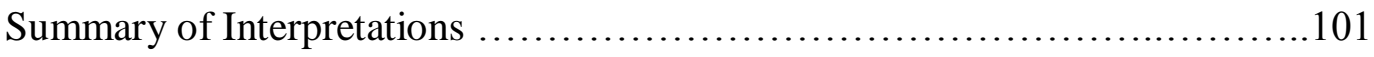

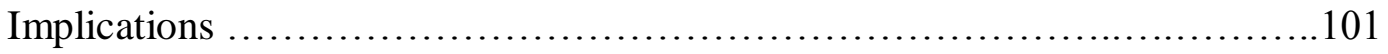

Child Welfare Research ......................................101

Child Welfare Policy and Practice .................................. 104

Child Welfare Education and Training .............................108

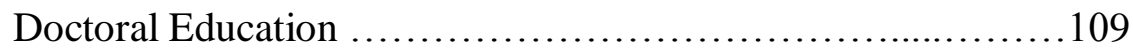

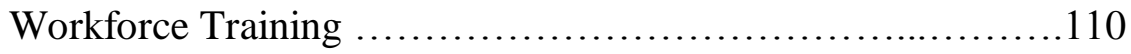

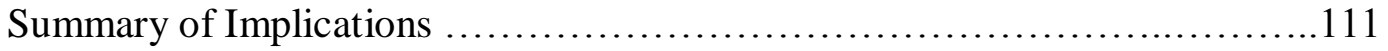




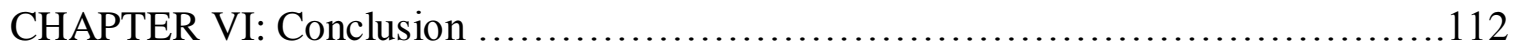

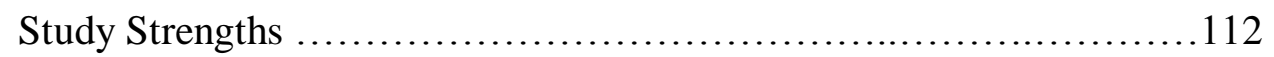

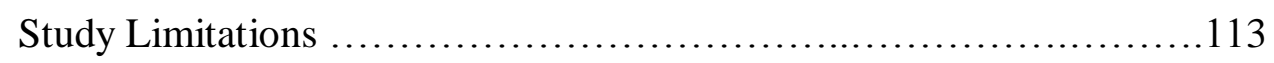

Future Research ............................................115

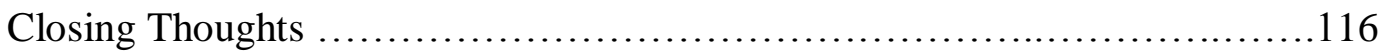

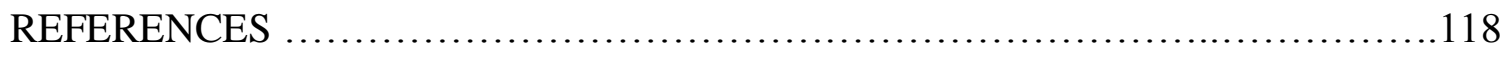

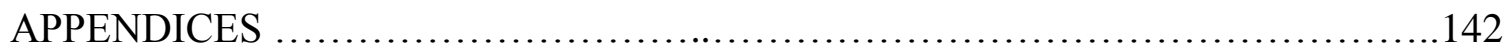

CURRICULUM VITAE .................................................... 145 


\section{LIST OF TABLES}

$\begin{array}{lll}\text { TABLE } & \text { PAGE }\end{array}$

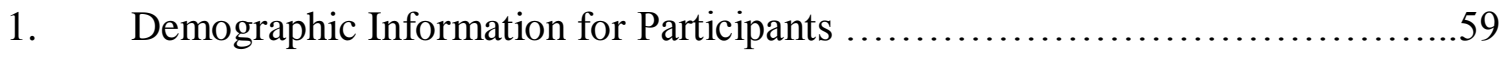

2. General Information about Youth Foster Care Experiences ..................61

3. Frequency Table for Overall Experience Item ...........................62

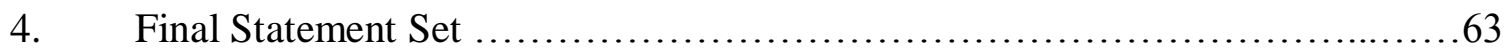

5. Mean Rating by Item............................................ 67

6. Portion of the Overall Similarity Matrix (Illustrative Example) ...............71

7. Clusters, Statements, and Bridging Values ............................... 75 


\section{LIST OF FIGURES}

$\begin{array}{lll}\text { FIGURE } & \text { PAGE }\end{array}$

1. Point Map with Statement Numbers .................................... 72

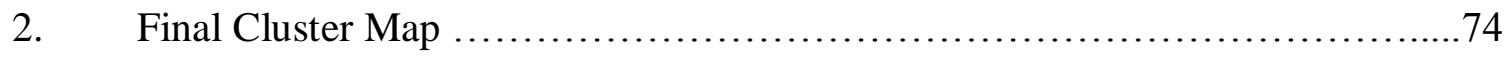

3. Cluster Bridging Map ............................................... 78

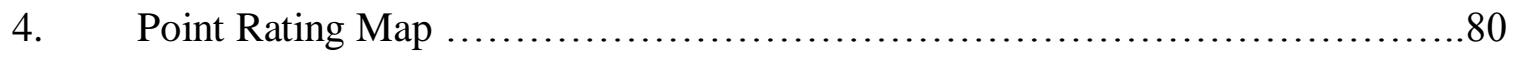

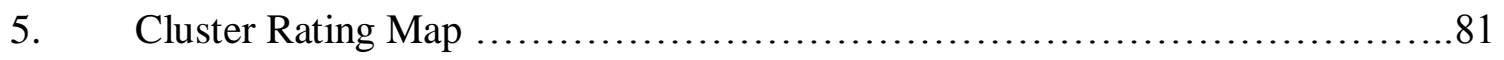

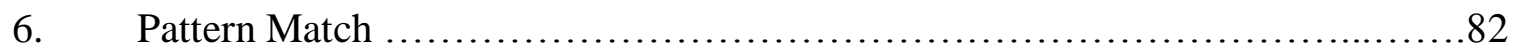

7. Social Work Cluster Go-Zone Graph ................................... 83

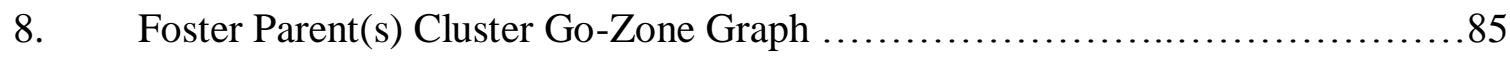

9. Foster Youth Cluster Go-Zone Graph ................................. 87

10. Foster Agency Cluster Go-Zone Graph ................................. 88 


\section{CHAPTER I: INTRODUCTION TO THE PROBLEM}

"If your success is not on your own terms, if it looks good to the world, but does not feel good in your heart, it is not success at all" - Anna Quindlen

Foster care is a fundamental component of the child welfare system.

Traditionally, foster care has been viewed as the "primary means" for caring for children placed outside of their home (Shireman, n.d., p. 1), and is considered one of the "central intervention strategies" for child welfare practitioners (Holland \& Gorey, 2004, p.117). Foster care services are regularly recommended for children who are abused and neglected (Bavolek, Wanberg, \& Dravage, n.d.). In 2011, there were an estimated 401,000 youths in foster care and approximately 646,000 youth were served by the foster care system (Administration for Children and Families, 2012). These services often extend to family members of youth in care (Pecora et al., 2010). Consequently, during the foster care experience, many of these youth and their families must learn coping processes to deal with histories of maltreatment (Riggs, Augoustinos, \& Delfabbro, 2009). Hence, youth must have positive and supportive foster care experiences (CrossTower, 2010).

Yet, despite the importance of foster care to child welfare, social work literature in general, and child welfare literature specifically, is devoid of a well-defined, conceptual framework for what success in foster care really means, from the perspective of those most impacted: foster youth. The complex nature of the system, its divergent 
terminology and the plethora of stake-holders involved in and with the foster care system contribute to this lack of clarity (e.g., Henderson \& Scannapieco, 2006). This dissertation sought to address this dearth in the research literature by posing two (2) distinct, yet interconnected queries:

(1) How do foster youth conceptualize successful foster care experiences?

(2) Is there a difference in the way that youth in foster care for abuse conceptualize successful foster care when compared to youth in foster care for neglect?

This study utilized a sample of youth, currently in foster care in Kentucky and employed a mixed-method approach known as Concept Mapping (CM). CM combines multi-dimensional scaling with hierarchical cluster analyses to form factors relevant to an area of study. This unique method allowed for foster youth to actively be involved in the study, and is suited to delineate a conceptual framework for defining success in foster care. Further, this study assisted in distinguishing how youth in care for abuse view success when compared to youth in care for neglect. In these ways, this study addressed gaps currently present in the child welfare literature array.

After a review of literature related to defining success as a general construct, this introductory chapter discusses the difficulties defining what it means to be successful in foster care. Then, this chapter examines how authors and researchers have sought to measure success in foster care. Next, this chapter investigates the pertinent distinctions between maltreatment types (abuse vs. neglect), and delves into reasons that the voice of foster youth is often excluded from child welfare research. This chapter concludes by examining the significance of this problem, and the probable consequences for not addressing the problem. 


\section{Problem Description}

The primary function of foster care is to provide safe care for youth, while simultaneously working towards reunification (Smith, 2009). While funding and regulatory statutes are demarcated by the federal government, state and local agencies implement and oversee the day-to-day tasks of foster care programs (Szilagyi, 1998). This multi-level, dynamic structure makes the foster care system one of unique complexity. Undoubtedly, this complexity has contributed to the difficulty in ascertaining what it means to be successful in foster care. Though myriad studies have discussed the term success in relation to out of home care (e.g. Ward, 1971; Boer \& Spiering, 1991; Reifsteck, 2005; Brown, 2008), none have clearly defined success from the perspective of youth in care.

\section{Conceptualizing Success: Defining a Construct}

Success, in any context, can be an elusive construct to define. In many instances, what it means to be successful can be affected by countless factors, and often these meanings may fall outside of orthodox definitions. The literature related to conceptualizing success as a general construct can likely be divided into two distinct categories: subjective and objective definitions. Traditionally, empirical research around what it means to be successful has focused on conventional, objective measures (e.g., Dyke \& Murphy, 2006). Gunz and Heslin (2005) explained that in objectivist approaches, researchers, or other vested parties, take it upon themselves to define the construct. Contrarily, the subjectivist approach permits "informants" to decide what success means. In this case, success would be based on personal standards and measures (Dyke \& Murphy, 2006) and requires informant "self-evaluation" (Dyke \& Duxbury, 2011, p. 219). The distinction between subjectivist and objectivist approaches was delineated by 
Hughes (1937). Hughes asserted that, in the contexts of discussing careers, subjectivity deals with the way a "person sees his [sic] life as a whole and interprets the meaning of his [sic] various attributes, actions, and the things which happen to him [sic]" (p. 410). Conversely, objective meanings are more "rigid" and can be assessed and evaluated by other persons. Other authors have discussed these differences utilizing different terminology. For example, Buscherhof and Seymour (1990) discussed extrinsic success (objective) and intrinsic (subjective) success, and Abele, Spurk, and Volmer (2011) described "real" (objective) versus "perceived" (subjective) definitions (p. 196).

\section{Difficulties Defining Success in Foster Care}

The difficulty in lucidly conceptualizing success, and the subsequent lack of a clear definition of success in foster care, is well documented in the literature. Napier (1972) described success in foster care as a "relative" term that "has not been rigorously defined" (p. 187). Miniely and Desgagne (1983) explained the perplexities that child welfare workers face in defining success when working with families. These authors shared sentiments similar to Napier, and concluded that "the question of what constitutes success or failure depends very much on the assumptions made and the criteria adopted by those making the judgment" (p. 139). More recently, in a review of published outcome studies related to treatment or therapeutic foster care for youth and adolescents, Reddy and Pfeiffer (1997) concluded that "consensus of what defines successful outcomes was absent" (p. 586). Cole and Eamon (2007) explained problems with a lack of clear definitions for success pertaining to foster care roles and discussed that definitions are "fraught with ambiguity, uncertainty, [and] conflict" (p. 656). Samuels and Pryce (2008) discussed a sense of abstruseness around success in their research about resilience of 
youth who are aging out of care. These authors further described that the field of child welfare "continues to wrestle" with defining success as a construct (p. 1209). Altshuler and Gleeson (1999) posited that conceptualizations of success in child welfare are often shortsighted and often exclude pertinent aspects germane to assessing foster care experiences (e.g., child well-being) and Katz (1999) found the need to "redefine" the way that success was defined in her study about concurrent planning. Hass and Graydon (2009) suggested that there is a dearth of knowledge, throughout the literature, about what success in foster care really means. Based on all of these observations, as Henderson and Scannapieco (2008) aptly summarized, conceptualizing successful foster care has proven to be an "arduous task" (p. 46).

The absence of a clear conceptualization of success from the perspectives of foster youth can be attributed to several distinct, yet connected dynamics related to the foster care system. First, literature related to foster care programs, evaluations, outcomes, and research is replete with contradictions and replications. This lack of clarity in research and literature indubitably contributes to the difficulty in delineating a clear definition of success in foster care. Several authors have documented these problems. For example, in a work published in the early 1990s, Pecora, Whittaker, Maluccio, Barth, and Plotnick (1992) pointed out that there had been no "clear picture" of the challenges that plagued the foster care system. These authors attributed this lack of clarity, in part, to the absence of federal leadership in data collection and analyses, insufficient reporting standards, and inadequate state databases. More recently, Courtney, Needell, and Wulczyn (2004) discussed a number of problematic factors related to data management and collection in child welfare at the federal level. These inconsistencies in data 
collection have almost certainly impacted foster care research. Besharov (1981) argued that inconsistent definitions have historically plagued child welfare research. He asserted that this divergent terminology could often be related to inabilities to draw suitable comparisons, a lack of measurement reliability, and unclear delineation between terms. Reddy and Pfeiffer (1997) concluded that the lack of consensus around what it means to be successful in out-of-home care is due to the wide variety of dependent variables used in foster care research and inconsistent operationalization of these variables.

Second, because of the ambiguity of its definition, "success" is often overused in the lexicon of Western society (Gunz \& Heslin, 2005). In child welfare, success is a construct of implied meaning. That said, the somewhat cumbersome use of this term has often led to divergent meanings and definitions. Oosterman, Schuengel, Slot, Bullens, and Doreleijers (2006) asserted that a "divergence in terminology" is among many "complications" that make it difficult to articulate what it means to be successful in foster care (p. 55). This premise is illustrated in the work of Henderson and Scannapieco (2008). These authors prefer the term effective foster care to successful foster care. However, like DeVizia (1974) who used these terms interchangeably, the meanings were implied to be similar. Green, Braley, and Kisor (1996) also discussed the use of "successful" and "effective" in discussing research related to foster parent perceptions of successful foster care. Since these terms are used interchangeably, it is difficult to define either of them.

Third, the foster care experience is not monolithic. These experiences are highly contextual and vary across a number of factors, such as agency location, foster care setting, foster parenting style, etc. (e.g., Samuels \& Pryce, 2008). These contextual 
factors greatly impact conceptualizations of success. In examining success in general, Jugdev and Muller (2005) described success as a very "context-dependent" construct (p. 19). Dunning, Leuenberger, and Sherman (1995) pointed out that individuals often develop self-serving, highly contextual definitions of what constitutes success. What's more, these different contexts greatly influence practice approaches related to foster care. Crea, Barth, and Chintapalli (2007) suggested that child welfare practices differ by agency, service level, and geographic location. As well, Bellamy (2008) asserted that varying contexts, such as geographic locations, contribute to differences in research findings. Given the complexity of the system and the wide spectrum of contextual diversity, it is no wonder why success in foster care is difficult to define.

Lastly, the foster care system includes a variety of stakeholders (e.g., child welfare agencies, social workers, foster parents, biological parents, foster youth, etc.) with a number of diverse perspectives. These distinct vantage points inherently impact the conceptualization of what success in foster care means. Thomas and Fernandez (2008) concluded that success means "different things to different people" (p. 733). In examining success in organizational systems, Dyke and Murphy (2006) explained that even individual characteristics, such as gender, could affect the way that success in conceptualized. Given these varying perspectives, researchers and practitioners must often make difficult choices about which viewpoint will be "paramount" (Perkins, 2001, p. 9) in the conceptualization of success.

The difficulty defining success is not unique to foster care. A number of authors have documented challenges associated with defining success. Dries, Pepermans, and Carlier (2008) explained the lack of a clear conceptual definition of success in the field of 
vocational behavior. Similarly, in the field of conflict mediation, Bercovitch (2007) asserted that "very little work has focused on developing a clear understanding of what constitutes success" (p. 289), and Heslin (2005) explained a similar dynamic in his study evaluating organizational behavior. A number of sociologists have documented the difficulties in measuring success associated with welfare reform (e.g., Lichter \& Jayakody, 2002). Moreover, others in areas such as the juvenile justice system (Peters \& Myrick, 2011), substance abuse (Lee \& Zerai, 2010), mental health arenas (Perkins, 2001), foreign language instruction (Sharkey \& Layzer, 2000), nursing (Buscherhof \& Seymour, 1990), psychology (Ebner \& Freund, 2007), perinatal drug treatment (Berkowitz, Brindis, \& Clayson, 1996), and public participation programs (Schweitzer, Carnes, Peelle, Wolfe, \& Munro, 1996) have documented difficulties identifying a conceptual definition for success. Perhaps Bercovitch summarized these difficulties best: "Too often, it seems success or failure is assumed, postulated, or defined on a case-bycase basis, and usually in an arbitrary and poorly reasoned manner" (p. 289).

\section{Measuring Success in Foster Care}

In spite of these challenges, success in foster care has been conceptualized and operationalized in a variety of ways (Brown \& Campbell, 2007). In many instances, success has been conceptualized based on objective criteria (e.g., Redding, Fried, \& Britner, 2000). These objective criteria are frequently evaluated based on foster care placement factors (e.g., length of placements, number of placements, reunification data, etc.) (Green, Braley, \& Kisor, 1996; Altshuler \& Gleeson, 1999). For example, in his article Success and Failure in Foster Care, Napier (1972) operationalized success on the criteria related to the length and stability of a placement. If a placement had been intact 
for five years or longer, it was defined as a success. Conversely, failures were cases in which the child had to be removed from a foster home before the five year time period had elapsed. Similarly, Boer and Spiering (1991) investigated sibling placements in foster care, and concluded that placement stability implied success, and placement disruption indicated an unsuccessful placement. Wilson, Petrie, and Sinclair (2003) proposed a model of successful foster care that examined relationships between the care provider and the foster youth, and viewed success as the "avoidance of disruption" of a placement ( $\mathrm{p}$. 991). Striker (2010) implied that success in his study constituted a placement that was "continuing" or otherwise not "prematurely ended" (p. 87). In a study examining foster care outcomes in England, Sinclair (2010) also discussed success regarding the stability of foster care placements. Other authors have used similar placement criteria to operationalize and define success in out of home care (e.g., McKelvey \& Stevens, 1994).

This emphasis on the stability of foster care placements as a measure of success is not surprising. Placement stability is viewed as paramount in foster care practice and research. Shireman (n.d.) explained that placement instability is the "greatest risk" to youth in foster care (p. 6). Consequently, researchers have spent a lot of time comparing successful (e.g., stable) and unsuccessful (e.g., unstable) placements (Sinclair \& Wilson, 2003). Such studies (e.g., Stone \& Stone, 1983; Street \& Davies, 1999; Cashmore \& Paxman, 2006) imply that instability is a measure related to a lack of success, or poor outcomes.

In addition to conceptualizing success based on placement factors, other authors have taken different approaches. For example, Jenkins (1965) and Barber, Delfabbro, and Cooper (2001) conceptualized success based on the foster child's ability to adjust to 
foster care. Ward (1971), in ascribing success to treatment (therapeutic) foster care, explained that foster youth whom were "more active and productive" in their placements could be deemed a "success story" (p. 746). In a study examining resiliency among foster youth, Hass and Graydon (2009) operationalized success based on academic achievement (e.g., graduation from or enrollment in a post-secondary institution), and further implied that success was the absence of "mental health treatment, special education, or intervention from the criminal justice system" (p. 461). Additional conceptualizations of success, whether implied or explicit, have included examinations of foster parent attitudes towards fostering (Rowe, 1976), permanency (Redding, Fried, \& Britner, 2000), and effective service delivery (Barth, Guo, \& McCrae, 2008), as well as adoptive parents' perceived satisfaction with the adoption process (Groothues, Beckett, \& O'Connor, 2001).

\section{Impact of Policy on Conceptualizing Success}

Generally speaking, in many instances success is defined as having achieved a goal. Merriam-Webster (2012) defined success as reaching a "favorable or desired outcome" (para. 3). This definition implies that one takes certain actions to be successful. In terms of child welfare, these goals are often dictated by the federal government via child welfare policy. In this way, because the goals of foster care are delineated by these federal policies, the way that success has been conceptualized in foster care is directly related to policy.

There are a number of examples that illustrate the impact that policy has had on conceptualizing success in foster care. For instance, Section 203 of the Adoption and Safe Families Act (AFSA) required the United States Department for Health and Human 
Services (DHHS) to delineate a number of outcome measures, such as time spent in foster care, number of foster care placements, etc., to assess state foster care programs (Courtney, Needell, \& Wulczyn, 2004). This focus undoubtedly impacted the way that states evaluated success of their foster care system. Moreover, this policy could explain the emphasis, in the literature, on using placement factors to define success.

Similarly, the Child and Family Services Review (CFSR), which was created by the 1994 amendments to Social Security Act (SSA), seeks to evaluate states on seven systemic factors, related to Safety, Permanency, and Well-Being (CFSR, 2006). According to CFSR (2006), each factor is rated based on the degree to which the state meets that particular outcome. States can be rated as "substantially achieved," "achieved," or "partially achieved." For a state to be successful on a particular outcome, a rate of $95 \%$ of the cases reviewed must be rated as "substantially achieved" on that particular outcome. Hence, states have paid particular attention to the measures of the CFSR, which has implicitly defined success based on the outcomes they have been able to achieve.

Another pertinent impact that policy has had on the way the children welfare system has conceptualized success relates to the funding associated with certain policies. Many of the policies related to foster care allocate monies for particular services. Courtney, Needell, and Wulczyn (2004) explained that in years following WWII, the federal government poured vast amounts of resources into social service programs, which led to the increased need for evaluation and accountability. In the mid-1980s, increased attention to budgetary constraints led some to call this time period the "age of accountability" in child welfare (Magura \& Moses, 1986). Often, the need to evaluate 
these programs led researchers to utilize objective measures to demonstrate meeting particular goals, garnering successful outcomes in order to obtain or keep funding. The Chaffee Act of 1999 offers a clear example. This act doubled the amount of money (from $\$ 70$ million to $\$ 140$ million) that states were given to implement independent living programs. In addition, this act also called for states to have a higher level accountability for these programs. This meant that states began tracking and developing objective measures for factors such as educational attainment, employment, homelessness, etc. (Graf, 2002). In this way, success was measured based on meeting certain goals related to this outcome. Because these were the factors that were being measured, the measures constituted success, or lack thereof.

\section{Success: Contributing Factors}

Much of the literature related to success in foster care has been less about explicitly defining the term, and more about identifying factors that may lead to success. Henderson and Scannapieco (2008) avowed that it is likely that an intersection of several factors contribute to conceptualizing what it means to be successful foster care. Farmer (2010) illustrated this premise in a study that analyzed factors contributing to success with adolescents in foster care. This author concluded that factors such as education, youth behavior, peer relationships, and foster parenting skills impacted whether a placement was deemed successful. Altshuler and Gleeson (1999) conceptualized success as the convergence of several permanency and safety factors.

Many studies that have examined factors related to successful fostering have done so from the perspective of foster parents. For example, Brown and Campbell (2007) articulated foster parent perceptions of success as the grouping of six dominant themes: 
security, family connections, positive relationships, positive family change, seamless agency involvement, and child growth and development. In assessing foster parents perceptions of factors needed for successful foster placements, Brown (2008) concluded that foster parents need the right personality and a well-developed skill set, pertinent information about the foster child, and good relationship with the foster agency, community support, individualized services, and self-care skills. Shireman (n.d.) concluded that foster parents perceived that "successful fostering" was related to flexibility, ability to appreciate differences, and outside support. (p. 30). Buehler, Rhodes, Orme, and Cuddeback (2006) proposed twelve domains for successful foster care, from the perspective of foster parents. These domains included providing a safe environment, promoting educational attainment, meeting physical and mental needs, and valuing diversity. Buehler, Cox, and Cuddeback (2003) reported that foster parents identified factors such as support from church, a concern for child-wellbeing, tolerance, and strong marriage, flexibility, and routine. Similarly, in examining kinship foster parent's perceptions about successful fostering, Coakley, Cuddeback, Buehler, and Cox (2007) delineated twelve perceived factors that contribute to success. These include faith, good parenting abilities, church involvement and flexibility. Brown and Campbell (2007) reported that success is defined, and subsequently evaluated, based on a convergence of factors, such as those discussed by Buehler et al., Hurley, and Coakley et al. However, as Wilson, Petrie, and Sinclair (2003) concluded: "there is uncertainty over which... relevant factors lead, whether alone or in combination, lead to success in foster care" ( $p$. 992). 
The implications of this literature review are clear: foster youth have not had a voice in defining, or operationalizing, what it means to be successful in foster care. The literature shows that success has often been conceptualized, based on objective notions primarily related to placement stability factors (e.g., number of moves, etc.). Though youth have been involved in studies that seek to examine their foster care experiences (Chapman, Wall, \& Barth, 2004; Whiting \& Lee, 2003; Gil \& Bogart, 1982; Fernandez, 2006; Sanchez, 2004), this review yielded no studies in which youth were asked to demarcate an explicit definition of success in foster care.

\section{Abuse and Neglect: Pertinent Distinctions}

As of late, there has been an increasing consensus that specific types of maltreatment need to be explored separately (Crittenden, Claussen, \& Sugarman, 1994; Barnett, Manly, \& Cicchetti, 1993; Jonson-Reid, Drake, Chung, \& Way, 2003). Barber and Delfabbro (2009) purported that the experiences of youth in foster care can differ significantly based on maltreatment type and Marquis, Leschied, Chiodo, and O’Neill (2008) added that "abused and neglected children who enter into the child welfare system have different needs and challenges" (p. 17). However, literature has often treated maltreatment type as a homogeneous subject, without making pertinent distinctions between how youth are impacted by different types of maltreatment (Clausen \& Crittenden, 1991; Hildyard \& Wolfe, 2002).

While much of the literature surrounding maltreatment intervention, prevention, and outcomes strategies encompass abuse (physical and sexual) and neglect, the patterns, outcomes, treatment and characteristics of these two types of maltreatment are very distinct. There are a number of studies that evince this distinction. For example, Garland, 
Landsverk, Hough, and Ellis-MacLeod (1996) examined service utilization based on maltreatment type. These authors concluded that children suffering from physical and sexual abuse were more likely to get services (e.g., mental health, etc.) than children who were removed from their homes due to neglect. In a study that investigated the impact of childhood maltreatment to physical health, Rodgers et al. (2004) stated that examining maltreatment types separately provided amply more detail about the impact of these variables (i.e., maltreatment types) on health-risk behavior later in life. Glassman, Weierich, Hooley, Deliberto, and Nock (2007) explored the relationship between child maltreatment and non-suicidal self-injury (NSSI) among a group of 86 adolescents. These authors deduced that there were significant associations between specific types of child maltreatment and recent NSSI, with emotional and sexual abuse having the strongest relationship to NSSI, when compared to other forms of maltreatment. Manly, Cicchetti, and Barnett (1994) and Hildyard and Wolfe (2002) suggested that maltreatment type may have an impact on behavioral functioning and development. Hildyard and Wolfe summarized that "relative to physically abused children, neglected children have more severe cognitive and academic deficits, social withdrawal and limited peer interactions, and internalizing” (p. 679). Similarly, Kinard (2004), who examined methodological issues related to maltreatment and behavioral adjustment of abused children, determined that the "role of maltreatment characteristics in children's behavioral functioning should be examined separately for each form of maltreatment" (p. 303). Moran, Vuchinich, and Hall (2004) studied the association between maltreatment type and substance use among adolescents. These authors concluded that the association between maltreatment and substance use varied by maltreatment type. Lobbestael, Arntz, and Bernstein (2010) 
described having found "clear evidence of differential relationships" between maltreatment types and personality disorders. A host of other authors (e.g., Wilson, Norris, Shi, \& Rack, 2010; Litrownik, et al., 2005) reported research results in which delineating between specific maltreatment types was an important factor. All of these studies are examples that lend credence to the premise that maltreatment types are unique and should be viewed accordingly. As Hahm, Lee, Ozonoff, \& Van Wert (2010) summarized, it is "no longer appropriate to assume that all types of maltreatment are equivalent...” ( p. 528).

To appreciate the uniqueness of maltreatment types, researchers must conduct studies that seek to examine maltreatment types, and the subsequent experiences of maltreated youth, separately (Trickett \& McBride-Chang, 1995). Kinard (2004) stated that "a better understanding of the effects of maltreatment characteristics is important for planning appropriate intervention and treatment services” (p. 317). Similarly, Berry, Charlson, and Dawson (2003) argued that prevention and intervention measures must adequately reflect distinctions in maltreatment types. Thus, distinguishing between types of maltreatment for youth in foster care is necessary for delineating which services should be expanded to improve foster care outcomes for youths and families (Reifsteck, 2005, p. 323). Concomitantly, discerning how youths in care for different types of maltreatment (i.e., abuse or neglect) conceptualize successful foster care will allow for more specifically targeted child maltreatment prevention and intervention initiatives.

\section{The Voice of Youth: A Missing Component}

While the importance of involving youth in foster care research is well documented (e.g., Bruskas, 2008; Gilligan, 2002), the actualization of this practice is 
seldom achieved (Brown \& Campbell, 2007; Goodyer, 2011). Foster care researchers have "rarely" involved foster youth as a primary unit of analysis (Goerge, Wulczyn, \& Fanshel, 1994, p. 531) and "the body of literature examining children's perspectives on care is relatively limited" (Fox \& Berrick, 2007, p. 23). Traditionally, federal policies have aimed to exclude children from research (Clark, 2009). In sum, this stance was taken to protect children from unethical research endeavors and exploitation. Fox and Berrick asserted that most of the information gathered in evaluation and research inquires comes, indirectly, from "caregivers, social workers, case workers, and administrative data systems" but not foster youth (p. 24). Historically, children and youth have often been viewed as "objects to be studied" and are often regarded as incompetent as to their own situations (Fargas-Malet, McSherry, Larkin, \& Robinson, 2010). In a study that examined youth in congregate care (e.g., group homes, residential care), Freundlich and Avery (2005) concluded that youth are seldom involved in care planning related to their foster care experiences citing that the "voices of youth are not sufficiently heard" (p. 130). Strolin-Goltzman, Kollar, and Trinkle (2010) contended that the "voice and experiences of youths within the system have been largely overlooked" (p. 47). These tenets are in line with Morris' (2007) study that suggested that foster youth are "victims" (p. 419) and felt that they were "deprived their rights as citizens" (p. 426). In this sense, it is easy to see why youth may be perceived as being inept about their experiences. In discussing the missing voice of foster youth in foster care, Mandell (1973) discussed the right of foster youth to share in decision making processes affecting their lives. Then, as now, youth are too seldom involved with decision making processes. Mandell illustrated this point by describing foster youth as "pawns on a chess board" (p. 67). Even after many 
considerations have been given to involving children in research in other areas of study (e.g., medical research), foster youth are still seldom involved in child welfare research (e.g. Samuels, 2009; Pecora, et al., 2010; Diehl, Howse, \& Trivette, 2011). Fenton (2002) appositely surmised the following: "though the system was created for children, it is too often only about them" (p. 59).

The fact that the voice of youth in care is excluded from the lexicon of foster care research is not surprising. Hill (2008) asserted that researchers feel less confident when dealing with children, and therefore often exclude them from studies. Chapman, Wall, and Barth (2004) purported that involving foster youth in research can be a "complex undertaking" (p. 294) and Gilbertson and Barber (2002) explained that including the voice of youth in care is not always a "straightforward matter" (p. 253). As well, there are a number of methodological challenges (e.g., access, etc.) associated with involving foster youth in research (Fernandez, 2007). For example, in an assessment of

methodological hurdles regarding research with youth in foster care, Berrick, Frasch, and Fox (2000) stated that access of youth in out of home care is often "tightly controlled" (p. 120). These authors further surmised "administrative, political, legal, and pragmatic barriers all conspire to limit researcher's access to and contact with foster children" (p. 119).

\section{Significance}

The needs and challenges of children and youth in foster care are becoming increasingly complex to determine and solve (McKelvey \& Stevens, 1994). Myriad studies have conjectured that placement in foster care is associated with a number of problematic outcomes. For example, foster youth and alumni are at increased risk for 
psychiatric disorders (McGuinness \& Schneider, 2007), marital problems and community involvement (Buehler, Orme, Post, \& Patterson, 2000), homelessness (Fowler, Toro, \& Miles, 2009), heightened risk for poor physical health (Takayama, Wolfe, \& Coutler, 1998), unemployment and addiction (Morris, 2007), and teen parenthood (National Campaign to Prevent Teen Pregnancy, 2010). Consequently, it is imperative that foster youth have positive and supportive foster care experiences to prevent long term adjustment problems. The first step in ensuring positive foster care experiences is seeking input from the youth about what constitutes success in foster care.

There are a number of problematic consequences of the poorly defined conceptual domain of success in foster care, from the perspective of foster youth. Buehler, Cox, and Cuddeback (2003) explained that a limited conceptualization of success is "detrimental" for foster youth (p. 63). The following paragraphs discuss four consequences related to not addressing this social condition.

First, defining success based on objective constructs for what it means to be successful in foster care is shortsighted, and somewhat uninformed. Kerman, Wildfire, and Barth (2002) suggested that using objective measures, such as those related to placements discussed above, "severely compromises our ability to know how much benefit we have provided" (p. 324). To fully understand the impact of foster care services, it is imperative that foster youth are included in defining success.

Second, because the system is not able to truly know the impact of foster care services, it becomes near impossible to accurately assess, evaluate, and/or research programmatic goals. Traditionally, there has been little accountability in the child welfare system, as it relates to outcomes for children in foster care (Bruskas, 2008, p. 72). 
Perhaps most often, success in child welfare is conceptualized by how well the system is able to meet its stated goals (Brown \& Campbell, 2007), which youth rarely help determine. Theoretically speaking, the overall goal of foster care is to protect children while simultaneously providing services aimed at reunifying the family (Foster, 2001; Chipungu \& Bent-Goodley, 2004; McCutcheon, 2010). This goal presupposes that service delivery is in the best interest of the youth involved. Some authors have argued that the child welfare system lags in meeting this goal (e.g., McGuinness \& Schneider, 2007; Christian \& Schwarz, 2010). Others have claimed that what is "best" for children placed in care cannot be known (McDonald, Allen, Westerfelt, \& Pivilian, 1996, p. 22). Additionally, there is often a "gap" between foster goals, and the evaluation of these goals (Reifsteck, 2005, p. 321). Defining success based on goal attainment, without the input of foster youth, can prove somewhat problematic. Woolf (1990) provided the following illustration pertaining to the evaluation of foster care outcomes: Evaluation becomes "a perpetual march down a road of good intentioned with the failure to check the quality of the road, and, indeed, whether the interim goals to be accomplished along the way coincide with those of the final destination" (p. 76).

Third, the lack of a clear conceptual definition of success, from the perspective of foster youth, hinders the development of cost-effective programs aimed at serving this population. It is estimated that federal, state, and local governments spend about $\$ 2$ billion annually on foster care services (Foster, 2001). These figures do not take into account the billions spent on health and mental health services, and the myriad other services that foster youths often utilize while in care. Reifsteck (2005) explained that managing costs associated with care is based on responsibly evaluating foster care 
services and programs. This responsibility requires that services take into account the definitions of relative terms and perspectives of involved stakeholders (e.g. foster youth).

Fourth, the lack of involvement of foster youth in conceptualizing success in foster care disempowers youth involved in the system. McFadden (1989) suggested that active involvement of youth in the foster care system can empower them. Empowering youth requires they have a voice in the systems in which they are involved (e.g., National Association for the Counsel for Children, 2012). In assessing run away behavior, Clark et al. (2008) implied that involving youth in their care can be the impetus for improved outcomes. This point is further illustrated in Gilligan's (2002) assertion that listening to and appreciating the story of young people in care can be therapeutic. Kaplan, Skolnik, and Turnbull (2009) stated that the "empowerment of youth in and transitioning out of care is essential and should be overtly facilitated through policy and program development" (p. 133). McFadden aptly stated that "ultimately, the children in foster care must speak for themselves" (p. 1). Empowerment will occur only if we ensure that foster youth have a voice in the system designed to serve them. 


\section{CHAPTER II: THEORETICAL FRAMEWORK}

"All theories are legitimate, no matter. What matters is what you do with them."

\section{— Jorge Luis Borges}

Theories offer a contextual framework through which we can view similar phenomena in a multitude of different ways. It is important that we carefully and critically examine and apply theories in a way that further facilitates the investigation of knowledge. Applying theories to social work praxis and research, particularly in the area of child welfare, should be done so with meticulous consideration of critical thought and ongoing reflection (e.g., Robins, Chatterjee, \& Canda, 2006).

This chapter will discuss the theoretical framework informing this study. While a number of theories can be applied to foster care in general, this chapter will briefly present the overarching framework influencing this study, and delve specifically into aspects of Piaget $(1936 ; 1945 ; 1952 ; 1957)$ and Erikson's $(1959 ; 1968)$ theories of human development and Bowlby's $(1969 ; 1973 ; 1977 ; 1980 ; 1982)$ Attachment Theory. The theoretical foundation presented here is similar to one demarcated by Goodyer (2011), in the sense that the theories discussed seek to offer insight into and explain dynamics related to foster care in general, and this study specifically.

\section{Overarching Theoretical Framework}

The overarching theoretical influence informing this study is rooted in a postmodern paradigm. Postmodernism has been applied in a plethora of ways in myriad 
social work contexts (Howe, 1994). Perhaps, the wide-ranging application of postmodernism in social work is not surprising. Ungar (2004) explained that the fundamental strength of a postmodern perspective is that it permits social workers to embrace multiple realities. In this context, social workers view knowledge as coconstructed. Because social work practice and research provides a unique situation for interaction between multiple actors (e.g., practitioners, researchers, clients, community systems, etc.), it is imperative that social workers recognize the importance of examining multiple, or shared, realities (Urek, 2005). One primary mechanism for examining these shared realities is the application of a postmodern theory: social constructionism.

Social Constructionism asserts that there is not a single reality, but rather, multiple realities based on varying perceptions of the world (Rogers, 2013, p 117). In short, actors are able to construct, in concert with others, their own realities. Hutchison (2008), like Howe (1994), argued that the inherent value in social constructionism is the recognition of multiple ways of knowing and understanding. These multiple ways of knowing are based on social interactions (Rogers, 2013, p. 118), and are shaped by the history, culture, language, and experiences the actors involved.

\section{Application}

This project is predicated on the premise that youth are able to construct their realities. Undoubtedly, this reality must include foster youths' perceptions of success in child welfare. The notion that a study, such as the one presented in this narrative, should be based on constructionism is not new. Rogers (2013) stated that increasingly researchers are building studies based on the foundation of constructionism. These studies "aim to better understand the worldview of participants, which guides the analysis 
and the application of the results" (p. 121). D'cruz (2004) explained that social

constructionism can be an integral tool in examining multiple realities, specifically in the context of child welfare.

The implication of the application for applying constructionist theory to this project is clear: if child welfare practitioners and researchers are to fully understand the complexity of the foster care system, they must value youth perceptions of success in foster care. Chapter one discussed the benefits of understanding this unique perception. Efforts to understand this perception must include research studies that allow youth to have a voice in constructing their own realities, thus drawing from a postmodern, social constructionist theoretical foundation.

\section{Human Development Theory}

Human development is the "physical, mental, social, and experiential changes that occur over a person's life cycle" (Barker, 2003, p. 202). Barker described these changes as cumulative and as occurring in structured sequences. While theories related to human behavior can be extremely complex, the overall goal of human behavior theory is to shed light on a simple question: Why do people act the way they do? (e.g., Zastrow \& KirstAshman, 2010).

Though the following section of this chapter will tersely discuss the entirety of the stages of Piaget and Erikson, it will conclude by emphasizing aspects of the theory most applicable to this study (e.g., Piaget's Concrete Operations Stage and Erikson's stage mastery concept and trust versus mistrust stage).

\section{Jean Piaget}


Jean Piaget $(1896$ - 1980) was a Swiss psychologist that put forth a theory to offer explanation to how human beings develop. Piaget's theory suggests that cognitive development occurs in schemes, which are "consistent, reliable patterns or plans of interaction with the environment" (Barker, 2003, p. 327). Piaget asserted that his stages of development occur in a fixed-order, and are based on four factors: maturation, physical experience, social interactions, and equilibrium, or the interaction of new experiences with existing ways of knowing (Robbins, Chatterjee, \& Canda, 2012). Piaget suggested that transitions through these stages occur based on the "growth of the child's logical capabilities" (Vosniadou \& Brewer, 1987, p. 52). Robbins, Chatterjee, and Canda (2012) argued that while Piaget's theory has been widely criticized (see Lourenco \& Machado, 1996) that many other cognitive developmental theories are based on some of the fundamental premises of Piaget's work.

\section{Piaget's Four Stages of Cognitive Development}

Sensorimotor Period. According to Piaget (1952), cognitive development occurs in four distinct stages, the first of which is the Sensorimotor Period. This stage of development begins at birth and last until approximately two (2) years of age. This period of life is characterized by three major accomplishments (Zastrow \& Kirst-Ashman, 2010). First, children learn that they can receive information through various senses. This is a time of heightened sensory and motor development for children and actions are often repetitive reflexes. The second accomplishment is that children will begin to exhibit goal directed behavior. This means that instead of varied simple responses to stimuli, children will decisively put together behaviors to reach a certain goal. Robbins, Chatterjee, and Canda (2012) used the example that children will move from suckling as a simple reflex, 
to intentionally suckling for food. Third is the idea of object permanence, or the idea that objects continue to exist even when out of sight and hearing ranges. Moreover, because of the developing sense of object permanence, children began to use "representation" or their imaginations to visualize objects.

Pre-operational Thought Period. The second stage of Piaget's developmental theory is the Pre-operational Thought Period. This stage begins at approximately age two (2) and ends at approximately age seven (7) years. Zastrow \& Kirst-Ashman (2010) explained that in this stage, a child's thinking continues to develop and they become more able to participate in abstract thought. In the Pre-operational Thought Period, children are not limited to concrete perception, but rather, they are more able to symbolize or imagine objects. As well, this stage is typified by a swift development in language capabilities and children are able to verbalize needs and wants. Robbins, Chatterjee, and Canda (2012) explained that during this stage, children seek to test their ideas through social interactions and communications. Despite the fact that children are gaining an increased ability to think logically, there are barriers such as egocentrism (not being able to see things from others' point of view), centration (concentrating on one detail of an object instead if viewing the objects as a whole), and irreversibility (the inability to reverse logical thinking patterns) that hinder this capability (Zastrow \& KirstAshman, 2010).

Concrete Operations Period. The third stage of cognitive development is the Concrete Operations Period, which lasts from approximately age seven (7) years to approximately age 12 years. According to Piaget (1952), during this stage children are able to think in a way that allows them to use information to discern between an array of 
choices and process information. Zastrow and Kirst-Ashman (2010) described this period as one in which children hone the ability "think logically at a concrete level" (p. 126). Aspects of egocentrism start to fall away and children are able to start to see ideas and information from the perspective of others. It is also during this time that the ideas of classification (the ability to sort items into categories), seriation (the ability to arrange objects in a particular, logical order), and conservation (the premise that aspects of an object can change while others stay the same) become fully understood.

Formal Operations Period. The final stage of Piaget's model for cognitive development is the Formal Operations Period. This stage begins at approximately 12 years of age and last until approximately 16 years of age, years also referred to as adolescence. Zastrow and Kirst-Ashman (2010) explained that abstract thought reaches its "culmination" during this phase (p. 127). In the context of discussing Piaget's theory, Rogers (2010) purported that in the formal operations stage, there is a formation for "meta-thought", which is the ability to "think about thinking" (p. 226). Nosich (2009) described the notion as the ability to think critically, or engage in critical thinking. During this stage, youth are able to make decisions based on taking into account an array of factors. Robbins, Chatterjee, and Canda (2012) explained that during this stage, young people are "able to reason correctly from hypothetical data, as they begin to solve problems and then check their answers" and that this group can recognize how change occurs over time (p. 267). Piaget (1957) asserted that after this stage, individuals persist in developing and defining ideas and in articulating decision making processes. In summarizing the characteristics of this stage, Zastrow and Kirst-Ashman postulated that there are three major occurrences related to thought that occur during this state: 
adolescents are able to take into account more than one factor in a given situation, they are able to analyze the impact that one variable has on another, and they can evaluate varying aspects of relationships between objects to arrive at a logical conclusion.

\section{Erik Erikson}

Erik Erikson (1902 - 1994) was a German-born psychologist. Erikson (1968) put forth a theory of psychosocial development included eight (8) stages. Erikson's theory was based on the premise of the epigenetic principle, or that "anything that grows has a ground plan" (Erikson, 1959, p. 52). Erikson elucidated that a mastery of each stage is required to move on to the next stage and he contended that as individuals move through each stage, they will work to remedy crisis that occur and that are unique to that stage. Rogers (2010) explained that crises are "psychological efforts to adjust to the demands of the social environment" (p. 64). Further, these crises are common to each stage and help individuals to develop as they progress through each stage.

\section{Erikson's Stages of Psychosocial Development}

Trust versus Mistrust. Trust versus mistrust is the first stage of Erikson's developmental scheme. This stage starts at birth and ends at approximately 18 months of age and the primary task for an infant during this stage it to build a trusting relationship with the outside world. Hutchison (2008) explained that this trust between the infant and the outside world develops based on the premise that the infant's needs will be met.

Erikson $(1959 ; 1968)$ asserted that this stage is based on mutual regulation between the infant and others, and that when this regulation fails, a child will attempt to control the environment by signaling duress (e.g., crying). Further, this mutual regulation is based on the infant receiving AND accepting what is given to them. Erikson argued that by 
receiving and accepting what is given, the child learns to be a giver, and this becomes a giving person. It is this relationship of trust that an infant is able to form relationships and emotional bonds that will be the foundation for future healthy relationships.

Autonomy versus Shame and Doubt. Autonomy versus Shame and Doubt starts at approximately age (2) and ends at age three (3) and is often referred to as early childhood. The central task of this stage is for youth to start to assert independence. Erikson (1968) described this entire stage as a battle for autonomy. He explained: "the overall significance of this stage lies in the maturation of the muscle system... and the enormous value with which the still highly dependent child begins to endow his autonomous will" (1959, p. 66). Hutchison (2008) explained that is through a heightened sense of self, that children are able to assert their independence and build a heightened sense of pride. Failure to do so, according to Erikson, will lead to shame and low selfesteem.

Initiative versus Guilt. Initiative versus Guilt last from approximately three (3) years of age until five (5) years of age and is often referred to as the pre-school stage for most children. Hutchison (2008) asserted that the primary focus of this stage is the focus on family relationships. Children begin to explore and learn family member roles and responsibilities, and learn to adhere to parental rules. Erikson (1959) marked this period as one in which the child knows that he or she is a person, but that they know must decide what kind of person they will be (p. 74). In exploring this question a child will often seek to be like their parents. Towards the end of this stage, there is a shift from focusing on familial relationships, to focusing on establishing social relationships outside of the 
family. During this stage, children will engage in play and typically enjoy peer relationships.

Industry versus Inferiority. Industry versus Inferiority is a stage that begins at approximately six (6) years of age and last until 11 years of age. Erikson (1959) explained that industry refers to the ability of children to do things and do them well, or to hold perceptions of being useful. Contrarily, inferiority refers to the feeling of not being adequate, or to not be able to appropriately solve conflict that arises in this stage. During this stage, the capacity to cooperate with others develops, and as a result, children in this stage either garner a sense of mastery or incompetence. Most of this sense of mastery or incompetence comes through play with peers, and education (both formal and informal). Erikson (1968) explained that during this stage children often attach themselves to teachers and roles that they can readily grasps (policeman, fireman, etc.).

\section{Identity versus Role Confusion. Identity versus Role Confusion last from} approximately 12 years of age until approximately 18 years of age and is typically referred to as adolescence. Hutchison (2008) elucidated that, for adolescents, development during this stage hinges on one simple question: "Who am I ?" According to Erikson (1959), individuals in this stage find their social place in the world through experimentation. Thus, youth in this stage often test being involved with different social roles and groups. Erikson summarized that during this time in life that childhood ends, and youth begins (p. 89). Erikson further described this stage in this way: "The growing and developing young people, faced with this physiological revolution within them, are now concerned with attempts at consolidating their social roles" (p. 89). Also, Erikson 
(1968) stated that it is during this stage that youth will seek meaning from different things and will seek ideas and concepts to "have faith in" (p. 128).

Intimacy versus Isolation. Intimacy versus Isolation is often referred to as young adulthood and ranges from approximately 19 years of age to 40 years of age. According to Erikson (1950) the primary task of this stage is the development of closeness, or intimacy. Erikson (1959) argued that intimacy can occur only after one has a healthy sense of self. The importance of establishing these intimate relationships is to avoid isolation and one moves through the remaining two phases.

\section{Generativity versus Stagnation. Generativity versus Stagnation starts at} approximately 40 years of age and ends at approximately 65 years of age. This stage is also commonly referred to as middle adulthood. The focus shifts on focusing on self, to focusing on others so as to ensure the well-being of others. Erikson (1959) explained that this stage if characterized by the desire of individuals to establish the "next generation" or to reproduce.

Ego Integrity versus Despair. Ego Integrity versus Despair is known as the age of maturity and starts at approximately 65 years of age and last until death. As the life span ends, individuals often become critical and highly reflective of the life they have lived. Erikson (1959) explained that integrity in this stage deals with one's acceptance of life and that perspective on others change. Further, true integrity can only come after one has thoroughly reflected on their life. This reflection should yield feelings of achievement. In contrast, despair is categorized as a feeling in which one has great regret about their past. Individuals experiencing despair often wish they could go back and 
change aspects of their life that they are not happy with. Consequently, the individuals feel a deep sense of fear regarding death.

\section{Human Development, Adolescence, and this Study}

Human development and the application of theory can be very informing when seeking to understand dynamics related to foster care and foster children (Dozier, Albus, Fisher, \& Sepulveda, 2002). What's more, understanding foster care and the unique circumstances surrounding the placement of children outside their homes can provide insight and context to developmental issues and challenges plaguing youth in foster care. Rutter (1987) suggested that placement in foster care can have a great impact on development. While being in foster care has the potential to greatly impact development at every stage of development, this impact is often externally manifest itself during adolescence (American Psychological Association, 2002).

\section{Adolescence}

Historically, adolescence and the impact that it has on individuals and society has been negatively portrayed. In perhaps the earliest work in this area, Hall (1904) went to great lengths to discuss all of the problems and challenges presented with this stage of life, and perpetuated a demonizing of adolescents and this life stage. The American Psychological Association (2002) specified that adolescence of often portrayed negatively in the media, and argued that much of the professional literature related to this stage of life overly emphasizes the challenges associated with this stage of life development.

The challenges faced by in the adolescence stage of human development are well documented. During this stage youth often endure significant changes in their physical 
development (Zastrow \& Kirst-Ashman, 2010). These drastic changes in the physical development of youth in this stage are only rivaled by their substantial cognitive development. In addition, adolescence is typically marked by young people asserting some autonomy and independence, and usually requires that young people distance themselves from rules, perspectives, and meanings levied by others (van Wormer, 2011). These actions often lead to adolescents being labeled or typified as being "rebellious" or as behaving poorly.

\section{Applying Theory to the Current Study}

As previously alluded to, this study sought to gather information from current foster youth regarding their perspectives on success in foster care. Human behavior theory, particularly that of Piaget and Erikson, informed this study and can be applied in a number of unique ways. This section will explore three of these applications.

Application \#1: The ability to think logically. Chapter one discussed the fact that foster youth are often excluded from child welfare studies (e.g., Hill, 2008; Chapman, Wall \& Barth, 2004; Gilbertson \& Barber, 2002 etc.). These youth are not included in foster care studies for a number of reasons: among them, is the premise that youth, specifically adolescents, do not have the ability to think through ideas and arrive at a logical conclusion. Said another way, adolescents have no knowledge about what is best for them. Undoubtedly, this thought has lead researchers to assume that youth are not knowledgeable about their situations, thus leading to the feeling that including their perspectives in foster care research is not pertinent (e.g., Mandell, 1973; Freundlich \& Avery, 2005). 
Based on the application of Piaget's theory, the assertion that teenage foster youth are not knowledgeable about their situation is certainly short sided, if not unequivocally wrong. Piaget termed adolescence as the Formal Operations Period. During this stage, according to Piaget (1945) and others (e.g., Zastrow \& Kirst-Ashman, 2010) individuals are able to reason utilizing a variety of data and information, and that youth are able to think critically. What's more, towards the end of this stage, individuals are able to thinking logically and arrive at logical conclusions (e.g., Rogers, 2010).

The implication of Piaget's theory of human development for this study is clear: foster youth, specifically adolescents, have valuable information and an ability to think logically about their foster care experiences. Additionally, according to Piaget, the Formal Operations Period is marked by adolescents shaping and forming their own ideas about how the world should work. This in mind, it is no longer acceptable to assume that adolescents in foster care have nothing valuable to contribute to the research landscape. This study seeks to leverage the ability of adolescents in foster care to think logically and critically about their own foster care experiences.

Application \#2: The ability to make thoughtful decisions. The application here builds on assertions made above regarding adolescents' ability to think logically. Robins, Chatterjee, and Canda (2012) proclaimed that in the Formal Operations Period, youth are able to make decisions, while taking into account an array of variables and factors. However, adolescents have often been given a bad rap in the media regarding their ability to make decisions (e.g., Stepp, 2002). Teens have often been criticized for making poor decisions and their capacity to make sound decisions is often underestimated. 
The topic of adolescent decision making has been extensively studied, however much of this literature has overwhelmingly focused on the immature aspects of decision making. Contrary to this premise, several authors have purported that adolescents have great decision making capacity. Albert and Steinburg (2011) asserted that "most adolescents demonstrate remarkable decision-making competence" (p. 212) and Steinberg, Cauffman, Woolard, Graham, and Banich (2009) pointed out that youth are more than capable of making decisions related to pertinent life choices. While these authors offer evidence that teens do possess the ability to make certain decisions, it is pertinent that child welfare researchers and practitioners know that youth cannot be expected to always make "appropriate" decisions. Perhaps the American Psychological Association (2002) best captured this premise by reminding that "just as adults sometimes make poor decisions, so do adolescents" (p. 12).

While decision making for teens can prove somewhat tricky to navigate, underestimating their ability to make decisions can be counterproductive to empowering youth to assert autonomy and building the capacity for future decision making. Adolescents who feel that they are not able to appropriately assert their own autonomy in decision making often that they are being treated unfairly (Albert \& Steinburg, 2011). This feeling of iniquitous treatment may lead to behavior issues (Rogers, 2010).

Similar to the first application noted above, the use of Piaget's theory here is pertinent to reframing the capabilities of adolescents. Teens in general, and foster teens specifically, do have the ability to make decisions related to abstract ideas and concepts. The study proposed here is based on this fundamental premise. And, while it may be true that youth do have some limitations related to decision making (e.g., the tendency to 
value immediate gratification) and may, on occasion, make poor decisions, they do have the capacity to provide insight regarding their own experiences. Piaget's assertion regarding the ability of teens speaks to the idea that these abilities have value and should be treated as such. Fleming (1963) captured the perspective, or lack thereof, of this premise as follows: “Adolescents are more like adults than adults have been tempted to suppose" (p. vii).

Application \#3: The Impact on Future Relationships. The application here shifts from Piaget's theory to the developmental theory posited by Erikson. There are several aspects of Erikson's theory that help to inform the understanding of foster care in general, and this study in particular. For example, Coleman (2000) stated that for many youth entering foster care, the first stage of trust is never achieved. Based on Erikson's assertion that a stage must be mastered before one can move on to the next phases, many foster youth may struggle with development under the auspices of Erikson's developmental theory. Ocasio and Knight (2003) made similar claims regarding trust. Because many of the issues related to the lack of mastery of this stage, some foster youth exhibit issues related to trust in later stages. This lack of trust can greatly impact foster youths' willingness to be involved in research studies.

Utilizing Erikson's developmental theory offers unique insight into understanding, and furthermore actively engaging, youth in research studies. A number of authors have discussed the complexities with involving youth in research (e.g., Chapman, Wall, \& Barth, 2004; Hill, 2008). Because youth in foster care may be dealing with a non-mastery of Erikson's first stage, or an unhealthy sense of trust, they may not wish to be involved, or be hesitant to participate in research studies. Hill (2009) described this 
premise as the wish to be minimally involved in ongoing research initiatives. With foster care, this is a likely scenario. The youth may view the researcher as part of a "system" and based on their experiences, youth may see their involvement in this study as a token gesture. Understanding that there may be trust issues related to involvement can help the researcher to engage in approaches that seek to build rapport and trust with the youth.

\section{Attachment Theory}

From a theoretical standpoint, practice in child welfare has long been focused on a family-centered approach to practice. This approach views the family as central to understanding a child's needs and is rooted in the premise that youth can only be understood in the context of social connections and relationships (Pecora, Whittaker, Maluccio, Barth, \& Plotnick, 1992). One theory that examines the importance, structure, and quality of these relationships is Attachment Theory.

Attention to attachment relationships began to gain attention in the early to mid1950s when clinicians became interested in the challenges suffered by children growing up in institutions (Barth, Crea, John, Thoburn, \& Quinton, 2005). John Bowlby was the first to significantly attribute major works and emphasis to Attachment Theory (Mann \& Kretchmar, 2006), and he made his first presentation on his work on attachment in late 1958 in London (Bretherton, 1992).

Attachment Theory is a developmental theory that asserts that healthy attachment to individuals, particularly attachment to a maternal figure, is the foundation for healthy development later in life (Bowlby, 1969; 1982). Bowlby (1977) stated that attachment is the "propensity of human beings to make strong bonds to particular others" (p. 201). The Centre for Parenting and Research (2006) expanded this notion and articulated that 
attachments are "best thought of as mutually reinforcing patterns of behavior between a caregiver and a child” (p. 2). According to Mikulincer, Shaver, and Pereg (2003), Bowlby believed that humans seek to be close to their primary attachment figures in times of need and distress (proximity maintenance) and that these individuals provide both emotional and physical comfort during times of need (safe haven). Through meeting these functions, an individual becomes a source of attachment security (Howe, 2006). The central premise of Attachment Theory is that human beings are born with a disposition to connect with other people.

Bowlby (1969) asserted that attachment occurs in four distinct phases. The first is the pre-attachment stage which last from birth to approximately six weeks. During this stage an infant will seek comfort from, and subsequently "attach" to caregivers. The second phase last from age six weeks until age eight months and is known as attachment in the making. During this stage, the child is able to discern the primary caregiver from other caregivers and prefers the comfort of the primary caregiver. The third phase of attachment is known as the clear-cut attachment stage and last from approximately six months until approximately two years. During this stage children begin to exhibit an anxiety or signal distress when separated from the primary caregiver. The final stage, known as the formal reciprocal relationships stage, starts at approximately 18 months and last until between two and three years of age. This stage is characterized by the child beginning to understand that when separated from the primary caregiver, the primary caregiver will return. While exploration of the environment around them greatly increases during this age, the child will always seek solace from the primary caregiver. 
The adequate development of these stages is pertinent to ensuring healthy attachments for children. Secure attachments enable young children to explore and learn about aspects of their environment (Schofield \& Beek, 2005). Children with secure attachment relationships will turn to caregivers in times of duress, and an appropriate caregiver will respond accordingly. The interaction leads to a mutually informing reciprocal relationship (Centre for Parenting and Research, 2006). Conversely, when a child does not have a secure attachment and does not feel that they can trust their caregiver to appropriately respond, the child will demonstrate intensified behaviors related to the duress (fussing more or becoming fussy, becoming more demanding, etc.). Additionally, these youth have a high-level of personal insecurity, distorted concepts of relationships, issues of mistrust, and a possible propensity for violence (Mann \& Kretchmar, 2006). There are a number of tools have been developed to objectively assess attachment with young people, including foster youth. These tools include measures such as the Relationship Structures (ECR-RS) Survey (Fraley, Niedenthal, Marks, Brumbaugh, \& Vicary, 2006), Strange Situation (Ainsworth, Blehar, Waters, \& Wall, 1978), CassidyMarvin System (Cassidy, 1988), and the Adult Attachment Interview (George, Kaplan, \& Main, 1984).

\section{Attachment, Foster Care, and this Study}

Over the last two decades, Attachment Theory has wielded an enormous influence over various fields of social sciences (Wylie \& Turner, 2011; Howe, 2009), none more so than in child welfare, particularly foster care (e.g., Centre for Parenting and Research, 2006). Stein (2006) contended that Attachment Theory provides a foundation for many research studies related to foster care, and has a profound impact on the way the 
researchers and practitioners work with foster youth. Kelly (2002) asserted that Attachment Theory is the "key theoretical perspective informing child-care decision making" (p. 20). While much of attachment research and literature is limited to the discussion around infants (Schofield \& Beek, 2005), this theory can prove very useful in discussing an array of youth and ages of youth in care. Several examples of the influence of Attachment Theory are documented in the literature.

For example, Attachment Theory has had a profound impact on the way that foster placements have been viewed and subsequently, developed. Based on the attachment orientation framework, child welfare workers moved away from viewing a foster placements as simply a safe place to live, and began emphasizing the importance of meeting emotional and psychological needs as well (Kelly, 2002). One such need is to address attachment issues. Schofield and Beek (2005) explained that foster youth often have to navigate attachment issues that relate to their current situations in foster care, in addition to deficits related to the lack of attachment in the past. Goldsmith, Oppenheim, and Wanlass (2004) stated that youth are often "torn between forming an attachment to their foster parents while simultaneously longing to return to their parents" (p. 1). Thus, as Kelly asserted, the impact of Attachment Theory led to practitioners to seek remedy for these issues through the development of appropriate foster care placements.

Attachment Theory has also had a great impact on the way that child welfare workers make placement decisions. Goldsmith, Oppenheim, and Wanlass (2004) stressed that attachment theory can be useful in matching foster youth with potential foster parents. Moreover, this theory has shed light on sibling placements. Bowlby (1973) reported that siblings may help to negate the absence of parental attachments. This idea 
has led to several studies (e.g., Boer \& Spiering, 1991; Whelan, 2003) that have examined the impact of placing siblings together in care. These studies were conducted on the theoretical foundation of Attachment Theory. Whelan suggested that when siblings contribute to a secure attachment environment then they should be placed together, but when the opposite is true, then child welfare practitioners must consider not placing the children together. Haight, Kagle and Black (2003) shared a similar sentiment regarding the visitation of siblings and other family members. These authors suggested that if a poor attachment exists, contact with that caregiver or sibling may be more detrimental than beneficial.

Another significant impact that Attachment Theory has had on foster care is in how negative attachment relationships can impact poor behaviors. For example, McWey (2004) examined attachment styles of children in foster care. This author found that many of the foster children in the foster care system had avoidant attachment styles, and that these styles may help to explain some behavior issues that these children exhibit. Further, McWey explained that based on these findings, youth may be mistrustful of new caregivers (e.g., foster parents) and that this may be the impetus for future behavior issues. McWey and Mullis (2004) found that foster youth with higher levels of attachment had less behavior problems, were less likely to be labeled "developmentally delayed" and were less likely to be taking psychotropic medications, when compared to foster youth with negative levels of attachment. Another example of the influence of Attachment Theory on foster care is illustrated in Fahlberg's (1991) influential work, $A$ Child's Journey Through Placement. In this book, Fahlberg explained that while the attachment process is a complex one that is not completely understood, Attachment 
Theory provides insight into the impact that attachment, or lack thereof, can have on a youth's development, behavior, and cognitive ability. Other authors (e.g., StovallMcClough \& Dozier, 2004; Whelan, 2003; Pearce \& Pezzot-Pearce, 2001; McWey, 2000) have also stressed the important role that Attachment Theory has played in understanding child welfare in general, and out of home care in particular. In summarizing the impact of Attachment Theory on understanding foster care, Barth, Crea, John, Thoburn, and Quinton (2005) explained that "Attachment Theory articulates the potential risk of experiencing multiple caregivers; emphasizes the importance of close social relationships to development; and recognizes that substitute parents may not always have close relationships with children who have experienced adversities before joining them" (p. 257).

While the application and analysis of Attachment Theory is a very complex process (Fahlberg, 1991), it provides a very important orienting framework for examining foster care. Specifically, Attachment Theory offers insight into two distinct aspects of this study. First, this theory helps to understand why success has often been conceptualized based on placement factors. Clearly, many of these factors (e.g., time in care, placement moves, visitation, etc.) impact a youth's attachment relationships. While it is ideal to assume that foster youth can develop healthy attachment relationships with foster parents, this is not always the case (Kelly, 2002). Given the emphasis of Attachment Theory on foster care, it becomes easier to understand conceptualizing success based on the existence, or not, of healthy attachments (e.g., Poulin, 1992).

Second, the application of Attachment Theory to foster care directly speaks to the need to involve youth in conceptualizing success in foster care. Bowlby's fourth stage of 
attachment asserts that youth come to rely on the attachment to the primary caregiver and understands that the primary caregiver will be around in times of need. Mann and Kretchmar (2006) explained that youth will even develop strong attachments and become to depend on caregivers that maltreat them. Given this premise, it is pertinent that the foster care system prepares and support foster youth in dealing with separation and loss of attachment relationships. Just by the very nature that they are in foster care, means that there has been some disruption in attachment. Helping youth deal with attachment issues can be actualized by affording the youth the space to voice concerns about their foster care experience. As well, any assessment of attachment experiences must explicitly involve seeking the perception and input of the foster youth. Goldsmith, Oppenheim, and Wanlass (2004) aptly concluded that child welfare workers should do all they can to promote secure attachments for youth in foster care. This effort certainly includes involving youth in research efforts related to their experiences. 


\section{CHAPTER III: METHODOLOGY}

"Basically, I'm not interested in doing research and I never have been. I'm interested in understanding, which is quite a different thing."

-David Blackwell

\section{Research Goals}

The purpose of this study was to delineate a conceptual domain of successful foster care, from the perspective of foster youth, and explore differences in this conceptualization, based on maltreatment type. As discussed in the preceding chapters, previous conceptualizations of success have overwhelmingly focused on objective criteria (e.g., placement stability, etc.) and have not included the perceptions of foster youth. This study utilized a unique, participatory methodology aimed at addressing these limitations in current child welfare literature. This aim in mind, the goal of this study was to answer the following research questions:

(1) How do foster youth conceptualize successful foster care experiences?

(2) Is there a difference in the way that youth in foster care for abuse conceptualize successful foster care when compared to youth in foster care for neglect?

It is at this point in the narrative that most studies would explicate specific hypothesis. This narrative will not follow this framework, and will not seek to hypothesize what the conceptualization of success for study participants will be. 
Traditionally, the voice of youth has been excluded from child welfare research (see Chapter 1). In instances where youth have been involved, the data is often collected and analyzed in the canon of existing priorities and through the purview of child welfare stakeholders other than foster youth. This in mind, this study sought to build a foundational conceptual domain of success, based on the perspectives of the youth involved in the study.

\section{Concept Mapping}

\section{Overview}

Concept mapping $(\mathrm{CM})$ is a mixed-methodology that utilizes quantitative processes to analyze qualitative data (Brown, 2008). This approach couples multidimensional scaling with hierarchical cluster analysis to create clusters in a two-

dimensional space ( $\mathrm{x}$ and $\mathrm{y}$ axes). Through these analyses, several pictorial representations of the data are constructed. $\mathrm{CM}$ is a process often utilized to articulate a conceptual framework around a focused area of study (Anderson, Day, \& Vandenburg, 2011) and has been proven useful in developing new, and expanding existing, theories (Burke et al., 2005; Haque \& Rosas, 2010; Rosas, 2005; ).

CM has gained in popularity over the past two decades (Rosas \& Kane, 2012). This participatory method has been employed in myriad studies with an array of different disciplines and perspectives. For example, $\mathrm{CM}$ has been utilized in areas of child welfare (Brown \& Calder, 2000; Brown, 2008; Brown, St. Arnault, George, \& Stinzel, 2009), secondary education (Keith, 1989; Truscott, Paulson, \& Everall, 1999; Stoyanov \& Kirschner, 2004), post-secondary education (Abrahams, 2010; Cash, Mathiesen, Barbanell, Smith, \& Graham, 2006; Marin et al., 2006), physical health care (Baldwin, 
Kroesen, Trochim, \& Bell, 2004; Batterham et al., 2002; De Ridder, Depla, Severens, Malsch, 1997; Gonzalez-Block, Rouvier, Becerril, \& Sesia, 2011), mental health and well-being (Bedi, 2006; Biegel, Johnsen, \& Shafran, 1997; Daughtry \& Kunkel, 1993; Gol \& Cook, 2004; White \& Farrell, 2001; Paulson \& Worth, 2002; Paulson, Truscott, \& Stuart, 1999), organizational and workforce culture (Hurt, Wiener, Russell, \& Mannen, 1999; Kolb \& Shepherd, 1997), and community organizing (Ridings et al., 2011; Ridings et al., 2008).

Kane and Trochim (2007) demarcated a six (6) step CM process: (1) Planning for the study; (2) Generating the ideas; (3) Structuring the statements; (4) CM analyses (multidimensional scaling, hierarchical cluster analysis, pattern matches, and go-zone bivariate graphing); (5) Interpreting the maps; and, (6) Composing and articulating a plan of utilization. The remainder of this chapter will outline this study within the context of this six (6) step framework.

\section{Planning for the Study}

Planning for this study was multifaceted. In addition to recruiting a sample and delineating logistics related to scheduling meetings with the participants, it was pertinent to build support from key stakeholders, namely Cabinet for Health and Family Services (CHFS) Social Service Workers (SSW) and Independent Living Coordinators. Independent Living Coordinators (ILCs) are state employees tasked with overseeing and delivering independent living services for teens in foster care throughout the state. The researcher conducted three "Informational Meetings" at various times and locations around the state. These meetings had two primary goals. First, stakeholders needed to understand the primary goal of the study, from its outset. Second, these meetings allowed 
stakeholders to provide insight about how to conduct pragmatic aspects of the study (recruiting the sample, scheduling brainstorming and sorting sessions, etc.).

In addition, planning for this study included submitting Institutional Review Board (IRB) Protocols to the CHFS IRB and the IRB at the University of Louisville. Subsequently, both protocols were approved by each entity, respectively. This study was conducted with cooperation from CHFS. Jim Grace (CHFS Assistant Director of Protection and Permanency) served as the primary CHFS contact and CHFS IRB sponsor for this research project. This study was supported through funding from the Doris Duke Foundation and Chapin Hall at the University of Chicago.

Foster Care Alumni Advisors. Foster care advisors and advisory groups have been convened to work on a plethora of different foster care initiatives around the country. The National Foster Care Youth Advisory Council (NFYAB) (2012) defined a foster care advisory group as one that "works to advise programs, organizations, government agencies, policymakers, and other individuals and groups" working to improve the foster care system (p. 3). The use of youth advisors can also prove useful for research initiatives (e.g., Crowe, 2007). This study utilized two foster alumni advisors to co-construct and analyze aspects of this study. These individuals informed processes related to all six (6) steps of the CM process.

Focus Prompt. Participants in the CM process share their ideas on the area of study via statements during the Brainstorming session. These ideas are captured in statement form and are generated in response to a focus prompt. The focus prompt should be drafted with the explicit goal of producing participant ideas relevant to the overall goals of the study. Kane and Trochim (2007) discussed two types of focus prompts. First, 
the statement form articulates an instruction for participants. For example, this type of statement may read "Generate statements about success in foster care." Second, the prompt form is an incomplete sentence and leaves open an idea for the participant to finish. An example of this type of prompt would be "Success in foster care can be defined as....".

Because $\mathrm{CM}$ is an iterative process, the statements derived from the brainstorming session could be considered the foundational building blocks of the analysis. Thus, it is imperative that the focus prompt be crafted in a way that solicits statements appropriate to the scope of the study. These things in mind, this study utilized the following prompt:

"Come up with statements that describe successful foster care."

This prompt is appropriate in that it solicited ideas related to describing successful foster care. In turn, these ideas were analyzed via CM processes, and resulted in an overall conceptualization of successful foster care.

Piloting a focus prompt is an integral aspect of ensuring appropriate data. This study utilized a two-step process test this prompt. This prompt was piloted with the advisors convened for this study. Also, the prompt was piloted with several state ILCs, during one of the stakeholder meetings.

Sampling and Participants. Trochim (1989a) stated that participants for CM projects should be selected based on their potential to contribute information relevant to answering the research question(s). Participants were selected via a non-random, purposive sampling procedure, which ensured an adequate representation of groups (e.g., maltreatment types, demographics, etc.) relevant to the foci of this study. Other studies have used similar sample sizes (Bedi, 2006; Carpenter, Van Haitsma, Ruckdeschel, \& 
Lawton, 2000) and Kane and Trochim (2007) contended that this procedure and sampling size is ideal for providing an optimal "framework" for ensuring a variety of perspectives and for data interpretation (p. 36).

The following criteria were used to recruit participants for this study:

- Participants will be in foster care in Kentucky;

- Participants will be age $14-18$;

- and, participants will be in the permanent custody of the state and will have completed termination of parental rights (TPR) procedures.

The gather the sample, the researcher emailed CHFS personnel about the possible participants for this study. The email included general information about the project, copies of the approved consent forms, and the approved participant recruitment flier (See Appendix 1). As a result of this process, 30 youths were identified, and participated, in this study.

Participants of this study were offered an incentive to participate in this research. While myriad research studies have used financial incentives when attempting to involve youth (e.g., Aroian, Katz, \& Kulwicki, 2006; Collins, Bronte-Tinkew, \& Burkhauser, 2008), there are no precise guidelines (e.g., type, amount, etc.) for offering incentives to participate in research (Fisher \& Wallace, 2000; Fry et al., 2005; Grant \& Sugarman, 2004). This lack of clarity aside, some authors have made recommendations about incentivizing participation in research for particular groups. For example, Petersen and Leffert (1995) suggested that adolescents may be more likely to respond to monetary incentives, when compared to other non-monetary incentives. Similarly, Kalish, Voigt, Rahimian, DiCara, and Sheehan (2010) reported that financial incentives can lead to 
meaningful participation among adolescents in youth programming and initiatives.

Permuth-Wey and Borenstein (2009) concluded that the use of any financial incentives in research should take into account the scope and goals of the study, benefits and risks of offering incentives, and norms surrounding the targeted population.

Using existing literature and previous studies as a guideline, participants in this study received a $\$ 10.00$ monetary gift card for their participation in the brainstorming session, and another $\$ 40.00$ monetary gift card for their participation in the subsequent statement structuring exercise. Several authors working in a variety of study contexts have reported that this amount is adequate for ensuring participation in research (e.g., Brigham, Winhusen, Lewis, \& Kropp, 2010) and this amount is conducive with what CM participants have received in other studies (e.g., Burke et al., 2005).

Scheduling and Logistics. Based on the above referenced criteria, this study recruited participants through regional ILCs, CHFS SSWs, and office supervisors. Once the participants were identified, informed consent was sought from the participants' SSW of record and participants were asked to provide assent. Scheduling for brainstorming sessions was set once the participants were identified. Before participants partook in the scheduled brainstorming sessions, each youth was asked to complete a brief demographic and general information questionnaire. In the event that youth were not able to complete the form, the researcher sought the missing information from the youth's SSW.

\section{Generating Ideas}

Brainstorming is a process for generating ideas while in a group (Diehl \& Stroebe, 1991). In CM, ideas were originally designed to be gathered via a single brainstorming session. However, as the method and technology have evolved, a frequent modification in 
this premise has been to gather data via several brainstorming sessions utilizing the same prompt (Johnsen, Biegel, \& Shafran, 2000).

A total of five (5) brainstorming sessions were held. These sessions convened in May and June, 2013 and were held in the following counties: Hardin, Boone, Greenup, and two separate sessions were held in Jefferson County. In total, 28 youths (of the 30 total participants) participated in these brainstorming sessions, and these youth received the $\$ 10$ incentive for their participation. All of these sessions utilized the same focus prompt. Similar approaches have been used in other studies (e.g., Biegel, Johnsen, Shafran, 1997; Borden et al., 2007). The researcher facilitated each of the brainstorming sessions. During the sessions, the facilitator explained the scope and purpose of the research in general, and the brainstorming activities specifically. In addition, the researcher led the participants in an ice-breaker exercise and engaged the participants in setting ground rules for the session. During this session, the statements were captured on a laptop and displayed via a projector so as to be visible to the participants.

Idea Synthesis. Idea synthesis refers to the action of editing the statement set to eliminate unclear, redundant, or irrelevant statements. It is not uncommon to eliminate significant number of statements during this process. For example, in a study that examined cancer research, Graham, Kerner, Quinlan, Vinson, and Best (2008) edited a set of 293 statements down to 87 statements. In much larger projects Groenewoud, van Exel, Berg, and Huijsman (2008) gathered statements via a review of existing data and reduced a set of 750 statements down to 178 statements, and Kagan, Kane, Quinlan, Rosas, and Trochim (2009) reduced more than 1500 participant ideas to a representative set of 91 statements. 
Rosas and Kane (2012) suggested a structured process for synthesizing statements and further discussed the need to ensure that the number of statements "minimize burden" for participants during the structuring phase and "maximize breadth" of participant ideas (p. 240). This study employed Giorgi's (1985) guidelines for synthesizing the ideas from the brainstorming session. The goal of the brainstorming session and subsequent idea synthesis was to come up with approximately $50-75$ total participant statements, that accurately represent the range of ideas collected during the brainstorming session. A literature review yielded a number of studies with a collection of statements within this range (e.g., Anderson et al., 2006; Abrahams, 2010; Galvin, 1989; Iris, Ridings, \& Conrad, 2010).

\section{Statement Structuring}

Statement structuring refers to the sorting and rating of statements. Once the list of statements was finalized, the list of statements and participant information was input into The Concept Systems ${ }^{\mathrm{TM}}$ proprietary software. Then, the statements were printed on 3 X 5 index cards (one statement per card). The participants from the brainstorming session were asked to reconvene to sort and rate the statements. Similar to the brainstorming phase discussed above, statements were structured (i.e., sorted and rated) via a number of meetings around the state. A total of four (4) structuring sessions were held. These sessions convened in June and July, 2013 and were held in the following counties: Greenup, Jefferson and two sessions in Boone. In total, 22 youths participated in these structuring exercises. Twenty of these youths also participated in the brainstorming exercise. That is, eight youths that participated in the brainstorming session, did not participate in the structuring exercise. Two youths that did not participate in the 
brainstorming sessions, did participate in the sorting exercise. The 22 youths that participated in the structuring exercise received the $\$ 40$ incentive for their participation. It is suggested that there be at least 15 participants for the structuring phase of the study (Jackson \& Trochim, 2002), a standard which this study met.

The sorting exercise seeks to examine a "meaning" relationship for the group of statements. For this exercise, the participants were given the instructions to sort the statements into piles that "make sense to you." Additionally, participants were advised to not sort any one statement into more than one pile, sort every statement into its own pile, or sort all of the statements into one pile (e.g., Kane \& Trochim, 2007, p. 12). Also, participants were asked to create a "pile name" that captures the theme of each of the sorted piles. Presumably, the statements were sorted into piles based on a perceived conceptual relationship.

Once the statements were sorted, the participants were asked to rate each of statements. The rating exercise seeks to examine a "significance" relationship between statements in the set. Participants were asked to rate each of the statements on the degree to which they feel the statement was important to success in foster care. This category was measured via a Likert-type scale.

\section{Data Analyses}

Once the data sorts and ratings were entered into the software, this information was analyzed. At the outset of the analysis, individual binary similarity matrices were computed for each participant. This matrix was based on a comparison of how each statement is sorted with each of the other statements generated in the brainstorming activities detailed above. Then, an aggregate of this matrix was computed utilizing all of 
the individual sort matrices. High similarity matrix values for a particular statement indicates consensus about the conceptual relationship in a particular "pile" of statements. Conversely, low values on the matrix suggest little (or no) conceptual link in the pile (Brown \& Bednar, 2004).

Multidimensional Scaling (MDS). After the overall similarity matrix was computed, it was analyzed using MDS. This procedure, using a two-dimensional solution, produced $\mathrm{x}$ and $\mathrm{y}$ coordinates for each of the statements. Said another way, each statement is represented as a numbered point in the two-dimensional space. In turn, these coordinates formed a point map illustrated along an $\mathrm{x}$ and $\mathrm{y}$ continuum.

Stress. In MDS, the primary statistic of interest the stress value. The stress value is an indication of the goodness of fit of the two-dimensional configuration provided by the point cluster map to the original similarity matrix. Stress values range from $0-1$, where a completely stable solution has a stress value of zero (0), and a completely unstable solution has a stress value of one (1) (Kunkel, Cook, Meshel, Daughtry, \& Hauenstein, 1999). Trochim (1993) and Kane and Trochim (2007) affirmed that stress values for CM projects ideally range from .205 - .365. Rosas and Kane (2012) affirmed these values and their pooled analysis of CM studies, and found that approximately $95 \%$ of the studies analyzed reported stress values within this range.

Hierarchical Cluster Analysis (HCA). HCA uses resemblance coefficients to analyze similarities in sets of data (Romesburg, 2004). In CM, HCA uses the coordinates derived from the MDS process as input, via Ward's algorithm (Rosas \& Camphausen, 2007). Ward's (1963) approach to cluster analysis looks at an analysis of variance to define cluster parameters. This analysis serves to divide the coordinates, or statements, on 
the point map into distinct clusters. At each stage of the analysis, clusters are combined until there is only one cluster. It is the task of the researcher to decide the ideal number of clusters to accurately represent the data. Ideally, these clusters include statements that are based on a conceptual relationship. Using the computations, a cluster map is computed.

Bridging Analysis. The pertinent statistic relevant to the cluster analysis is the bridging statistic. This statistic ranges from $0-1$, and examines how frequently a statement is sorted with a particular cluster, when compared to how often the statement is sorted in other clusters (Donnelly, Huff, Lindsey, McMahon, \& Schumacher, 2005). Statements with lower bridging values are better indicators of the "meaning" for that particular part of the map. As such, these statements are considered anchors. Statements with higher bridging values mean that the statement serves as a bridge to other sections of the map.

Finalizing the Cluster Solution. There are no set criteria for deciding on the final number of clusters that a map should include (Kane \& Trochim, 2007). Rather, it is the job of the researcher, working in conjunction with key stakeholders, to make a decision regarding the number of clusters appropriate for a particular study. This decision should take into account relevant standards and statistics listed above. For this study, the researcher worked with members of the dissertation committee, the project advisors, and study participants to arrive at a final cluster solution suitable to meeting the goals of this study.

\section{Map Interpretation}


There are several visual representations of data computed by the software. These include the Point Map, the Cluster Map, the Point Rating Map and the Cluster Rating Map.

Pattern Matching. Trochim (1989b) explained that "pattern matching minimally involves the specification of a theoretical pattern, the acquisition of an observed pattern, and an attempt to match these two" (p. 355). A pattern match image compares the ratings of participants when separated on a particular variable.

As previously mentioned in this narrative, this study asked participants to rate each statement on the degree to which they thought it was important to success in foster care. The pattern match for this study examined differences based on the variable: reason for entering foster care. So, instead of examining the pattern match based on variables such as importance and feasibility (as illustrated used in some studies), this study examined the pattern match between two groups: those in care for abuse (physical and sexual) and those in care for neglect.

Go-Zone Graphs. Go-zone graphs are bivariate graphs that are divided into quadrants and demarcate Go-zones for statements with ratings above the mean on both variables. For this study, the Go-zone will illustrate statements for each cluster that rate above the mean for both groups (e.g., abuse and neglect).

\section{Utilization/Interpretation}

Once all of above steps have been completed, the researcher invited participants in the brainstorming and structuring exercises to a third meeting. The project advisors were also invited to participate in this interpretation meeting. The goal of this meeting was to ensure that the final data and map solution represents the participants' ideas. This 
includes assessing the statement list, point maps, clusters, and labeling of clusters.

Critical questions were asked of the participants and advisors. These questions included the following: What do you think of the map? Do these maps accurately depict what the participants meant? And, do these maps make sense to you? Based on this meeting, the results were finalized. 


\title{
CHAPTER IV: RESULTS
}

\author{
"What we find changes who we become." \\ -Peter Morville
}

The overarching aim of this study was to develop a better understanding of youth experiences in foster care. Specifically, the goal was to delineate a conceptual domain of successful foster care, from the perspective of foster youth, and explore differences in this conceptualization, based on maltreatment type. Findings related to the following research questions will be described in this chapter: (1) How do foster youth conceptualize successful foster care experiences? (2) Is there a difference in the way that youth in foster care for abuse conceptualize successful foster care when compared to youth in foster care for neglect? For consistency, this chapter will discuss findings using the CM process explicated in Chapter 3. Additionally, due to the complexity and multiple steps involved in the analyses of this study, certain aspects of the process presented earlier in the narrative, will be reviewed in this chapter.

\section{Participants}

For the 30 participants in this study, primary data were collected utilizing the approved Demographic and General Information Questionnaire (See Appendix 2). Of the 30 youths that participated, 19 identified as being female and 11 identified as male. Participants ranged in age from $14-19$ years, with a mean of $17.13(\mathrm{SD}=1.46)$, and a median and mode of 18 years. The sample was overwhelmingly Caucasian. Twenty-four 
participants reported being Caucasian, four identified as being Black or AfricanAmerican, one identified as American Indian/Native American, and 1 identified as "other", but did not specify. Collectively, participants reported being from 15 different counties across Kentucky, and one participant reported being from another state. Table 1 offers a summary of demographic information for these participants.

Table 1

Demographic Information for Participants $(N=30)$

\begin{tabular}{lc}
\hline \multicolumn{1}{c}{ Category } & Frequency \\
\hline Gender & \\
Male & 11 \\
Female & 19 \\
Race & \\
Caucasian & 24 \\
Black/African-American & 4 \\
American Indian/Native American & 1 \\
Other, Not Specified & 1 \\
Age & \\
14 years & 2 \\
15 years & 4 \\
16 years & 3 \\
17 years & 2 \\
18 years & 17 \\
19 years & $2 * *$ \\
\hline
\end{tabular}

**Note. While two (2) of the participants were 19 at the time data were collected, when the participants agreed to be a part of the study, they were 18 years old.

General Information. In addition to the demographic information presented above, the approved questionnaire solicited general information related to the participants' foster care experiences. As a group, the participants spent an average of 3.91 $(\mathrm{SD}=2.94)$ years in foster care, with a median and mode of 3.0 years. Time in care ranged from .5 years to 11.5 years. Participants in this study had a mean of 5.33 placements $(\mathrm{SD}=5.96)$, with a median of 2.5 placements, and a mode of 2.0 placements. 
Number of placements ranged from one placement, to one participant reporting having 23 placements. Eleven of the participants reported being in high school, and 18 reported having recently graduated from high school. One participant reported completing a General Equivalency Diploma (GED). Participants reported one of three reasons for entering care: Abuse (including physical and sexual) $(\mathrm{n}=14)$, neglect $(\mathrm{n}=15)$, and dependency $(\mathrm{n}=1)$. Kentucky Revised Statute (KRS) 600.020(19) described a child in care for dependency, or a "dependent child" is "any child, other than an abused or neglected child, who is under improper care, custody, control, or guardianship that is not due to an intentional act of the parent, guardian, or person exercising custodial control or supervision of the child" (p. 4). Lastly, two participants reported that they are currently parenting and seven youths reporting being employed. Table 2 offers a summary of general information for these participants. 
Table 2

General Information about Youth Foster Care Experiences $(N=30)$

\begin{tabular}{lc}
\hline \multicolumn{1}{c}{ Category } & Frequency \\
\hline Time in Care & 3 \\
.50 year & 1 \\
.75 year & 2 \\
1 year & 4 \\
2 years & 1 \\
2.5 years & 6 \\
3 years & 2 \\
4 years & 2 \\
4.5 years & 2 \\
5 years & 3 \\
6 years & 1 \\
8 years & 1 \\
9 years & 1 \\
11 years & 1 \\
11.5 years & \\
Number of Placements & 5 \\
1 & 10 \\
2 & 5 \\
3 & 2 \\
4 &
\end{tabular}


Table 2

Continued

\begin{tabular}{lc}
\hline \multicolumn{1}{c}{ Category } & Frequency \\
\hline Employed & 7 \\
Yes & 23 \\
No & \\
Reason For Being In Care & 14 \\
Abuse & 15 \\
Neglect & 1 \\
Dependency & \\
\hline
\end{tabular}

In order to assess participants' overall foster care experience, the approved questionnaire included the following item: Overall, how would you rate your foster care experience? Youth were asked to rate their foster care experience utilizing a five-point Likert-scale, anchored at 1 with "Bad", at 3 with "Neither Good nor Bad", and at 5 with "Good." Participants in this study had a mean rating of $3.77(\mathrm{SD}=1.07)$. There were three modes, with 9 participants each indicating ratings of 3, 4, and 5, respectively. Participant ratings ranged from a rating of 1 to a rating of 5. Table 3 delineates participant responses to this item.

Table 3

Frequency Table for Overall Experience Item $(N=30)$

\begin{tabular}{cccccc}
\hline & Bad & Neither Good Nor Bad & Good \\
Item & 0 & 1 & 3 & 4 & 5 \\
\hline $\begin{array}{l}\text { Overall, how would you rate } \\
\text { your foster care experience? }\end{array}$ & 1 & 2 & 9 & 9 & 9 \\
\hline
\end{tabular}

\section{Generating the Ideas}

The approach to generating the ideas is consistent with the outline specified in the previous chapter. During each of the brainstorming sessions, the researcher obtained the necessary consent/assent forms, and conducted a brief "ice-breaker" exercise with the 
participants. Then, participants were asked to generate statements in response to the focus prompt. After the session, the researcher and the advisory panel met to review all statements to ensure that all statements were clear and that all redundant statements were removed from the statement set. After this process, a statement set of 53 statements was finalized. See Table 4 for the final statement set.

NOTE: These statement numbers delineated in Table 4 will be utilized for reference for the duration of this narrative.

Table 4

Final Statement Set $(N=53)$

\section{Statements}

1 Successful foster care means that relatives should not be excluded from being a placement just because they have a criminal record.

2 Successful foster care means that youth are not judged based on their "records" (such as a case file).

3 Successful foster care means that there are more age-appropriate events and activities for teens in care.

4 Successful foster care offers incentives, like money, for participating in foster care programs.

5 Successful foster care helps youth get jobs once they leave foster care.

6 Successful foster care means that foster parents are not just fostering for the money.

7 Successful foster care has consistent rules for foster homes that are enforced across the board.

8 Successful foster care means not being ashamed of being in foster care.

9 Successful foster care will place youth with foster parents and other kids that are the same race.

10 Successful foster care means being placed in a safe home.

11 Successful foster care means having foster parents that don't "front" (i.e., act one way in front of workers and a different way at home).

12 Successful foster care allows foster youth to visit with friends without having background checks on those friends.

13 Successful foster care allows youth to "give back" and help youth once they leave care.

14 Successful foster care allows foster parents to make decisions on behalf of the youth without having to always ask the social worker.

15 Successful foster care means that youth are placed close to the home they are removed from. 
Table 4

Continued

Statements

16 Successful foster care means having social workers that LISTEN more.

17 Successful foster care allows responsible youth to get a driver's license at 16.

18 Successful foster care means training a foster parents' biological kids about foster care.

19 Successful foster care means that people don't have to feel sorry for foster kids.

20 Successful foster care supports youth who choose to go to college.

21 Successful foster care means that youth are better matched with foster parents.

22 Successful foster care allows youth to NOT identify as being a foster kid.

23 Successful foster care means that foster parents don't threaten to have kids removed from their home for "little stuff."

24 Successful foster care means that youth are able to connect with others in foster care.

25 Successful foster care supports youth to participate in after-school activities.

26 Successful foster care means that foster parents treat their foster kids and their birth kids the same.

27 Successful foster care means that youth are able to meet with foster parents before being placed with them.

28 Successful foster care allows foster youth to have more input in developing their goals.

29 Successful foster care requires that people (social workers, judges, etc.) trust youth to make good decisions.

30 Successful foster care means having a social worker that personally cares about their foster kids.

31 Successful foster care requires that foster parents work to build a relationship with the foster kid's biological parents.

32 Successful foster care means that foster kids have a consistent worker and are not changing workers all the time.

33 Successful foster care means that foster kids are treated the same as kids not in foster care.

34 Successful foster care uses foster parents that really try to understand what the foster kid is going through.

35 Successful foster care means having foster parents that are comfortable with themselves (e.g., not insecure).

36 Successful foster care means that youth are able to visit with appropriate family members (biological parents, siblings, etc.) on a regular basis.

37 Successful foster care recruits "young" foster parents.

38 Successful foster care means that youth are able to easily re-enter care if they change their mind about re-committing.

39 Successful foster care means being in a loving foster family. 
Table 4

Continued

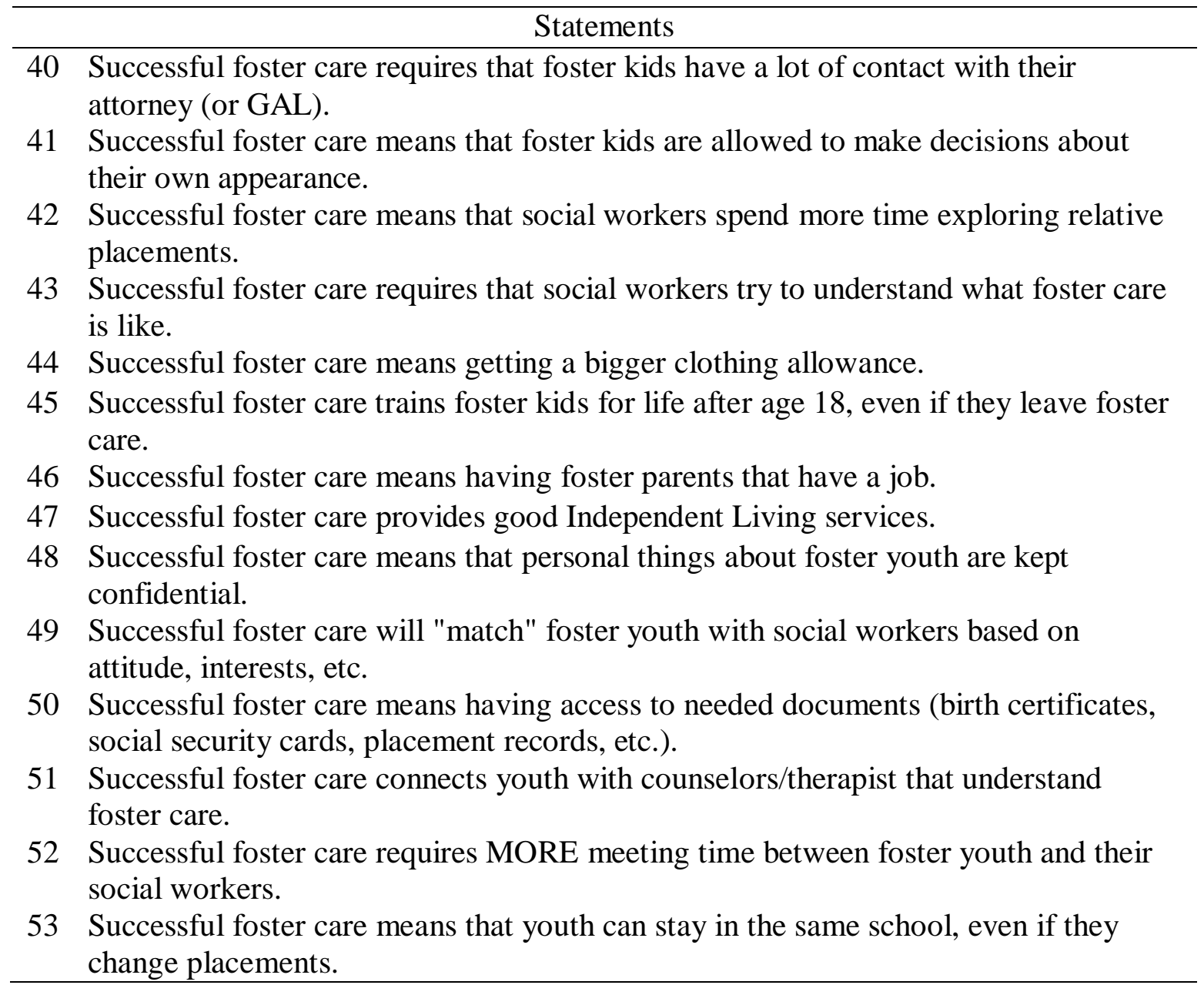

\section{Structuring the Statements}

The approach to structuring the statements is consistent with the outline specified in the previous chapter. Participants rated each of the 53 statements on one variable: importance. To ascertain these ratings, participants were asked the following question: How important do you feel this statement is to successful foster care? This category was measured via a Likert-type scale ranging from one to five. For this scale, 1 indicated "Not at all Important", 2 indicated "Unimportant", 3 indicated "Neither Important nor 
Unimportant", 4 indicated "Important", and 5 indicated "Very Important." This query and rating scale was reviewed by the project advisors before it was administered. For each participant, sorting and rating data were collected during one session, at each location, respectively.

Mean ratings for each of the items in the statement set ranged from 1.86 to 4.91 . Statement 10 "Successful foster care means being placed in a safe home" was rated most important by the participants with a mean rating of $4.91(\mathrm{SD}=.43)$. Statement 9 "Successful foster care will place youth with foster parents and other kids that are the same race" was rated at the least important statement in the set with a mean rating of 1.86 $(\mathrm{SD}=1.36)$. Table 5 delineates mean rating scores for each item in the statement set. 
Table 5

Mean Ratings by Item

\begin{tabular}{|c|c|c|}
\hline Item & $\begin{array}{l}\text { Mean } \\
\text { Rating }\end{array}$ & SD \\
\hline $\begin{array}{l}\text { Successful foster care means that youth can stay in the same school, even } \\
\text { if they change placements. }\end{array}$ & 3.50 & 1.14 \\
\hline $\begin{array}{l}\text { Successful foster care requires MORE meeting time between foster youth } \\
\text { and their social workers. }\end{array}$ & 3.64 & 1.14 \\
\hline $\begin{array}{l}\text { Successful foster care connects youth with counselors/therapist that } \\
\text { understands foster care. }\end{array}$ & 3.95 & 1.05 \\
\hline $\begin{array}{l}\text { Successful foster care means having access to needed documents (birth } \\
\text { certificates, social security cards, placement records, etc.). }\end{array}$ & 4.64 & .58 \\
\hline $\begin{array}{l}\text { Successful foster care will "match" foster youth with social workers } \\
\text { based on attitude, interests, etc. }\end{array}$ & 3.68 & 1.36 \\
\hline $\begin{array}{l}\text { Successful foster care means that personal things about foster youth are } \\
\text { kept confidential. }\end{array}$ & 4.68 & .57 \\
\hline Successful foster care provides good Independent Living services. & 4.55 & .67 \\
\hline Successful foster care means having foster parents that have a job. & 3.68 & 1.29 \\
\hline $\begin{array}{l}\text { Successful foster care trains foster kids for life after age } 18 \text {, even if they } \\
\text { leave foster care. }\end{array}$ & 4.59 & .67 \\
\hline Successful foster care means getting a bigger clothing allowance. & 3.73 & 1.28 \\
\hline $\begin{array}{l}\text { Successful foster care requires that social workers try to understand what } \\
\text { foster care is like. }\end{array}$ & 4.18 & 1.05 \\
\hline $\begin{array}{l}\text { Successful foster care means that social workers spend more time } \\
\text { exploring relative placements. }\end{array}$ & 4.00 & 1.02 \\
\hline $\begin{array}{l}\text { Successful foster care means that foster kids are allowed to make } \\
\text { decisions about their own appearance. }\end{array}$ & 4.23 & .81 \\
\hline $\begin{array}{l}\text { Successful foster care requires that foster kids have a lot of contact with } \\
\text { their attorney (or GAL). }\end{array}$ & 3.77 & 1.34 \\
\hline Successful foster care means being in a loving foster family. & 4.59 & .73 \\
\hline $\begin{array}{l}\text { Successful foster care means that youth are able to easily re-enter care if } \\
\text { they change their mind about re-committing. }\end{array}$ & 4.09 & .68 \\
\hline Successful foster care recruits "young" foster parents. & 3.23 & 1.19 \\
\hline $\begin{array}{l}\text { Successful foster care means that youth are able to visit with appropriate } \\
\text { family members (biological parents, siblings, etc.) on a regular basis. }\end{array}$ & 4.45 & .74 \\
\hline $\begin{array}{l}\text { Successful foster care means having foster parents that are comfortable } \\
\text { with themselves (e.g., not insecure). }\end{array}$ & 4.00 & 1.20 \\
\hline $\begin{array}{l}\text { Successful foster care uses foster parents that really try to understand } \\
\text { what the foster kid is going through. }\end{array}$ & 4.55 & .74 \\
\hline $\begin{array}{l}\text { Successful foster care means that foster kids are treated the same as kids } \\
\text { not in foster care. }\end{array}$ & 4.68 & .65 \\
\hline $\begin{array}{l}\text { Successful foster care means that foster kids have a consistent worker and } \\
\text { are not changing workers all the time. }\end{array}$ & 4.73 & .63 \\
\hline $\begin{array}{l}\text { Successful foster care requires that foster parents work to build a } \\
\text { relationship with the foster kid's biological parents. }\end{array}$ & 3.59 & 1.22 \\
\hline
\end{tabular}


Table 5

Continued

\begin{tabular}{|c|c|c|}
\hline Item & $\begin{array}{l}\text { Mean } \\
\text { Rating }\end{array}$ & SD \\
\hline $\begin{array}{l}\text { Successful foster care means having a social worker that personally cares } \\
\text { about their foster kids. }\end{array}$ & 4.32 & .89 \\
\hline $\begin{array}{l}\text { Successful foster care requires that people (social workers, judges, etc.) } \\
\text { trust youth to make good decisions. }\end{array}$ & 4.00 & .93 \\
\hline $\begin{array}{l}\text { Successful foster care allows foster youth to have more input in } \\
\text { developing their goals. }\end{array}$ & 4.18 & .91 \\
\hline $\begin{array}{l}\text { Successful foster care means that youth are able to meet with foster } \\
\text { parents before being placed with them. }\end{array}$ & 4.32 & .84 \\
\hline $\begin{array}{l}\text { Successful foster care means that foster parents treat their foster kids and } \\
\text { their birth kids the same. }\end{array}$ & 4.55 & .74 \\
\hline $\begin{array}{l}\text { Successful foster care supports youth to participate in after-school } \\
\text { activities. }\end{array}$ & 4.27 & .77 \\
\hline $\begin{array}{l}\text { Successful foster care means that youth are able to connect with others in } \\
\text { foster care. }\end{array}$ & 4.32 & .94 \\
\hline $\begin{array}{l}\text { Successful foster care means that foster parents don't threaten to have } \\
\text { kids removed from their home for little stuff. }\end{array}$ & 4.50 & .80 \\
\hline Successful foster care allows youth to NOT identify as being a foster kid. & 3.91 & 1.23 \\
\hline $\begin{array}{l}\text { Successful foster care means that youth are better matched with foster } \\
\text { parents. }\end{array}$ & 3.91 & 1.20 \\
\hline Successful foster care supports youth who choose to go to college. & 4.59 & .73 \\
\hline $\begin{array}{l}\text { Successful foster care means that people don't have to feel sorry for } \\
\text { foster kids. }\end{array}$ & 4.23 & .87 \\
\hline $\begin{array}{l}\text { Successful foster care means training a foster parents' biological kids } \\
\text { about foster care. }\end{array}$ & 3.82 & .96 \\
\hline $\begin{array}{l}\text { Successful foster care allows responsible youth to get a driver's license at } \\
16 .\end{array}$ & 4.14 & .89 \\
\hline Successful foster care means having social workers that LISTEN more. & 4.59 & .50 \\
\hline $\begin{array}{l}\text { Successful foster care means that youth are placed close to the home they } \\
\text { are removed from. }\end{array}$ & 3.05 & 1.55 \\
\hline $\begin{array}{l}\text { Successful foster care allows foster parents to make decisions on behalf } \\
\text { of the youth without having to always ask the social worker. }\end{array}$ & 4.18 & 1.14 \\
\hline $\begin{array}{l}\text { Successful foster care allows youth to "give back" and help youth once } \\
\text { they leave care. }\end{array}$ & 4.23 & .87 \\
\hline $\begin{array}{l}\text { Successful foster care allows foster youth to visit with friends without } \\
\text { having background checks on those friends. }\end{array}$ & 4.09 & 1.02 \\
\hline $\begin{array}{l}\text { Successful foster care means having foster parents that don't front (act } \\
\text { one way in front of workers and a different way at home). }\end{array}$ & 4.82 & .50 \\
\hline Successful foster care means being placed in a safe home. & 4.91 & .43 \\
\hline $\begin{array}{l}\text { Successful foster care will place youth with foster parents and other kids } \\
\text { that are the same race. }\end{array}$ & 1.86 & 1.36 \\
\hline Successful foster care means not being ashamed of being in foster care. & 4.23 & 1.10 \\
\hline
\end{tabular}


Table 5

\section{Continued}

\begin{tabular}{lcc}
\hline \multicolumn{1}{c}{ Item } & $\begin{array}{c}\text { Mean } \\
\text { Rating }\end{array}$ & SD \\
\hline $\begin{array}{l}\text { Successful foster care has consistent rules for foster homes that are } \\
\text { enforced across the board. }\end{array}$ & 4.23 & 1.10 \\
$\begin{array}{l}\text { Successful foster care means that foster parents are not just fostering for } \\
\text { the money. }\end{array}$ & 4.73 & .63 \\
$\begin{array}{l}\text { Successful foster care helps youth get jobs once they leave foster care. } \\
\text { Successful foster care offers incentives, like money, for participating in }\end{array}$ & 4.55 & .74 \\
$\begin{array}{l}\text { foster care programs. } \\
\text { Successful foster care means that there are more age-appropriate events }\end{array}$ & 4.05 & 1.10 \\
$\begin{array}{l}\text { and activities for teens in care. } \\
\text { Successful foster care means that youth are not judged based on their }\end{array}$ & 4.27 & .98 \\
$\begin{array}{l}\text { "records" (such as a case file). } \\
\text { Successful foster care means that relatives should not be excluded from } \\
\text { being a placement just because they have a criminal record. }\end{array}$ & 4.41 & .91 \\
\hline
\end{tabular}




\section{Analyses}

Data were analyzed utilizing The Concept Systems ${ }^{\mathrm{TM}}$ proprietary software. First, a similarity matrix was computed. The matrix was calculated based on the collective sort data for all participants who took part in the data structuring exercises specified above (n =22). The possible matrix values for the statements in this set could range from zero (i.e., the statements were not sorted into the same pile together) to 22 (i.e., every participant sorted the statements into the same pile), the total number of sorters utilized for this study.

Table 6 is an illustrative example of a portion of the overall similarity matrix computed, based on the participant sorting data. As this table illustrates, the statements were sorted into piles at various rates. For example, Statement 11 "Successful foster care means having foster parents that don't "front" (i.e., act one way in front of workers and a different way at home)", was sorted with Statement 6 "Successful foster care means that foster parents are not just fostering for the money", a total of 21 times. This total means that only one of the participants in the statement structuring phase of this study did not sort those two statements into the same pile. Conversely, Statement 6 and Statement 1 "Successful foster care means that relatives should not be excluded from being a placement just because they have a criminal record", was not sorted together by any of the participants, thus the zero on the similarity matrix. These examples are demarcated by the red circles on the table. Sort frequencies for this study ranged from $0-22$. 
Table 6

Portion of the Overall Similarity Matrix (Illustrative Example)

\begin{tabular}{ccccccccc}
\hline Statement Index & 1 & 2 & 3 & 4 & 5 & 6 & 7 & 8 \\
\hline 1 & & 4 & 6 & 9 & 6 & 0 & 8 & 3 \\
2 & 4 & & 13 & 9 & 9 & 3 & 6 & 11 \\
3 & 6 & 13 & & 16 & 9 & 0 & 9 & 8 \\
4 & 9 & 9 & 16 & & 10 & 0 & 12 & 5 \\
5 & 6 & 9 & 9 & 10 & & 4 & 5 & 5 \\
6 & $\mathbf{0}$ & 3 & 0 & 0 & 4 & & 7 & 0 \\
7 & 5 & 6 & 9 & 12 & 5 & 7 & & 3 \\
8 & 3 & 11 & 8 & 5 & 5 & 0 & 3 & \\
9 & 15 & 4 & 9 & 8 & 3 & 1 & 6 & 2 \\
10 & 14 & 3 & 6 & 5 & 8 & 5 & 7 & 2 \\
11 & 1 & 3 & 0 & 0 & 5 & $\mathbf{2 1}$ & 7 & 0 \\
12 & 13 & 1 & 3 & 3 & 2 & 1 & 3 & 0 \\
13 & 3 & 9 & 11 & 9 & 11 & 0 & 4 & 11 \\
14 & 4 & 2 & 1 & 0 & 3 & 14 & 8 & 1 \\
15 & 15 & 1 & 5 & 5 & 4 & 0 & 5 & 1 \\
\hline
\end{tabular}

After the similarity matrix was computed, it was analyzed using MDS. This

procedure utilized a two-dimensional solution to produce $x$ and $y$ coordinates for each of the statements.

Based on these coordinates, a point map was computed. The point map for this study can be found in Figure 1. This point map merged after 13 iterations and had an overall stress value of 0.1346 . This stress value is below the typical range for studies, as explicated by Kane and Trochim (2007). This is likely due to the number of statements utilized to calculate this solution. This stress value indicates that the point map represents a "good fit" for the actual data structure. As an example of how this map is configured, one statement is highlighted in Figure 1. The selection of this statement does not indicate anything pertaining to analysis, and just serves as an illustrative example. 
Figure 1. Point Map with Statement Numbers

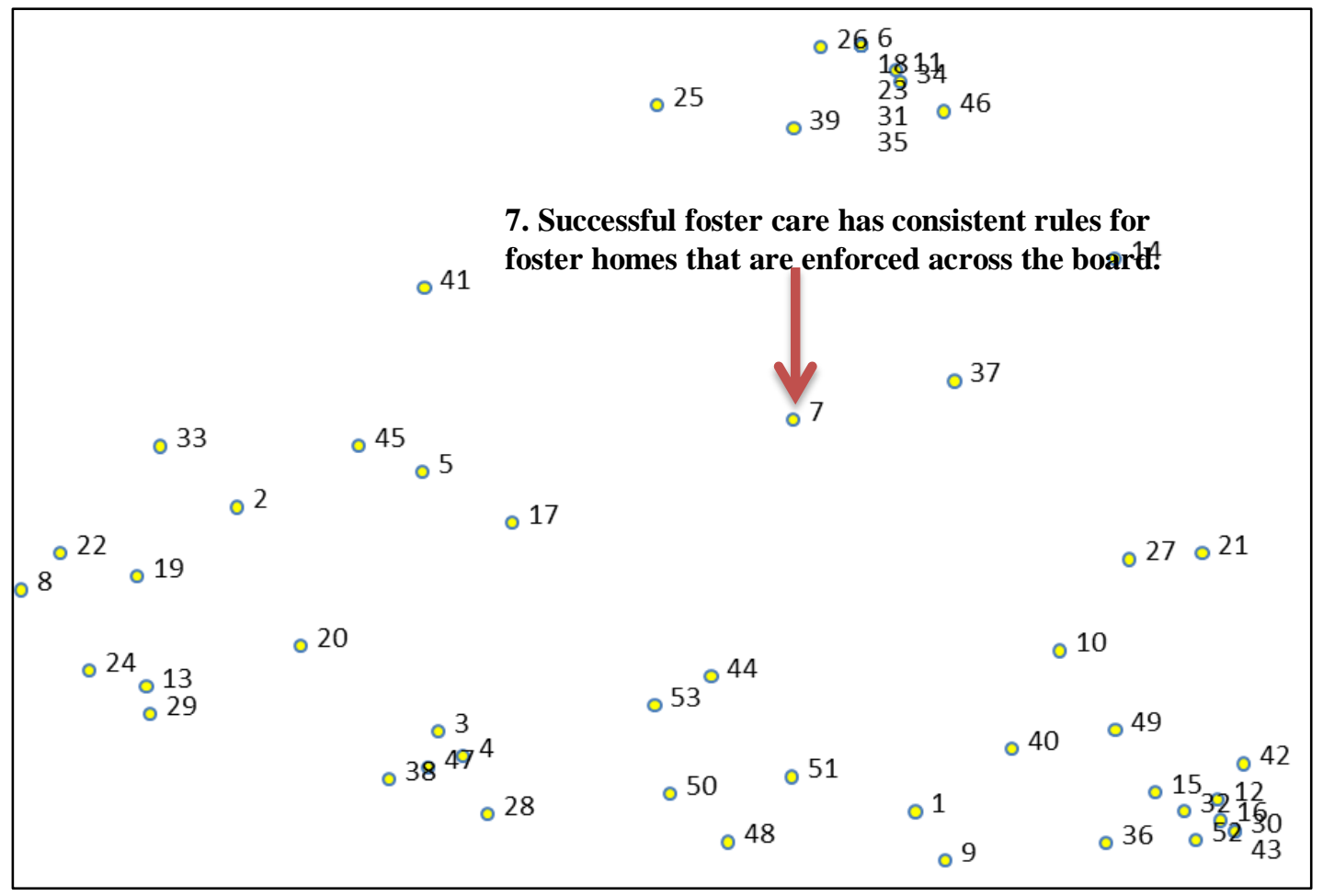


Once the point map was configured, a HCA used resemblance coefficients to analyze similarities among the pairs of data. For this study, the coordinates derived from the MDS process, and utilized to compute the point map, were used as the input for the HCA. In turn, the coordinates on the point map were divided into distinct clusters. After the HCA analyses, the clusters were labeled. These labels were based on the labels provided by the participants during the sort phase of this project. Labels are selected based on the extent to which the label represents the statements, or overall theme, of the cluster. Figure 2 illustrates the final four Cluster Map and labels computed for this study. As this figure elucidates, the final cluster solution for this study contains four distinct clusters: Social Work, Foster Parent(s), Foster Youth, and Foster Agency. 
Figure 2. Final Cluster Map

\section{Foster Parent(s)}
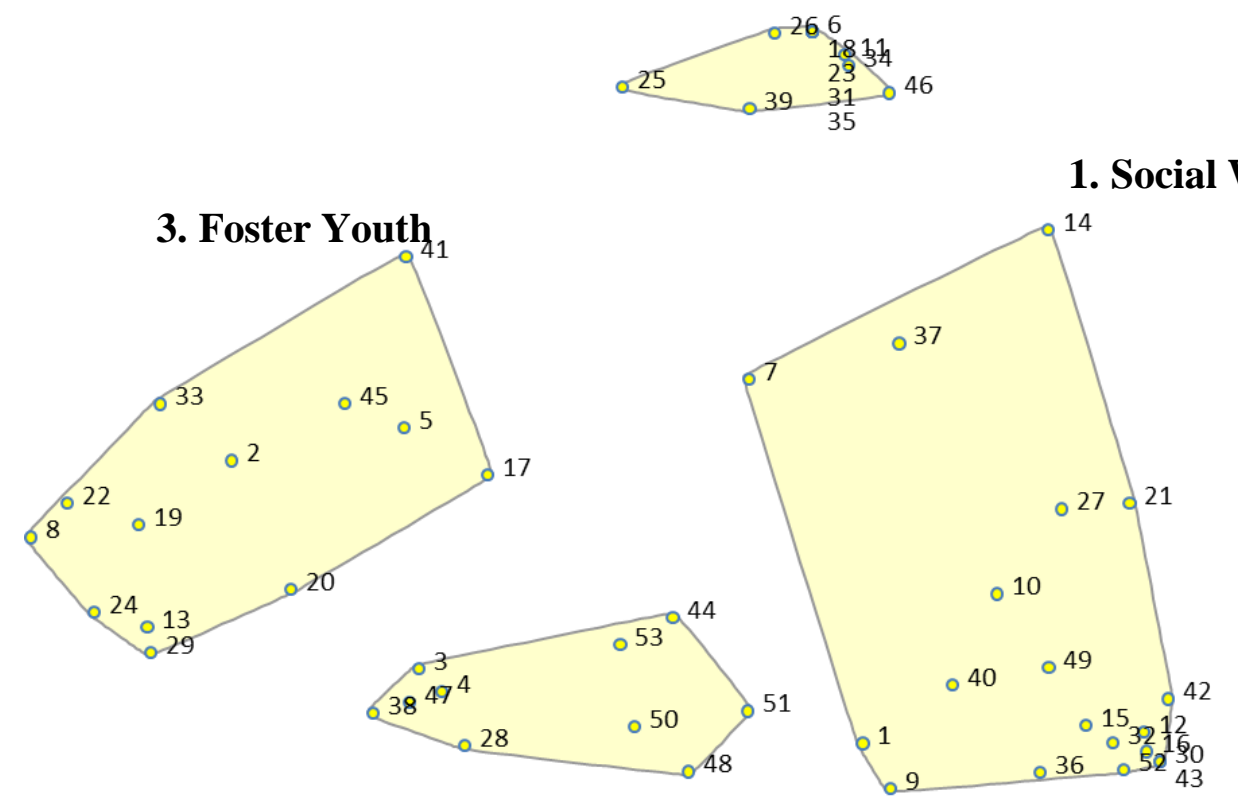

2. Foster Agency

Bridging values and number of statements included in each of the clusters are delineated in Table 7. Mean cluster bridging values for the final four cluster solution ranged from 0.15 to 0.64 . Lower bridging values indicate more cohesiveness between the statements within the cluster. For this study, the Foster Parent cluster was the most cohesive, with a mean bridging value of 0.15 . This statistic indicates that statements in this cluster were sorted together at a higher rate. The Foster Youth cluster showed the least cohesiveness, with a mean bridging value of 0.64 . This statistic signifies that statements in this cluster were not sorted together as often as the statements contained in other clusters. 
Table 7

Clusters, Statements, and Bridging Values

\begin{tabular}{|c|c|}
\hline Statements & Value \\
\hline \multicolumn{2}{|l|}{ Cluster 1: Social Work } \\
\hline $\begin{array}{l}\text { Successful foster care means that relatives should not be excluded from being a } \\
\text { placement just because they have a criminal record. }\end{array}$ & 0.44 \\
\hline $\begin{array}{l}\text { Successful foster care has consistent rules for foster homes that are enforced across } \\
\text { the board. }\end{array}$ & 0.79 \\
\hline $\begin{array}{l}\text { Successful foster care will place youth with foster parents and other kids that are } \\
\text { the same race. }\end{array}$ & 0.53 \\
\hline Successful foster care means being placed in a safe home. & 0.54 \\
\hline $\begin{array}{l}\text { Successful foster care allows foster youth to visit with friends without having } \\
\text { background checks on those friends. }\end{array}$ & 0.23 \\
\hline $\begin{array}{l}\text { Successful foster care allows foster parents to make decisions on behalf of the } \\
\text { youth without having to always ask the social worker. }\end{array}$ & 0.84 \\
\hline $\begin{array}{l}\text { Successful foster care means that youth are placed close to the home they are } \\
\text { removed from. }\end{array}$ & 0.2 \\
\hline Successful foster care means having social workers that LISTEN more. & 0.15 \\
\hline Successful foster care means that youth are better matched with foster parents. & 0.73 \\
\hline $\begin{array}{l}\text { Successful foster care means that youth are able to meet with foster parents before } \\
\text { being placed with them. }\end{array}$ & 0.67 \\
\hline $\begin{array}{l}\text { Successful foster care means having a social worker that personally cares about } \\
\text { their foster kids. }\end{array}$ & 0.14 \\
\hline $\begin{array}{l}\text { Successful foster care means that foster kids have a consistent worker and are not } \\
\text { changing workers all the time. }\end{array}$ & 0.16 \\
\hline $\begin{array}{l}\text { Successful foster care means that youth are able to visit with appropriate family } \\
\text { members (biological parents, siblings, etc.) on a regular basis. }\end{array}$ & 0.29 \\
\hline Successful foster care recruits "young" foster parents. & 0.84 \\
\hline $\begin{array}{l}\text { Successful foster care requires that foster kids have a lot of contact with their } \\
\text { attorney (or GAL). }\end{array}$ & 0.42 \\
\hline $\begin{array}{l}\text { Successful foster care means that social workers spend more time exploring relative } \\
\text { placements. }\end{array}$ & 0.26 \\
\hline $\begin{array}{l}\text { Successful foster care requires that social workers try to understand what foster care } \\
\text { is like. }\end{array}$ & 0.14 \\
\hline $\begin{array}{l}\text { Successful foster care will "match" foster youth with social workers based on } \\
\text { attitude, interests, etc. }\end{array}$ & 0.37 \\
\hline $\begin{array}{l}\text { Successful foster care requires MORE meeting time between foster youth and their } \\
\text { social workers. }\end{array}$ & 0.17 \\
\hline Mean Bridging Value & 0.41 \\
\hline \multicolumn{2}{|l|}{ Cluster 2: Foster Parent(s) } \\
\hline Successful foster care means that foster parents are not just fostering for the money. & 0 \\
\hline $\begin{array}{l}\text { Successful foster care means having foster parents that don't front (act one way in } \\
\text { front of workers and a different way at home). }\end{array}$ & 0.12 \\
\hline $\begin{array}{l}\text { Successful foster care means training a foster parents' biological kids about foster } \\
\text { care. }\end{array}$ & 0 \\
\hline
\end{tabular}


Table 7

Clusters, Statements, and Bridging Values

\begin{tabular}{|c|c|}
\hline Statements & Value \\
\hline $\begin{array}{l}\text { Successful foster care means that foster parents don't threaten to have kids removed } \\
\text { from their home for little stuff. }\end{array}$ & 0 \\
\hline Successful foster care supports youth to participate in after-school activities. & 0.55 \\
\hline $\begin{array}{l}\text { Successful foster care means that foster parents treat their foster kids and their birth } \\
\text { kids the same. }\end{array}$ & 0.08 \\
\hline $\begin{array}{l}\text { Successful foster care requires that foster parents work to build a relationship with } \\
\text { the foster kid's biological parents. }\end{array}$ & 0 \\
\hline $\begin{array}{l}\text { Successful foster care uses foster parents that really try to understand what the foster } \\
\text { kid is going through. }\end{array}$ & 0.15 \\
\hline $\begin{array}{l}\text { Successful foster care means having foster parents that are comfortable with } \\
\text { themselves (e.g., not insecure). }\end{array}$ & 0 \\
\hline Successful foster care means being in a loving foster family. & 0.4 \\
\hline Successful foster care means having foster parents that have a job. & 0.31 \\
\hline Mean Bridging Value & 0.15 \\
\hline \multicolumn{2}{|l|}{ Cluster 3: Foster Youth } \\
\hline $\begin{array}{l}\text { Successful foster care means that youth are not judged based on their "records" (such } \\
\text { as a case file). }\end{array}$ & 0.64 \\
\hline Successful foster care helps youth get jobs once they leave foster care. & 0.72 \\
\hline Successful foster care means not being ashamed of being in foster care. & 0.55 \\
\hline $\begin{array}{l}\text { Successful foster care allows youth to "give back" and help youth once they leave } \\
\text { care. }\end{array}$ & 0.51 \\
\hline Successful foster care allows responsible youth to get a driver's license at 16 . & 0.65 \\
\hline Successful foster care means that people don't have to feel sorry for foster kids. & 0.53 \\
\hline Successful foster care supports youth who choose to go to college. & 0.47 \\
\hline Successful foster care allows youth to NOT identify as being a foster kid. & 0.62 \\
\hline Successful foster care means that youth are able to connect with others in foster care. & 0.56 \\
\hline $\begin{array}{l}\text { Successful foster care requires that people (social workers, judges, etc.) trust youth } \\
\text { to make good decisions. }\end{array}$ & 0.64 \\
\hline $\begin{array}{l}\text { Successful foster care means that foster kids are treated the same as kids not in foster } \\
\text { care. }\end{array}$ & 0.71 \\
\hline $\begin{array}{l}\text { Successful foster care means that foster kids are allowed to make decisions about } \\
\text { their own appearance. }\end{array}$ & 1.0 \\
\hline $\begin{array}{l}\text { Successful foster care trains foster kids for life after age } 18 \text {, even if they leave foster } \\
\text { care. }\end{array}$ & 0.77 \\
\hline Mean Bridging Value & 0.64 \\
\hline \multicolumn{2}{|l|}{ Cluster 4: Foster Agency } \\
\hline $\begin{array}{l}\text { Successful foster care means that there are more age-appropriate events and } \\
\text { activities for teens in care. }\end{array}$ & 0.48 \\
\hline $\begin{array}{l}\text { Successful foster care offers incentives, like money, for participating in foster care } \\
\text { programs. }\end{array}$ & 0.42 \\
\hline
\end{tabular}


Table 7

Clusters, Statements, and Bridging Values

\begin{tabular}{lc}
\hline \multicolumn{1}{c}{ Statements } & Value \\
\hline $\begin{array}{l}\text { Successful foster care allows foster youth to have more input in developing their } \\
\text { goals. }\end{array}$ & 0.6 \\
$\begin{array}{l}\text { Successful foster care means that youth are able to easily re-enter care if they change } \\
\text { their mind about re-committing. }\end{array}$ & 0.52 \\
$\begin{array}{l}\text { Successful foster care means getting a bigger clothing allowance. } \\
\text { Successful foster care provides good Independent Living services. }\end{array}$ & 0.55 \\
$\begin{array}{l}\text { Successful foster care means that personal things about foster youth are kept } \\
\text { confidential. }\end{array}$ & 0.46 \\
$\begin{array}{l}\text { Successful foster care means having access to needed documents (birth certificates, } \\
\text { social security cards, placement records, etc.). }\end{array}$ & 0.56 \\
$\begin{array}{l}\text { Successful foster care connects youth with counselors/therapist that understand } \\
\text { foster care. }\end{array}$ & 0.58 \\
$\begin{array}{l}\text { Successful foster care means that youth can stay in the same school, even if they } \\
\text { change placements. }\end{array}$ & 0.53 \\
Mean Bridging Value & $\mathbf{0 . 5 3}$ \\
\hline
\end{tabular}

Figure 3 illustrates the Cluster Bridging Map and serves as a supplement to Table

9. In the Cluster Bridging Map, the mean bridging values are displayed in a third

dimension. For this graph, the fewer levels a cluster has, the more cohesive the cluster is, relative to other clusters on the map. 
Figure 3. Cluster Bridging Map

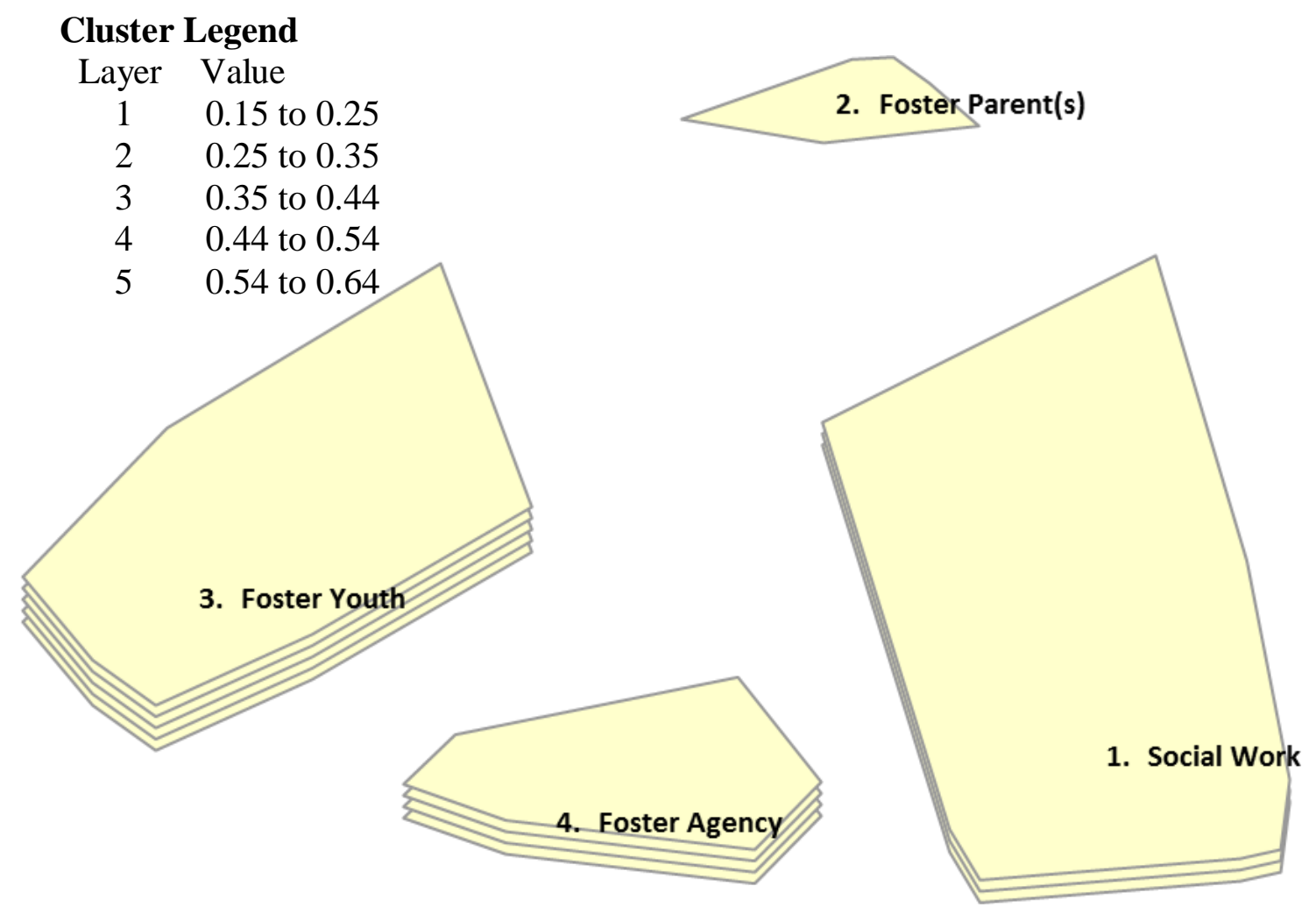

CM Item and Cluster Ratings Analyses. For the rating exercise, data were used for the 22 participants that participated in this phase of the study. As indicated above, participants rated each of the 53 statements on the variable of importance. Specifically, participants rated each statement on the degree to which they thought it was important to success in foster care. Figure 4 is a Point Rating Map. This figure illustrates the ratings for each individual item, and is a calculation of mean ratings for all 22 participants. This figure serves as a supplement to Tables 5 and 6 presented earlier in this chapter and are based on the Point Map (Figure 1). For the Point Rating Map, the number of "blocks" in the column's height indicates the mean importance ratings for each item, relative to other items on the map. In Figure 4, for example, many items are clearly of high importance in 
the upper and lower right sides of the map. As an example of how this map is configured, one statement is highlighted in Figure 4. The selection of this statement does not indicate anything pertaining to analysis, and just serves as an illustrative example. 
Figure 4. Point Rating Map

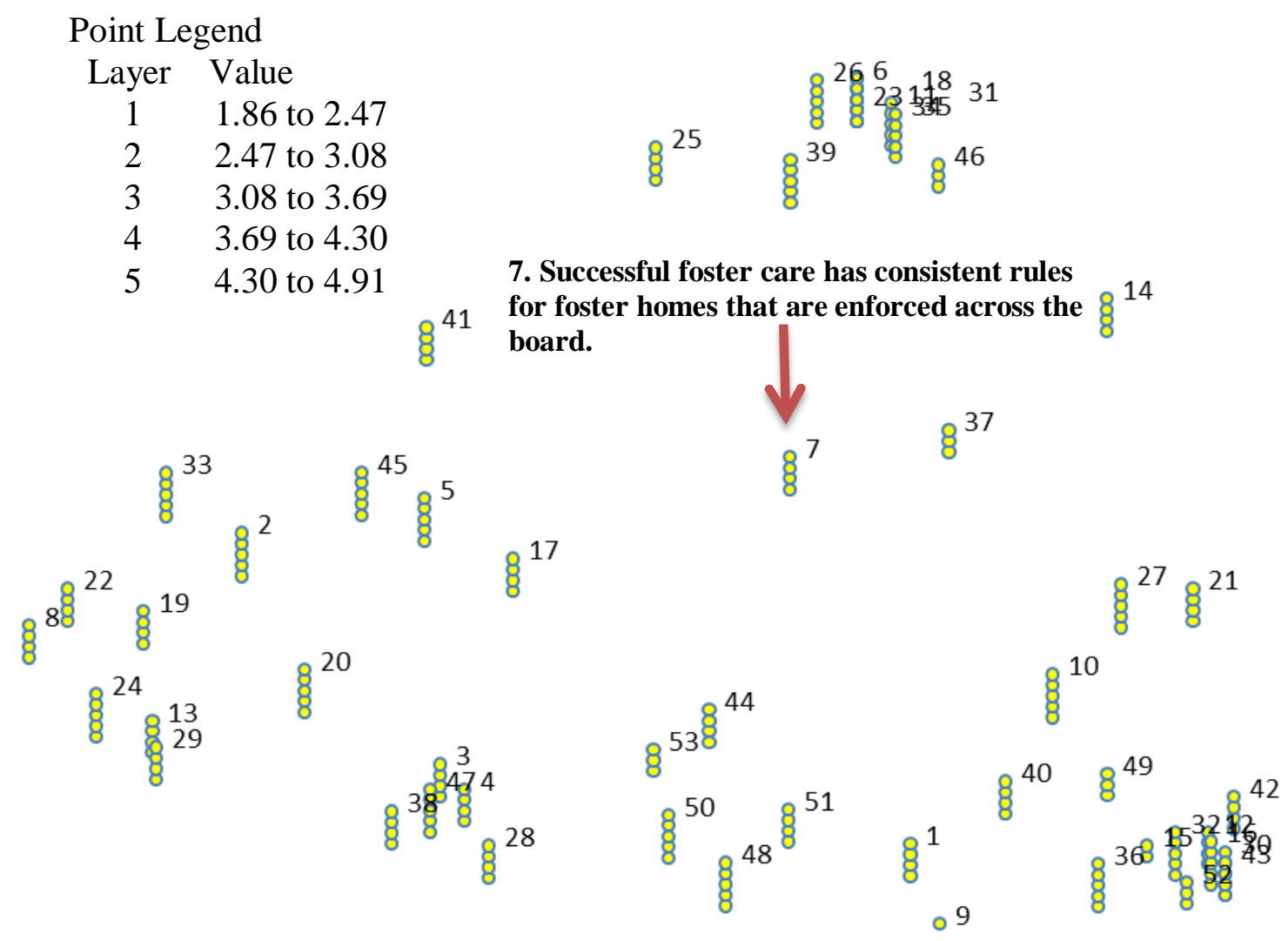

Figure 5 is a Cluster Rating Map. This map is similar to the Point Rating Map, except, instead of providing ratings for individual statements, the analysis is based on the overall mean importance ratings for items contained in each cluster. For Figure 5, the relative height of each cluster is indicative of the relative importance of each cluster, when compared to others on the map. That is, the more layers a cluster has, the more important statements in that cluster were rated. For this study, the Foster Youth cluster had five layers, indicating that participants viewed statements in this cluster as most important. The Social Work cluster had only one layer, indicating that statements in that cluster were viewed as the least important. 
Figure 5. Cluster Rating Map

$\begin{array}{cl}\text { Cluster Legend } \\ \text { Layer } & \text { Value } \\ 1 & 3.95 \text { to } 4.02 \\ 2 & 4.02 \text { to } 4.10 \\ 3 & 4.10 \text { to } 4.17 \\ 4 & 4.17 \text { to } 4.24 \\ 5 & 4.24 \text { to } 4.31\end{array}$

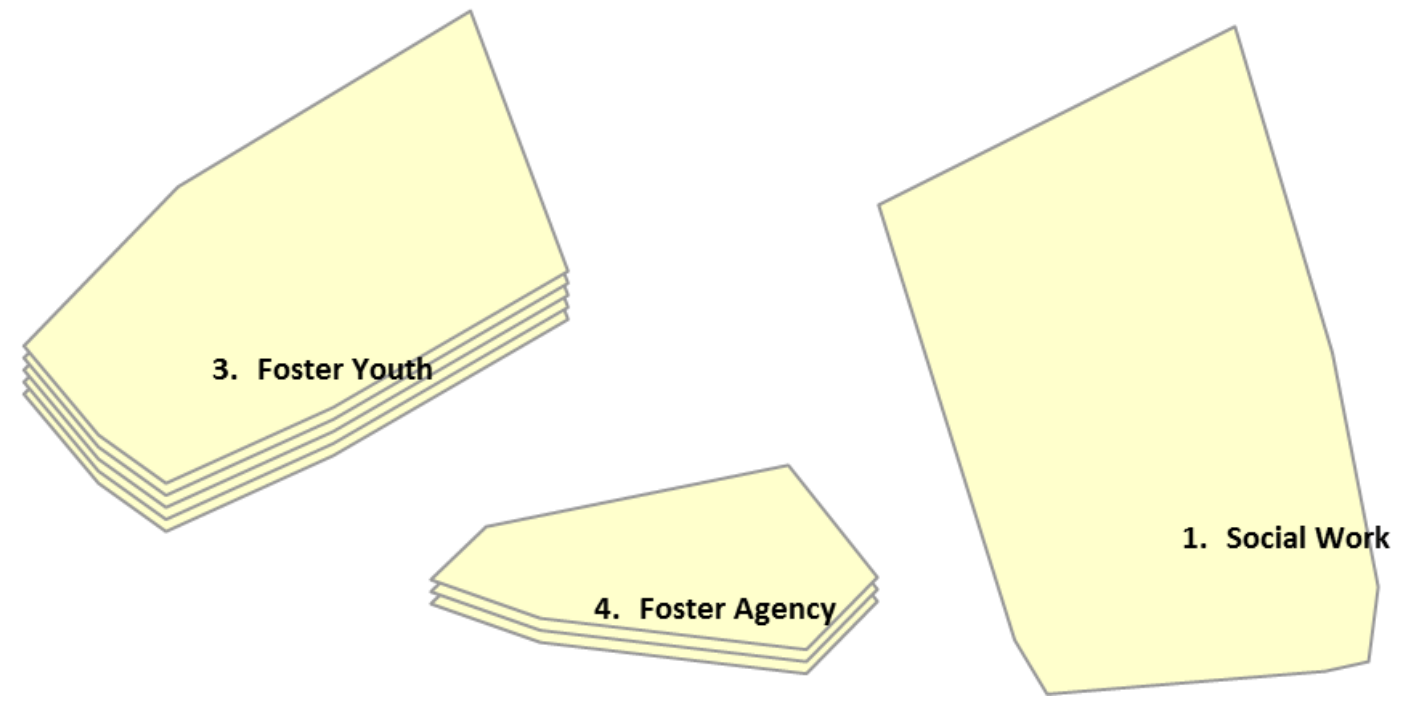

Group Differences. In order to explore the difference in conceptualizations of success, based on maltreatment type, a pattern match was initiated. This analysis separated ratings and compared those for youth in care for abuse, to the ratings of those in care for neglect. For the participants that provided rating data, 12 reported being in foster care for neglect, whereas 10 reported being in foster care for abuse (to include sexual and physical).

Figure 6 shows the pattern match between ratings for abused youth, when compared to that of neglected youth. As indicated in this figure, youth in care for abuse and youth in care for neglect rated the Foster Youth cluster as the most important. 
Similarly, both of these groups rated the Social Work cluster as the least important. The correlation statistic between the two groups, for all cluster ratings, was 0.75 .

Figure 6. Pattern Match

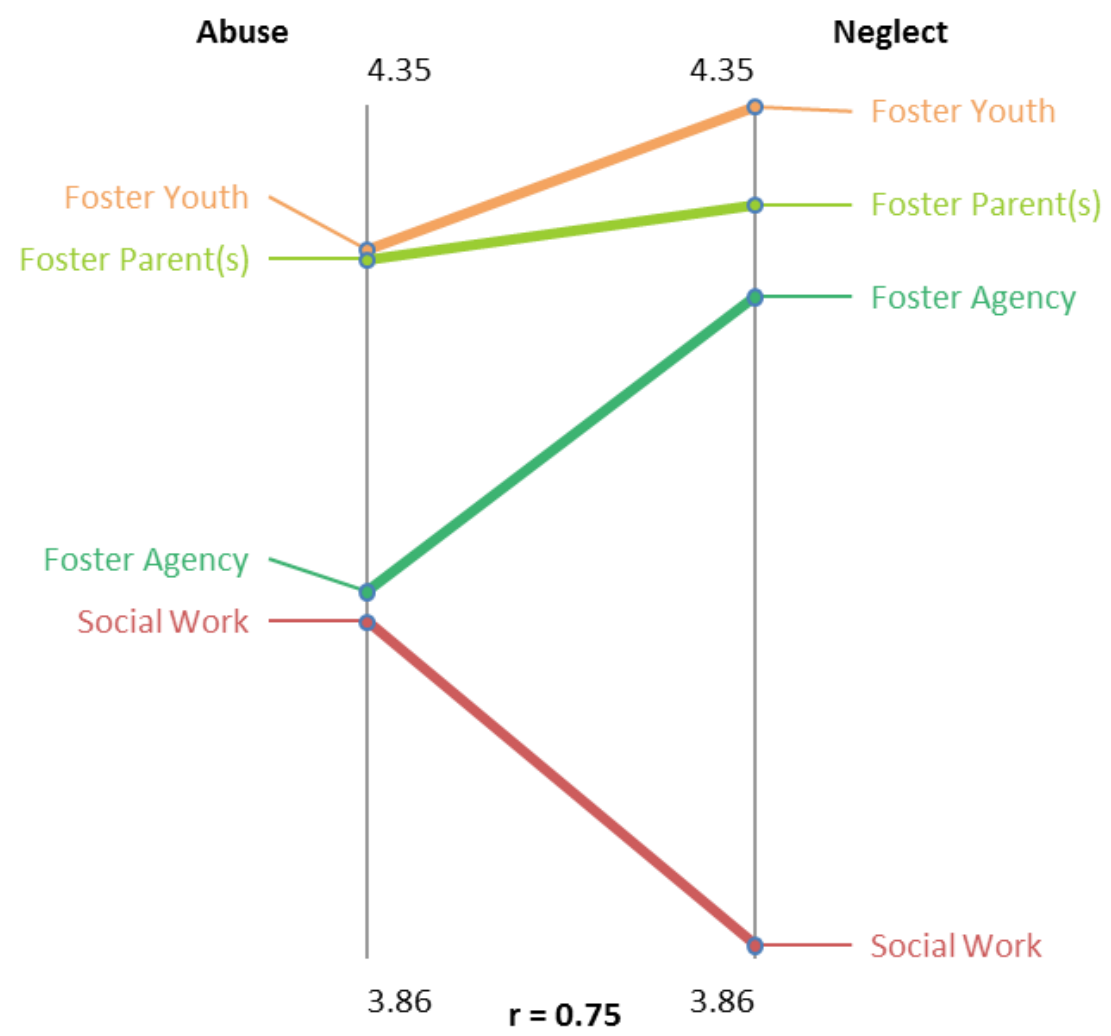

A t-test was used to assess differences in mean ratings for each cluster, by reason for being in care. For the Social Work cluster, the mean rating for youth in care for abuse was $4.05(\mathrm{SD}=0.32)$ and for youth in care for neglect, the mean rating for this cluster was $3.86(\mathrm{SD}=0.64)$. Results from a t-test showed no significant difference between these mean ratings $(\mathrm{t}(36)=0.84, \mathrm{p}>.05)$. For the Foster Parent cluster, the mean rating for youth in care for abuse was $4.26(\mathrm{SD}=0.19)$, compared to that of $4.29(\mathrm{SD}=0.23)$ for youth in care for neglect. Results from a t-test showed no significant difference between these mean ratings $(\mathrm{t}(20)=-0.16, \mathrm{p}>.05)$. For the Foster Youth cluster, the mean 
rating for youth in care for abuse was $4.27(\mathrm{SD}=.09)$ and for youth in care for neglect, the mean rating for this cluster was $4.35(\mathrm{SD}=.08)$. Results from a t-test showed no significant difference between these mean ratings $(t(24)=-0.72, \mathrm{p}>.05)$. For the Foster Agency cluster, the mean rating for youth in care for abuse was $4.07(\mathrm{SD}=0.22)$ and was $4.24(\mathrm{SD}=0.21)$ for youth in care for neglect. Results from a t-test showed no significant difference between these mean ratings $(\mathrm{t}(18)=-0.82, \mathrm{p}>.05)$.

Go-Zone Graphs. In addition to the maps and pattern match previously outlined, CM output includes bivariate graphs for each cluster. The graphs are divided into quadrants and demarcate Go-Zones for statements with a rating above the mean on the rating variable, for both groups. Figures 7 - 10 are Go-Zone Graphs for each of the four clusters in the final solution, respectively.

Figure 7. Social Work Cluster Go-Zone Graph

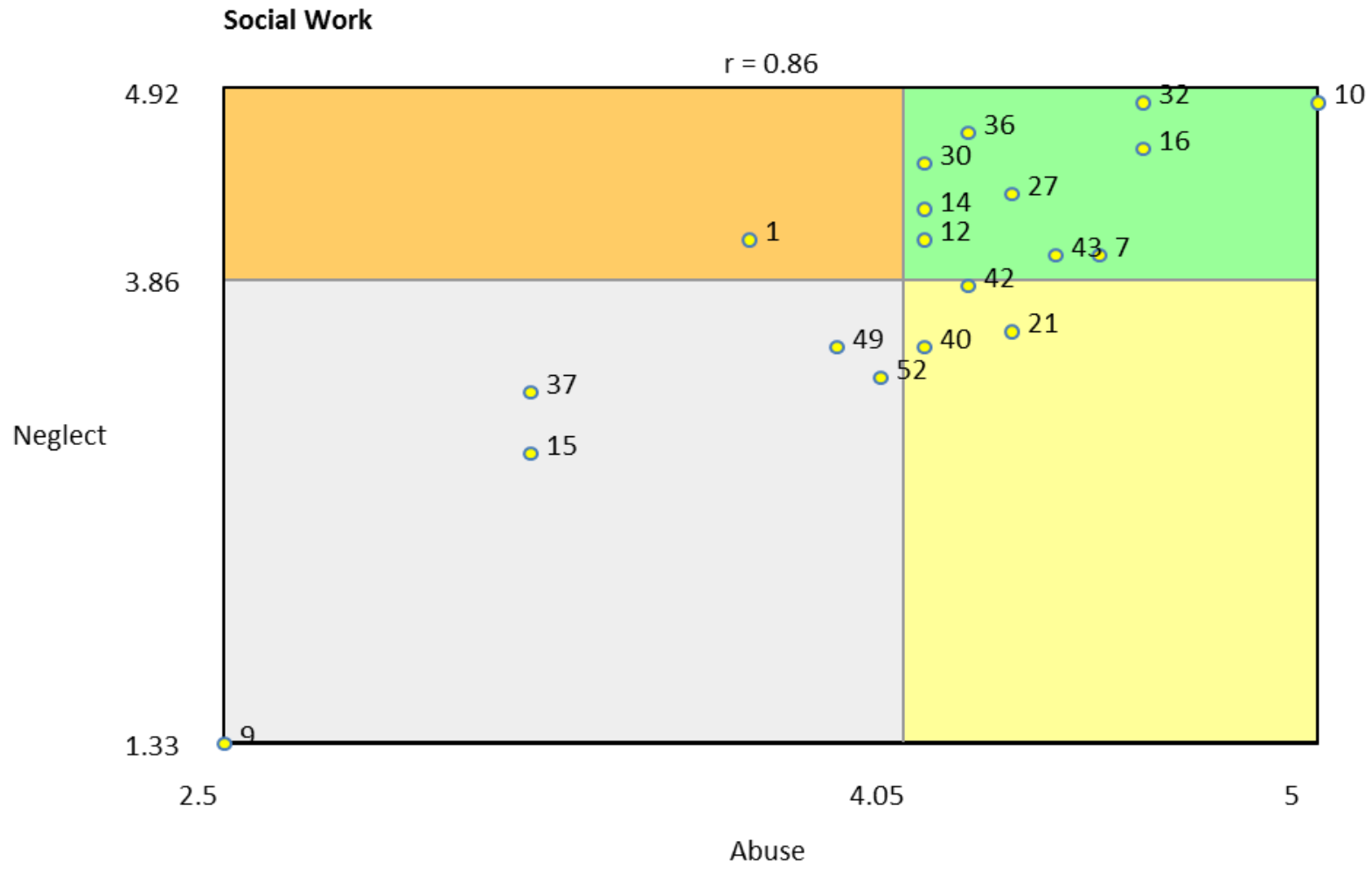


For the Go-Zone Graphs, statements in the top right quadrant, or Go-Zone, were seen as the most important by both youth in care for abuse and youth in care for neglect. For the Social Work cluster, the following statements fell into the Go-Zone: 7. Successful foster care has consistent rules for foster homes that are enforced across the board; 10. Successful foster care means being placed in a safe home; 12. Successful foster care allows foster youth to visit with friends without having background checks on those friends; 14. Successful foster care allows foster parents to make decisions on behalf of the youth without having to always ask the social worker; 16. Successful foster care means having social workers that LISTEN more; 27. Successful foster care means that youth are able to meet with foster parents before being placed with them; 30 . Successful foster care means having a social worker that personally cares about their foster kids; 32 . Successful foster care means that foster kids have a consistent worker and are not changing workers all the time; 36 . Successful foster care means that youth are able to visit with appropriate family members (biological parents, siblings, etc.) on a regular basis; and, 43. Successful foster care requires that social workers try to understand what foster care is like.

Conversely, statements in other parts of the Go-Zone graphs were not viewed as important for both groups of participants. Statements in the lower left quadrant rated below the mean rating for both groups. Statements in this category included: 9 . Successful foster care will place youth with foster parents and other kids that are the same race; 15 . Successful foster care means that youth are placed close to the home they are removed from; 37. Successful foster care recruits "young" foster parents; 49. Successful foster care will "match" foster youth with social workers based on attitude, 
interests, etc; and, 52. Successful foster care requires MORE meeting time between foster youth and their social workers.

Statements in the lower right quadrant rated above the mean for importance, only for youth in foster care for abuse. These statements included: 21. Successful foster care means that youth are better matched with foster parents; 40 . Successful foster care requires that foster kids have a lot of contact with their attorney (or GAL); and, 42. Successful foster care means that social workers spend more time exploring relative placements. The top left quadrant was reserved for statements that rated above the mean on importance for youth in care for neglect. Only one statement fell into this quadrant: 1 . Successful foster care means that relatives should not be excluded from being a placement just because they have a criminal record.

Figure 8. Foster Parent(s) Cluster Go-Zone Graph

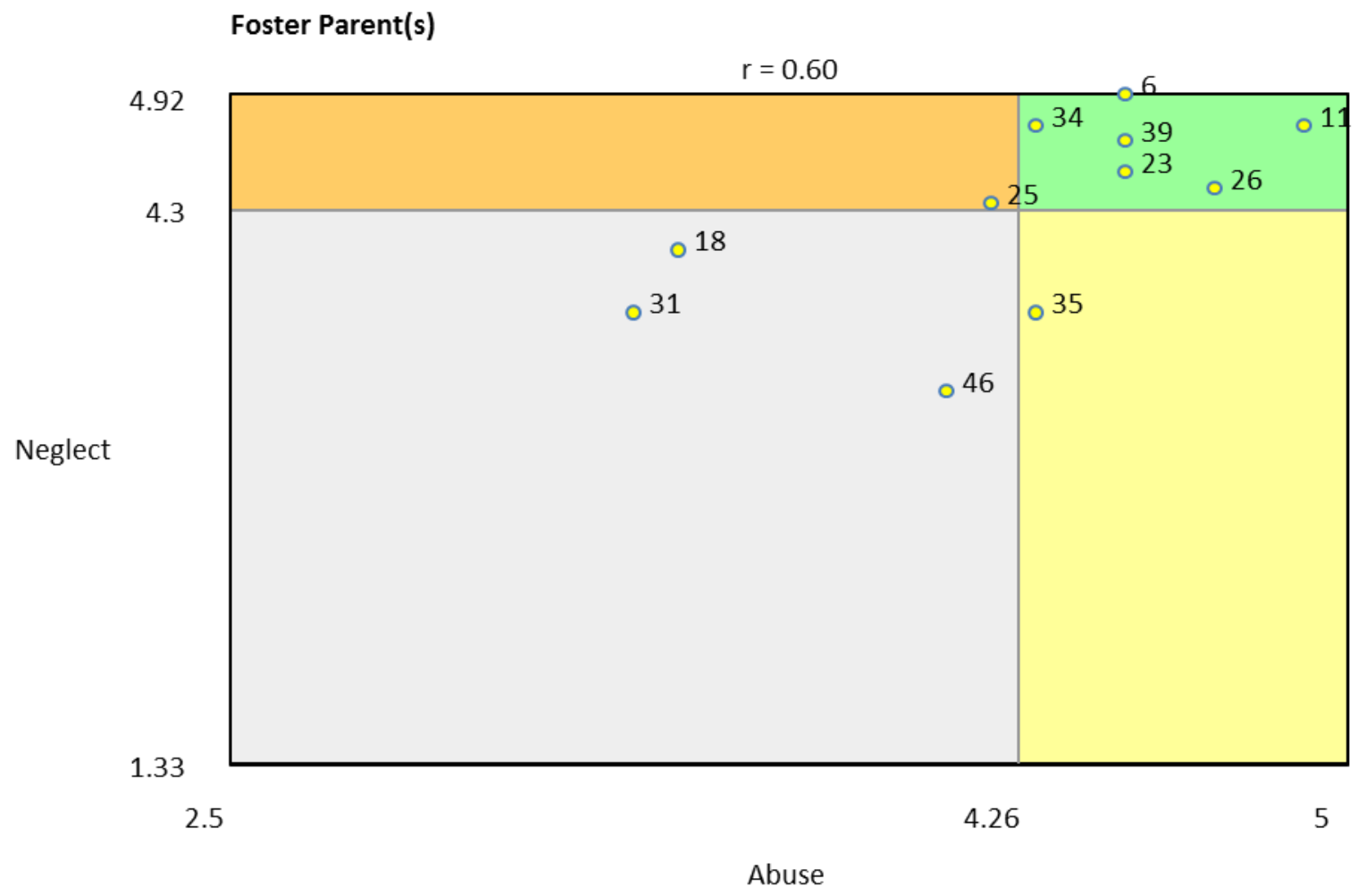


For the Foster Parent(s) cluster, the following statements fell into the Go-Zone: 6. Successful foster care means that foster parents are not just fostering for the money; 11 . Successful foster care means having foster parents that don't front (act one way in front of workers and a different way at home); 23. Successful foster care means that foster parents don't threaten to have kids removed from their home for little stuff; 26. Successful foster care means that foster parents treat their foster kids and their birth kids the same; 34 . Successful foster care uses foster parents that really try to understand what the foster kid is going through; and, 39. Successful foster care means being in a loving foster family. Statements that rated below the mean for both groups (lower left quadrant) include: 18. Successful foster care means training a foster parents' biological kids about foster care; 31 . Successful foster care requires that foster parents work to build a relationship with the foster kid's biological parents; 46. Only one statement was rated above the mean for importance (lower right quadrant) for youth in care for abuse: 35 . Successful foster care means having foster parents that are comfortable with themselves (e.g., not insecure). Likewise, only one statement was rated above the mean for those in care for neglect (top left quadrant): 25. Successful foster care supports youth to participate in after-school activities. 
Figure 9. Foster Youth Cluster Go-Zone Graph

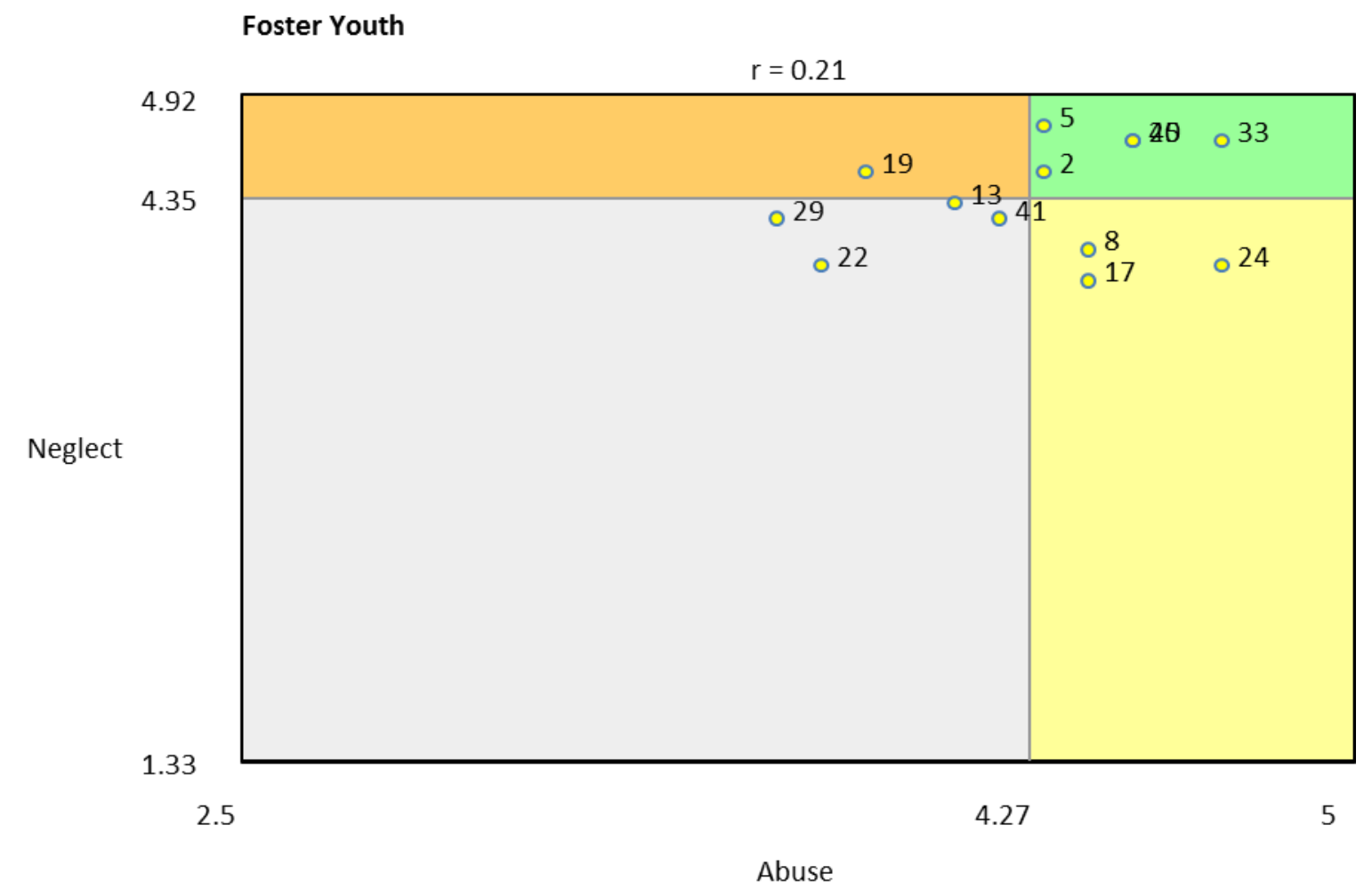

The Foster Youth cluster included a total of five statements: 2. Successful foster care means that youth are not judged based on their "records" (such as a case file); 5. Successful foster care helps youth get jobs once they leave foster care; 20. Successful foster care supports youth who choose to go to college; 33. Successful foster care means that foster kids are treated the same as kids not in foster care; and, 45. Successful foster care trains foster kids for life after age 18, even if they leave foster care.

Statements that rated below the mean for both groups (lower left quadrant) include: 13. Successful foster care allows youth to "give back" and help youth once they leave care; 22. Successful foster care allows youth to NOT identify as being a foster kid; 29. Successful foster care requires that people (social workers, judges, etc.) trust youth to make good decisions; and, 41. Successful foster care means that foster kids are allowed to make decisions about their own appearance. Three statements rated above the mean for 
importance (lower right quadrant) for youth in care for abuse: 8 . Successful foster care means not being ashamed of being in foster care; 17. Successful foster care allows responsible youth to get a driver's license at 16; and, 24. Successful foster care means that youth are able to connect with others in foster care. One statement appeared in the top left quadrant, indicating that it rated above the mean for those in care for neglect: 19.

Successful foster care means that people don't have to feel sorry for foster kids.

Figure 10. Foster Agency Cluster Go-Zone Graph

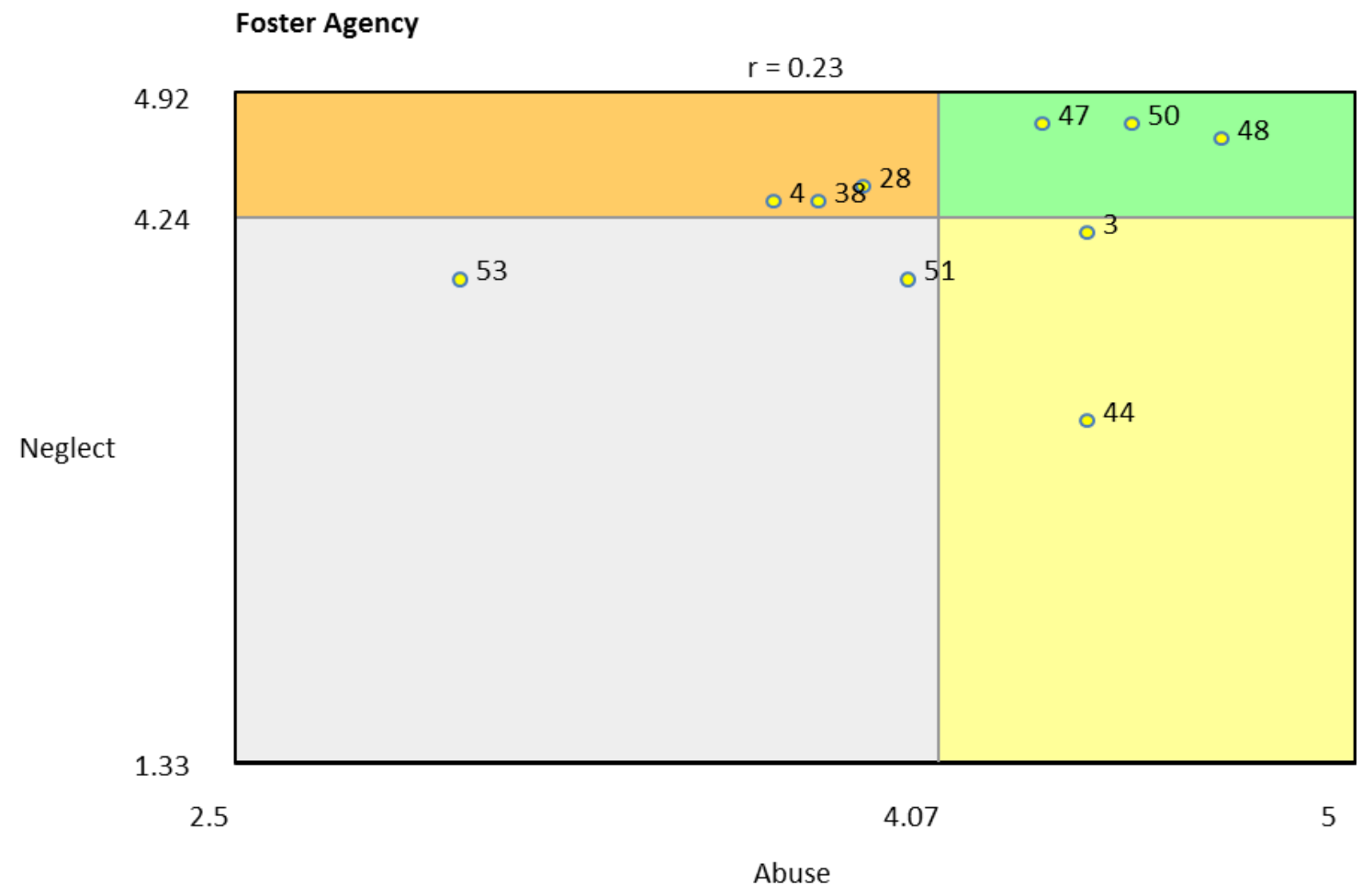

The Foster Agency cluster contained 10 statements overall, three of which were in the Go-Zone: 47. Successful foster care provides good Independent Living services; 48. Successful foster care means that personal things about foster youth are kept confidential; and, 50. Successful foster care means having access to needed documents (birth certificates, social security cards, placement records, etc.). 
Statements that rated below the mean for both groups (lower left quadrant) include: 51. Successful foster care connects youth with counselors/therapist that understand foster care; and, 53. Successful foster care means that youth can stay in the same school, even if they change placements. Two statements were rated above the mean for importance (lower right quadrant) for youth in care for abuse: 3. Successful foster care means that there are more age-appropriate events and activities for teens in care; and, 44. Successful foster care means getting a bigger clothing allowance. Lastly, three statements were rated above the mean for those in care for neglect (top left quadrant): 4 . Successful foster care offers incentives, like money, for participating in foster care programs; 28. Successful foster care allows foster youth to have more input in developing their goals; and, 38. Successful foster care means that youth are able to easily re-enter care if they change their mind about re-committing.

\section{Finalizing the Results}

In $\mathrm{CM}$, an integral component of finalizing the results related to a study is to garner feedback from participants to ensure that the final computations accurately reflect their perspectives. After all analyses were computed, the researcher invited all participants to a meeting to discuss the results. Six of the participants, as well as the project advisors, opted to participate in this meeting. These individuals provided feedback and confirmed that the results presented in this chapter accurately depicted their perspectives. Implications and interpretations of these results will be discussed in the next chapter. 


\section{CHAPTER V: DISCUSSION}

"The way to do research is to attack the facts at the point of greatest astonishment."

\section{- Celia Green}

The purpose of this dissertation was to delineate a conceptual domain of successful foster care, from the perspective of foster youth, and explore differences in this conceptualization, based on maltreatment type. The previous chapter outlined the results of this study; this chapter will discuss salient points based on these results, thus offering explicit interpretations of the results. Additionally, this chapter will examine implications related to the processes for this research study, as well as implications for child welfare practice, policy, and education.

At the outset of this chapter, it is imperative that one thing be made clear. While this chapter will explore specific aspects of the previously presented results, these data cannot be fully understood separate from the overall analyses. As discussed, CM is a multi-step, complex process. As such, data must be critically and cautiously assessed in the context of the overall scope of this study.

\section{Map Interpretations}

As described previously, the final cluster solution for this study contained four

clusters: Social Work, Foster Parent(s), Foster Youth, and Foster Agency. These clusters were based on the sorting of 53 unique ideas collected during the brainstorming phase of the study. Based on the bridging values, the Foster Parent $(s)$ cluster was the most cohesive, meaning that participants sorted those statements at a higher rate, when 
compared to other clusters. In terms of cohesiveness, this cluster was followed by the Social Work cluster, the Foster Agency cluster, and lastly, the Foster Youth Cluster.

Interpreting Statements: Success. The statements collected during the brainstorming phase served as the fundamental component on which all other analyses were conducted. Statements, and subsequently the clusters, for this study captured ideas about foster care that lend credence to existing literature regarding successful foster care experiences. For instance, several authors have discussed aspects of permanency as indicative of success in foster care (e.g., Redding, Fried, \& Britner, 2000; Altshuler \& Gleeson, 1999). The National Resource Center for Youth Development (NRCYD; 2013) explained that, for adolescents, permanency "is not necessarily the living arrangement. It is not simply providing independent living services, and it is not just offering adoption. It is providing that youth with life-long permanent connections to people the youth identifies as important to him/her" (para. 2). As this definition indicates, teens view permanency in terms of connections, based on healthy and consistent relationships with people in their lives. Further, research indicates that the exploration of kinship or relative placements is pertinent to aspects of permanency for this population (Northern California Training Academy, 2008).

Several statements in the final statement set allude to facets of permanency in general, and healthy relationships and connections, specifically. These statements include: 1. Successful foster care means that relatives should not be excluded from being a placement just because they have a criminal record; 15. Successful foster care means that youth are placed close to the home they are removed from; 31. Successful foster care requires that foster parents work to build a relationship with the foster kid's biological 
parents. 32. Successful foster care means that foster kids have a consistent worker and are not changing workers all the time. 36. Successful foster care means that youth are able to visit with appropriate family members [biological parents, siblings, etc.] on a regular basis; 39. Successful foster care means being in a loving foster family. 42. Successful foster care means that social workers spend more time exploring relative placements); and, 53. Successful foster care means that youth can stay in the same school, even if they change placements. All of these statements are indicative of positive and/or stable connections and living arrangements, and some these statements explicitly capture the idea of thoroughly examining relative placements. Thus, these statements suggest notions of permanency consistent with the literature pertaining to perceptions of permanency for this population.

The convergence between conceptualizations of success in the literature, and ideas gathered during the brainstorming sessions for this study are apparent in other areas as well. As discussed in Chapter 1, authors such as Napier (1972), Boer and Spiering (1991), and Wilson, Petrie, and Sinclair (2003) conceptualized success based on foster care placement stability factors. In summary, these authors contended that if a placement was stable (e.g., the foster youth isn't moved between placements), than the foster care experience is successful. Placement stability is impacted by factors such as caregiver mental health, stable relationships among caregivers, positive foster parenting practices, and safety issues, to name a few (Harden, 2004).

Several statements in the final set indicated aspects of placement stability as a factor for successful foster care. Examples of these statements include: 10. Successful foster care means being placed in a safe home; 23. Successful foster care means that 
foster parents don't threaten to have kids removed from their home for little stuff; 39. Successful foster care means being in a loving foster family; and, 49. Successful foster care will "match" foster youth with social workers based on attitude, interests, etc. These statements include dynamics of placement stability, as outlined by Harden (2004), and others noted above.

Another pertinent aspect of success, as conceptualized by the participants, had to do with autonomy. As discussed extensively in Chapters 1 and 2, many foster youth have little control over situations that impact them. Simply stated, almost every aspect of their lives is dictated by others (e.g., foster agencies, governmental systems, social workers, etc.). The theoretical framework discussed earlier in this narrative informs the notion that teens, at this state of human development, would be looking to assert independence. Several statements in the final set indicate that being or acting independently, or allowing the family unit to act independently, is important for successful foster care experiences, during this life phase. These statements include: 3. Successful foster care means that there are more age-appropriate events and activities for teens in care; 14. Successful foster care allows foster parents to make decisions on behalf of the youth without having to always ask the social worker; 28. Successful foster care allows foster youth to have more input in developing their goals; 29. Successful foster care requires that people (social workers, judges, etc.) trust youth to make good decisions; and, 41. Successful foster care means that foster kids are allowed to make decisions about their own appearance).

Likewise, several statements in the set indicated that youth believed success in foster care was related to being treated, or viewed, as teens that are not in foster care. In 
other words, foster teens want to be treated like every other teen. There are several statements in the set that capture this concept (e.g., 8. Successful foster care means not being ashamed of being in foster care; 12. Successful foster care allows foster youth to visit with friends without having background checks on those friends; 17. Successful foster care allows responsible youth to get a driver's license at 16; 19. Successful foster care means that people don't have to feel sorry for foster kids; 22. Successful foster care allows youth to NOT identify as being a foster kid; 25. Successful foster care supports youth to participate in after-school activities; 26. Successful foster care means that foster parents treat their foster kids and their birth kids the same; and, 33. Successful foster care means that foster kids are treated the same as kids not in foster care).

Interpreting Sorts: Responsibility. In examining the patterns in sorting data, it appears that youth sorted the ideas based on one overarching factor: responsibility. One of the reasons that foster care is so complex is the fact that many individuals and systems are involved in providing adequate care. Based on the sorting data from this study, youth seemed to sort the statements based on whom they thought was responsible for that particular item. For example, examine the statements in the Social Work cluster. In this cluster, several statements relate to identifying and overseeing foster care placements. These statements include statements such as: 15. Successful foster care means that youth are placed close to the home they are removed from; 21. Successful foster care means that youth are better matched with foster parents; and, 42. Successful foster care means that social workers spend more time exploring relative placements.

This pattern clearly indicates that youth see social workers as responsible for ensuring adequate placements. To understand this notion, one needs look no further than 
the process for entering foster. In Kentucky, while other parties are able to remove youth from their home (e.g., police officers, etc.), removals are most often handled by social service workers (SSW). CHFS practice dictates that these youth be placed in an approved foster home (when no relative placements available). Once a placement is identified, the SSW usually transports the youth to the placement, visits the youth while at the placement, and handles any problematic challenges that arise during the duration of the placement. In this context, from the perspective of youth in care, social workers are viewed as responsible for most facets related to placing youth in care.

Other statements in the Social Work cluster include what appear to be characteristics of social workers. These statements include: 16. Successful foster care means having social workers that LISTEN more; 30. Successful foster care means having a social worker that personally cares about their foster kids; 32. Successful foster care means that foster kids have a consistent worker and are not changing workers all the time; 43. Successful foster care requires that social workers try to understand what foster care is like; and, 52. Successful foster care requires MORE meeting time between foster youth and their social workers. While these statements may indicate youth perspectives on the qualities of good social workers, it is likely that youth feel that it is the worker's responsibility to demonstrate these qualities in order to support successful foster care experiences.

The theme of responsibility is evident in the sort data for other clusters as well. For instance, statements in the Foster Parent(s) cluster included statements such as: 11. Successful foster care means having foster parents that don't front (act one way in front of workers and a different way at home); 23. Successful foster care means that foster 
parents don't threaten to have kids removed from their home for little stuff; 25:

Successful foster care supports youth to participate in after-school activities; 26.

Successful foster care means that foster parents treat their foster kids and their birth kids

the same; and, 31. Successful foster care requires that foster parents work to build a

relationship with the foster kid's biological parents. Similarly to the Social Work cluster

above, while several of the statements in the Foster Parent( $(s)$ cluster may be

characteristics of good foster parents, it is likely that youth expect it is the responsibility of foster caregivers to exhibit these qualities.

Interestingly, the notion of these foster parent characteristics and/or qualities being framed as responsibilities of foster parents is not new. Case in point, the Rights and Responsibilities portion of the Kentucky CHFS Resource (Foster) Parent Handbook (2011) explicated myriad responsibilities of foster parents. Among these noted responsibilities are to support involvement of the biological family with the youth, attend school activities and meetings, and treat the youth with respect and support, to name a few. As is evident, the responsibilities explicated by this handbook are congruent with the statements included in the Foster Parent( $(s)$ cluster. Given the contextual framing in the handbook, it is not surprising that youth in this study sorted statements in this cluster based on the idea of responsibility.

Similarly, the Foster Agency cluster contained statements that demonstrated elements of responsibility. DePanfilis and Salus (2003) explained that child welfare agencies have the responsibility to ensure that information about foster youth is kept confidential, develop case plans in a collaborative fashion (e.g., input from all stakeholders), and that agencies provide appropriate services for youth and their families. 
Several statements in this cluster coincide with the responsibilities delineated by these authors. These statements include: 28. Successful foster care allows foster youth to have more input in developing their goals; 47. Successful foster care provides good Independent Living services; 48. Successful foster care means that personal things about foster youth are kept confidential; and, 51. Successful foster care connects youth with counselors/therapist that understand foster care. Again, if the ideas contained in this cluster have been viewed as the responsibility of foster agencies in other instances, it is likely that youth may have sorted these statements in that way.

Given the overarching goal of this study, which is to understand the foster care experience, perhaps the most interesting cluster was the Foster Youth cluster. This cluster was comprised of several statements related to responsibility, specifically the personal responsibility of foster youth. Statements in this cluster include: 5. Successful foster care helps youth get jobs once they leave foster care; 8. Successful foster care means not being ashamed of being in foster care; 22. Successful foster care allows youth to NOT identify as being a foster kid; and, 45. Successful foster care trains foster kids for life after age 18, even if they leave foster care, to name a few.

Even though these statements may appear to be a function of other aspects of the foster care system, youth in care likely believe that, ultimately, they have responsibility to ensure successful foster care experiences. For example, even though youth may believe the agency has responsibility for training them to get a job, the youth may believe thateven if they are not adequately prepared for employment - they are ultimately responsible for securing employment. One of the participants in the post-analyses meeting (discussed at the end of the previous chapter) summed up this theme of 
responsibility. In discussing this cluster, the foster teen explained: "For all of these statements, even if no one does it for us, we have to do it for ourselves. At the end of the day, we have to make our experience successful, even if others won't. That is our responsibility."

\section{Why Responsibility?}

Perhaps, the fact that teens in this study sorted the statements on the basis of perceived responsibility is not surprising. There are several possible reasons that youth sorted the data in this way. For example, as the literature referenced in the preceding paragraphs demonstrates, there are a multitude of instances where the statements contained in particular clusters, have been framed in the context of responsibility in other instances (e.g., CHFS Resource Parent Handbook, etc.). This in mind, it is likely that youth may share views with others regarding responsibility of stakeholders identified via the cluster labels, and thus sorted the statements accordingly.

Second, from a developmental perspective, adolescence can be a trying time for individuals. Many young people that experience troubles, do so as a result of the "mismatch between the needs of developing adolescents and the opportunities afforded them by their social environments" (Eccles et al., 1993, p. 90). These unmet needs can be especially impactful for youth in foster care (Bruskas, 2008). When the needs of foster youth are unmet, like everyone else, they inherently seek to meet those needs. For teens, who have limited power in our societal context, meeting their basic needs means looking to, and being dependent on, others. Thus, foster youth may be conceptualizing successful foster care experiences based on their perceptions of having their needs met, and sorting data based on who is responsible for meeting needs. 
A third plausible reason for sorting data based on the notion of responsibility involves the idea of accountability. Bruskas (2008) stated that "historically, child welfare has not been held accountable for performance outcomes related to children in foster care” (p. 72). This idea notwithstanding, Bivins (2006) explained that individuals seek to know who is responsible for actions, and accountable for outcomes related to those actions. The lack of accountability for outcomes in foster care does not diminish the desire for youth to know who is responsible for tasks associated with successful foster care experiences. Pragmatically, being accountable starts with ascribing responsibility. Hence, foster youth may be looking to aver responsibilities for particular foster care stakeholders, thus initiating the notion of holding these stakeholders accountable. This could explain why the data was sorted based on the idea of responsibility.

\section{Rating Interpretations}

In addition to delineating an overall conceptual map for successful foster care, this study sought to ascertain any differences in the conceptualization, based on maltreatment type. This aspect of the study was addressed by exploring ratings, by maltreatment type, for the final four cluster solution.

As the pattern match data in the previous chapter indicates, both groups of youth (i.e., youth in care for abuse and youth in care for neglect) rated items for all four of the clusters in very similar ways. Data indicated that, as far as rank order, both groups ranked the four clusters in the exact same way. The most important cluster was the Foster Youth cluster, with the Foster Parent(s), Foster Agency, and Social Work clusters descending in rank, respectively.

The rank order of the clusters, specifically the Foster Youth cluster, explicated in the pattern match can likely be understood in the context of existing literature. For 
example, as discussed above, participants seemed to sort the data based on who they perceived to be responsible for the particular statement. Thus, participants may have believed they had more power and/or control over statements in this cluster. Being responsible for statements in this cluster would require that youth be resilient, as indicated in the participant dialogue shared above. In the context of foster care, it is welldocumented that resiliency is a characteristic necessary to navigate challenging foster care experiences (e.g., Hines, Merdinger, \& Wyatt, 2005). As such, it is no surprise that this cluster would be viewed as the most important cluster, in relation to the other clusters, by both groups.

Rating Differences. In order to examine differences between mean ratings for statements in each cluster, by group, a series of t-tests were performed. These analyses revealed no significant differences in mean ratings for each of the two groups.

The interpretation of the data related to ratings for each of the clusters in this study is clear: youth in care for abuse and youth in care for neglect did not conceptualize success in foster care differently. There may be several considerations impacting the fact that no difference was found. For example, recent developments in child welfare literature suggest that youth seldom experience only one form of child maltreatment (e.g., Herrenkohl \& Herrenkohl, 2009; Finkelhor, Turner, Hamby, \& Ormrod, 2011). Thus, if any of the participants in this study have suffered multiple types of maltreatment, documented or not, it becomes very difficult, if not impossible, to capture differences in conceptualizations that are based on maltreatment type. Further, factors such as the severity of child maltreatment (e.g., Clemmons, Walsh, DiLillo, \& Messman-Moore, 2007), multiple instances of one type of abuse (e.g., several incidents of physical abuse), 
and/or duration of maltreatment (e.g., Springer, Sheridan, Kuo, \& Carnes, 2007) may impact youth experiences, and as such, the way they view success. Or, conversely, it is possible that factors related to maltreatment may not impact perceptions of successful foster at all. Certainly, further research in this area is needed.

\section{Summary of Interpretations}

This study reveals that success is a complex, multi-faceted construct. Youth in this study conceptualized success based on 53 statements. As evidenced by the final statement set, youth were able to critically delineate abstract concepts, as well as very detailed ideas related to conceptualizing successful foster care. These concepts and ideas were configured into four distinct clusters, based on sorting exercises. These clusters seemed to be sorted based on who the participants believed were responsible.

Furthermore, subsequent rating data showed no differences in ratings by maltreatment type.

\section{Implications}

Foster care practices, policy developments, research, and education trends and approaches are interconnected and impact one another. Practices are dictated by policies. In turn, these practices must be evaluated. This need leads to research initiatives aimed at this goal. Then, research illustrates areas of need, which further impacts policy development. All of these impact the education and training developed for and offered to the child welfare workforce. This study has several key implications on multiple levels, from various standpoints. These implications are also informed by the existing body of literature. The following paragraphs delineate a number of these implications.

\section{Child Welfare Research}


Child welfare researchers have an ethical obligation to conduct quality studies aimed at meeting the needs of the populations served. Numerous relevant implications for the process of conducting foster care research can be derived from this study, thus moving towards this obligation. While the following paragraphs discuss these implications, specific areas for further child welfare research are covered in Chapter 6.

First, research aimed at assessing the holistic experience of foster youth must take into account an array of constructs, including evaluation of social workers, foster parents, and so forth. Findings from this study suggest that youth understand success in the context of multiple perspectives, including a variety of key stakeholders involved in foster care. Evaluating very specific aspects of the foster care experience can be inadequate for interpreting the experiences of youth in care. This specificity can lead to a fragmented body of research literature and inadequate service provisions. In order to address these issues, researchers must design studies aimed at concurrently assessing multiple aspects (e.g., social work services, foster parent services, etc.) of the foster care experience.

Second, as it pertains to process, this study demonstrates that the act of building consensus and getting input from relevant stakeholders is key in conducting research with the foster care population. As indicated in previous chapters, conducting research with foster youth can prove difficult. These difficulties include navigating consent and assent issues (e.g., Berrick, Frasch, \& Fox, 2000) and recruiting an adequately sized and vested sample (e.g., Fernandes, 2008), to name a few.

This study exhibits explicit strategies for addressing these challenges, via building relevant stakeholder buy-in. For example, conducting informational meetings for 
stakeholders around the state proved integral for recruiting a sample to participate in this study. These meetings provided a platform for stakeholders to receive information about the study and how the results would be framed and utilized, which allayed apprehension about supporting the study. Further, these meetings permitted the researcher to get feedback regarding the process for carrying out the study, specifically sampling and recruiting protocol.

In terms of sampling, it is imperative that foster care researchers demarcate sample recruitment criteria that assuage challenges, and make it more likely that a vested sample can recruited. A pertinent aspect of navigating consent challenges for this study was recruiting youth whom were post-TPR, which is an idea discussed at one of the stakeholder meetings. Utilizing this criterion permitted the researcher to only have to get consent from the youths' social workers, not birth parents. While it would have been ideal to have a CHFS designee with the ability to consent for all youth, recruiting youth who were post-TPR alleviated some challenges related to getting consent for the youth to participate.

Third, results from this study have the potential to impact child welfare research by offering specific remedy to the lack of foster care practice and programmatic evaluation tools. CM is especially useful in the development of program evaluation tools (Rosas \& Camphausen, 2007; Kane \& Trochim, 2007), and this usefulness certainly has implications for the possibilities related to evaluating these programs. This study demonstrates that program evaluation tools must be multi-dimensional. That is, these tools must include aspects of social work, foster parents, and foster agencies. In order to fully evaluate successful foster care experiences, program evaluation tools must include 
aspects of all these dimensions. This study can be the impetus for the development of such a tool, by focusing on developing tools based on statements and/or clusters highly rated by the participants (e.g., statements in the Go-zone).

Perhaps the fourth point is well-known. Incentives can be a valuable part of recruiting a sample invested in the research. The benefits of offering incentives, especially for teens, is documented in the literature (e.g., Kalish, Voigt, Rahimian, DiCara, \& Sheehan, 2010; Permuth-Wey \& Borenstein, 2009; Brigham, Winhusen, Lewis, \& Kropp, 2010). Because this study required that youth engage in two, very involved phases of the research, the staggered structure of the incentive proved especially valuable in encouraging youth to participate in the latter phases of the study. While finding funding to offer incentives to teen participants can be difficult (Graham \& Fitzgerald, 2010), and may present challenges related to navigating IRB protocols, the benefit of offering the incentive for participants can outweigh navigating this challenge, as was the case for this study.

\section{Child Welfare Policy and Practice}

A number of explicit policy and practice implications result from this study. For instance, this study demonstrates that youth have clear and crucial insight about their foster care experiences. These perspectives can be beneficial in foster care program development. For this particular study, providing clarity regarding successful foster care will promote more suitable service delivery for those served by the foster care system. Other implications include specific areas of consideration for foster care practices.

One significant implication for foster care practice and policy is the way that

placement decisions are made. Findings for this study suggest that youth overwhelmingly view placement characteristics as integral to successful foster care experiences. Of the 53 
statements collected during the brainstorming phase of this study, approximately 20 of the statements are directly associated with placements (e.g., Statements 1. Successful foster care means that relatives should not be excluded from being a placement just because they have a criminal record; 9. Successful foster care will place youth with foster parents and other kids that are the same race; 10. Successful foster care means being placed in a safe home; 11. Successful foster care means having foster parents that don't front [act one way in front of workers and a different way at home], 49. Successful foster care will "match" foster youth with social workers based on attitude, interests, etc.), and other statements are indirectly associated with foster placements. What's more, these statements span more than one cluster, specifically the Social Work and Foster Parent(s) clusters, and several of the statements are in the Go-zones for each of these clusters.

Based on the importance of placement factors illustrated in these data, there are practical practice implications that can be derived from the results. For example, the data indicates that there needs to be more attention paid to stabilizing placement, via better front-end decisions about matching foster parents with foster youth. This notion is also evident in the literature. Dupree and Stephens (2002) explained that "placement decisions should take into account the fit between the respective temperaments of the children and prospective foster parents." (p. 2). These authors further expounded that the nature of the process for placing youth, means that foster parents have minimal, if any, time to adjust to the caregiving needs of the youth. These things in mind, foster care workers and agencies could possibly facilitate "match meetings" between youth and foster parents BEFORE a placement decision is made. Or, as the data suggest, youth and foster parents 
could be matched based on the use of particular criteria (e.g., interests, parenting practices, etc.). The implementation of these practices could possibly improve placement stability for youth, and thus, impact their perceptions of successful foster care experiences.

Another significant implication is associated with the continued development of an integrated system of care. Miles, Bruns, Osher, and Walker (2006) suggested that a system of care is one that recognizes various stakeholders as pertinent in ensuring adequate services for at risk youth. Dupree and Stephens (2002) further explained that in this system of care, foster care policy and practice must allow for the ongoing monitoring and support of a variety of individuals involved in the foster youths' experience. These authors stated that this system includes individuals such as biological parents, foster parents, case workers, medical and mental health professionals.

The importance of specific attention to models for the implementation of systems of care is evident in the data. The fact that youth conceptualized success, based on the responsibility of various stakeholders lends credence to that notion. Results from this study suggest that for youth to have successful foster experiences, this system must be predicated on the concept of open communication and mutual accountability, by a number of individuals/systems. Specifically, foster care programs and policies must be developed in a way that permits social workers, foster parents, and foster agencies to actively be involved in foster care services, thus creating a healthy and efficient system of care.

The results of this study also have potential implications for practice and policy related to the privacy of individuals in foster care. Undoubtedly, protecting the privacy, 
or confidentiality, of foster youth can be a complex issue. At the federal level, subsections of the aforementioned Title IV-B and Title IV E delineate myriad rules and regulations pertaining to the confidentiality of foster youth. Additionally, Section 106 of the Child Abuse and Prevention Act (CAPTA) also discusses information that can be shared about maltreated young people. Indeed, as the United States Department for Health and Human Services (2013) explicated "Developing and coordinating a system of policies and practices that guides information sharing among the agencies that serve families is an important part of providing sound and ethical services" (para. 1).

This study exhibits the need to potentially revisit issues of privacy and confidentiality in the context of foster care practice. In theory, while complex, there are policies related to confidentiality (as indicated above). However, in practice these policies often fall short of protecting youth information, including their right to not identify as a foster youth. This is a pertinent idea derived from this study (e.g., Statements 22. Successful foster care allows youth to NOT identify as being a foster kid; 48. Successful foster care means that personal things about foster youth are kept confidential, etc.), and is congruent with aspects of the foster care literature. For example, Gilligan (2000) asserted that there is often a negative stigma associated with being in foster care. Further, those in care often deal with social exclusion (Stein, 2006). Consequently, foster youth and alumni "can often be extremely protective and secretive" about having been in foster care (Rogers, 2011, p. 416). Taking these points into account, it is a necessity to ensure that foster care programs work to protect the information, and identity of foster youth. This effort includes training for systems involved with foster 
youth (e.g., school systems, etc.), foster parents AND their families (e.g., biological children, etc.), and treatment providers.

Lastly, this study indicates that foster care policy development and practices need insight from foster youth and alumni. Statements in each cluster lend credence to the notion that youth are somewhat concerned about the fact that stakeholders in the foster care system may not understand the foster care experience. These statements include ones such as: 16. Successful foster care means having social workers that LISTEN more; 51. Successful foster care connects youth with counselors/therapist that understand foster care; and, 34. Successful foster care uses foster parents that really try to understand what the foster kid is going through, to name a few.

The importance of the involvement of youth in policy and practice decisions is discussed, at length, in Chapter 1. However, despite the assertions discussed in Chapter 1, the practice of involving youth and alumni in informing current foster care practice and policy has been largely unrealized (e.g., Curran \& Pecora, 1999; Brown \& Seita, 2009; Pecora et al., 2010; Gilligan, 2000). Specifically, foster care organizations seldom employ qualified foster care alumni (e.g., Seita, 2004). Based on this literature, and the findings from this study discussed in the preceding paragraph, foster care agencies need to incorporate the perspective and experience of youth and alumni into foster care practices. Foster care groups can work towards this involvement by supporting foster care alumni groups and associations, working to develop youth advisory boards and councils, and hiring foster care alumni as employees.

\section{Child Welfare Education and Training}

Child welfare education does not occur in a bubble. That is, teaching and training methodologies for current and future child welfare professionals are impacted by the 
context in which foster care practice occurs. The following paragraphs briefly outline implications for this study on child welfare education and training.

Doctoral Education. This study offers a number of considerations for child welfare education, specifically at the doctoral level. One overarching implication is the need for specific education related to non-traditional, mixed-method participatory methodologies. Participatory research methods actively seek to involve research participants in the construction and analyses of data (Gallagher, 2008), and involve intended beneficiaries of the research in every facet of design, implementation, and analysis (Cancian, 1993). Participatory research characteristics include mutual development of research methods and questions (Kemmis \& McTaggart, 2005) and as Boser (n.d.) explained, participatory methods inherently close the gap between the researcher and the researched.

Literature indicates a number of challenges associated with training students in research methodologies (e.g., Elliot, Choi, \& Friedline, 2013; Khinduka, 2001), particularly the participatory types. Methods such as CM are contradictory to traditional approaches, and often require substantial training and education (e.g. Graham \& Fitzgerald, 2010). Thus, doctoral education programs must ensure that students are afforded opportunities to learn and explore these methods. The opportunities include specific class offerings and targeted research practica, as well as community learning experiences that extend beyond the traditional classroom settings. This study demonstrates the effectiveness that such training can have in the completion of research studies, such as the one presented in this narrative. 
Another pertinent implication for education programs is offering frameworks that encourage students to actively consult with outside entities, specifically child welfare agencies. Partnerships between academic institutions and community agencies can be somewhat strained and contentious (Pugach \& Johnson, 2002). As such, students may have difficulty framing their academic interests in a way that makes collaboration likely.

This study demonstrates the importance of researchers, particularly doctoral students, being able to collaborate and engage with stakeholders, outside of the university. For example, as discussed in Chapter 1, there are often many barriers to accessing youth in care for research purposes. For this study, the stakeholder meetings and the collaborative relationship forged with Jim Grace made this study possible by helping to navigate potential IRB challenges, sampling approaches, etc. Additionally, since this study would not have been possible without external funding, it is imperative that social work faculty support students in seeking outside funding streams to fund dissertation research.

Workforce Training. Educating and training the child welfare workforce can prove challenging. As this study confirms, successful foster care experiences are constituted by a number of distinct areas (i.e., cluster). These areas include foster care agencies, youth, foster parents, and social workers. To ensure that the foster care workforce is adequately prepared to deal with the complexities of the foster care system, training programs must teach holistic approaches to viewing foster care. These training methods should include efforts to teach child welfare workers about the multiple stakeholders involved in the lives of foster youth, foster familial dynamics, agency policy analysis procedures, to name a few. As well, workers must be permitted to cross-train. 
That is, train in agency departments outside the departments in which they typically work, in order to comprehensively understand the foster care experience.

\section{Summary of Implications}

This study offers pertinent implications for foster care research, practice and policy development, and child welfare education. These implications include ensuring that: (a.) the experience of foster youth are holistically assessed and evaluated, (b.) child welfare researchers are adept in diverse research methods, and (c.) child welfare workers are adequately trained in the complexities of foster care. If positive changes related to successful foster care experiences are to be realized, these implications must be taken into account. 


\section{CHAPTER VI: CONCLUSION}

"In life we ultimately pursue, not conclusions, but beginnings."

- Sam Tanenhaus

The purpose of this study was to delineate a conceptual domain of successful foster care, from the perspective of foster youth, and explore differences in this conceptualization, based on maltreatment type. To this end, this study offered a direct and positive impact on this primary goal. This final chapter will offer a critical analysis on the strengths and limitations of this study, and will conclude with a proposed agenda for future research studies in this area.

\section{Study Strengths}

There is no "gold standard" of evidence related to research approaches (Haight, 2010). Rather, Haight explained that social work knowledge and evidence should be "obtained through diverse social science traditions" (p. 102). When choosing a research method, the researcher must take into account the strengths and limitations of the proposed research protocol. The following paragraphs outline several strengths of the study presented in this narrative.

First, the overarching strength of this study is that it addresses several gaps and limitations in the current foster care research literature. As discussed throughout this dissertation, a literature review found a dearth in the literature related to conceptualizing successful foster care. Further, few studies have sought to actively involve the voice of 
foster youth, or explored differences in foster care based on maltreatment type. This study uniquely addresses these confines in the literature.

Second, there are no published studies that employ CM with foster youth. This participatory approach allowed the researcher to gather unique insight on the experiences and perspectives of foster youth. Haight (2010) stated that "a broader, deeper understanding of clients' perspectives, particularly those whose voices are hidden, is an important contribution of applied social science research" (p. 103). The use of CM in this study demonstrates the ability of youth to positively contribute to research in an active and insightful way. This facet provides a foundation on which to build future research.

Third, while CM employs rather complicated statistical computations, the CM process seemed to be easily understood by the youth in this study. This assertion is similar to findings in other studies of this type (Mpofu et al., 2008; Miller et al., 2012). This ease of understanding may be attributed to the many visual depictions of data (e.g., Fargas-Malet, McSherry, Larkin, \& Robinson, 2010), such as those outlined in Chapter 4.

\section{Study Limitations}

No research study is without limitations. Critical discourse related to research must be explicitly discussed. This section will discuss limitations related to this study.

$\mathrm{CM}$ couples qualitative and quantitative methods. Thus, there are a number of limitations associated with this method, particularly issues of validity and reliability. Because foster care is highly contextual, the perceptions of foster youth can be products of the environment in which they are formed. Hence, the data yielded by a study such as the one presented in this dissertation can vary. In this sense, validity and reliability can be somewhat difficult to assess. 
In CM, validity is assessed by examining how each visual representation of the data reflects reality (Trochim, 1989). For this study, the researcher sought to address issues of validity by clarifying statements as they were given in the brainstorming session. Further, the data was "checked" by the advisory group and during the presentation to the participants. Other researchers have suggested examining validity of the conceptual representations by comparing statistically computed concept maps, with those structured by hand (e.g., Dumont, 1989).

Reliability is the ability to "replicate" aspects of a study. In CM, assessing reliability ensures critical attention to all stages of the research process (e.g., generating statements, sorting/rating, developing the cluster maps, etc.). There are several ways to address issues of reliability for studies such as the one documented here. For example, participants could be asked to sort and rate the same statements at a later time and the data for both occasions could be compared (e.g., Jackson \& Trochim, 2002). Also, additional brainstorming sessions could be conducted at a later time, and cluster solutions could be compared. However, in the event that this process occurs, the researcher must be aware that participant fatigue may occur if replicating aspects of the study.

Clearly, more work is needed related to assessing validity and reliability, as these concepts pertain to the use of CM with this population. If this work is to be realized, more research in this area must be conducted and documented.

Limitations related to generalizability include the small sample size. At the end of fiscal year 2011, there were 6, 779 youths in foster care in Kentucky, of which approximately 2,345 (34.6\%) of these youths fell into the age group specified for this study (U.S Department of Health and Human Services, Adoption and Foster Care 
Analysis and Reporting System, 2013). While the 30 youths utilized for this study is ideal for the goals of this study, additional participants might have yielded additional ideas (e.g., statements) related to success in foster care. Further, several of the participants who took part in the initial brainstorming exercise, did not participate in the statement structuring exercise. This discrepancy may have impacted the final sorting and rating results. Other factors associated with generalizability include that fact that this sample of youth was all post-TPR, were all in foster care in Kentucky, and were recruited via a nonrandom, purposive procedure.

Finally, this study lacked a number of cultural considerations worth noting. For example, this sample is overwhelmingly Caucasian, all adolescent, and resides in three concentrated areas throughout the state. Further, this study did not assess factors such as sexuality, religion, etc. These limitations may have hindered cultural considerations related to notions of success in foster care.

\section{Future Research}

Primarily, future research in this area needs to further explore conceptualizations of success from the perspective of foster youth. While this study does take a small step in this area, it is just that: a small step. This study suggests that success is a dynamic, complex construct. Success is an idea that changes and fluctuates, and can be impacted by a number of distinct factors. Further, it is likely that achieving success is not a linear process, and that one may "fall" out of success. Thus, it is likely that conceptualizations of success may change very rapidly.

Future studies can build on this study in several ways. For example, aspects of this study could be replicated with foster youth in different age categories. It is likely 
that, based on developmental factors, youth at different ages may conceptualize success in different ways. Conducting research with these populations could further shed light not only on success as a construct, but on characteristics of developmental stages for youth in foster care.

Another way to more fully explore the construct of success is to juxtapose aspects of perceived "failure" with those of success articulated in this study. For instance, this study found that successful foster means that youth have a "caring" social worker (e.g., Statement \# 30). So, if a foster child has a social worker who is perceived as not caring, is that indicative of a "failed" or negative foster care experience? Likewise, future research could use an appreciative inquiry approach to delineate characteristics of social workers perceived as "caring."

Lastly, more research needs to be conducted in the area of delineating notions of success based on maltreatment. While this study explored differences between abuse and neglect, future studies might explore differences between multiple maltreatment (e.g., physical, sexual, emotional, neglect, etc.) victims. These studies need to take into account duration, severity, and number of specific incidents of maltreatment. As well, this differentiation can further be explored on different variables (e.g., race, gender, geographic location, placement type, etc.).

\section{Closing Thoughts}

The problems facing the foster care system, and those involved with the system, are unique, dynamic, and multi-faceted. Approaches to addressing the challenges associated with foster care must be equally unique and complex. This study has explored the problem of not having a well-defined and articulated idea of success from a variety of 
perspectives, primarily of current foster youth. While this research is not meant to be an end-all for defining success, it does seek to contribute to the conversation around foster care in a unique way, from a perspective that is often ignored.

Rappaport (1977) discussed the process by which solutions to social problems, such as the one discussed in the beginning of this narrative, often become the problem itself. This sentiment is particularly accurate to foster care. While out of home care was developed in response to a need to protect maltreated children, over the years it seems as though foster care itself has become the problem. Addressing challenges associated with foster care requires more subjective notions of success. If the child welfare system is to provide optimal service, youth must have a voice, and researchers and practitioners must respond to that voice. In her pivotal work, Festinger (1983) made an apposite point that uniquely applies to this study. In discussing the youth who participated in her study, she aptly concluded: "They have spoken... they raised questions... they are waiting for answers"...(p. 211). It is our job to provide these answers. After all, the future of our foster youth depends on it. 


\section{REFERENCES}

Abele, A.E., Spurk, D., \& Volmer, J. (2011). The construct of career success: Measurement issues and an empirical example. Journal for Labour Market Research, 43, 195-206.

Aberdeen, S., Leggat, S., \& Barraclough, S. (2010). Concept mapping: A process to promote staff learning and problem solving in residential dementia care. Dementia, 9(1), 129 - 151.

Abrahams, D. (2010). Technology adoption in higher education: A framework for identifying and prioritizing issues and barriers to adoption of instructional technology. Journal of Applied Research in Higher Education, 2(2), 34 - 49.

Administration for Children and Families. (2012). Foster care stats. Retrieved from: www.acf.hhs.gov/programs

Ainsworth, M., Blehar, M., Waters, E., \& Wall, S. (1978). Patterns of attachment: A psychological study of the strange situation. Hillsdale, NJ: Lawrence Erlbaum.

Altshuler, S., \& Gleeson, J. (1999). Completing the evaluation triangle for the next century: Measuring child well-being in family foster care. Child Welfare, 78(1), $125-147$.

American Psychological Association (APA). (2002). Developing adolescents. A reference for professionals. Washington, DC: Author.

Anderson, L., Day, K., \& Vandenburg, A. (2011). Using a concept map as a tool for strategic Planning: The Healthy Brain Initiative. Preventing Chronic Disease, $8(5), 1-7$.

Anderson, L., Gwaltney, M., Sundra, D., Brownson, R., Kane, M., Cross, A., Mack, R., Schwartz, R., Sims, T., \& White, R. (2006). Using Concept Mapping to develop a logic model for the Prevention Research Centers program. Preventing Chronic Disease, 3(1), 1- 9.

Aroian, K., Katz, A., \& Kulwicki, A. (2006). Recruiting and retaining Arab Muslim mothers and children for research. Journal of Nursing Scholarship, Third quarter, $255-261$. 
Baldwin, C., Kroesen, K., Trochim, W., \& Bell, I. (2004). Complementary and Conventional medicine: A concept map. BioMed Central, 4, 1-15.

Barber, J., Delfabbro, P., \& Cooper, L. (2001). The predictors of unsuccessful transition to foster care. Journal of Child Psychology and Psychiatry, 42(6), 785 - 790.

Barber, J., \& Delfabbro, P. (2009). The profile and progress of neglected and abused children in long-term foster care. Child Abuse and Neglect, 33, $421-428$.

Barker, R. (2003). The social work dictionary. (5 ${ }^{\text {th }}$ ed.). Washington, D.C.: NASW Press.

Barnett, D., Manly, J. T., \& Cicchetti, D. (1993). Defining child maltreatment: The interface between policy and research. In D. Cicchetti \& S. L. Toth (Eds.), Child abuse, child development, and social policy (pp. 7-74). Norwood, NJ: Ablex.

Barth, R., Guo, S., \& McCrae, J. (2008). Propensity score matching strategies for evaluating the success of child and family service programs. Research on Social Work Practice, 18(3), $212-222$.

Barth, R., Crea, T., John, K., Thoburn, J., \& Quinton, D. (2005). Beyond Attachment Theory and therapy: Towards sensitive and evidenced-based interventions with foster and adoptive families in distress. Child and Family Social Work, 10, $257-$ 268.

Batterham, R., Southern, D., Elsworth, G., Fabris, S., Dunt, D., \& Young, D. (2002). Construction of a GP integration model. Social Science and Medicine, 54, 1225 1241.

Bavolek, S., Wanberg, L., \& Dravage, K. (n.d.). Understanding foster families. Retrieved from

http://nurturevalidation.com/PDF_files/Articles_for_Professionals/understanding_ foster_families.pdf

Bedi, R. (2006). Concept Mapping the client's perspective on counseling alliance formation. Journal of Counseling Psychology, 53(1), 26- 35.

Bellamy, J. (2008). Behavioral problems following reunification of children in long-term foster care. Children and Youth Services Review, 30, 216 - 228.

Bercovitch, J. (2007). Mediation success or failure: A search for the elusive criteria. Journal of Conflict Resolution, 7, 289 - 302.

Berkowitz, G., Brindis, C., \& Clayson, Z. (1996). Using a multi-method approach to measure success in perinatal drug treatment. Evaluation of Health Profession, $19(1), 48-67$. 
Berrick, J., Frasch, K., \& Fox, A. (2000). Assessing children's experiences of out-ofhome care: Methodological challenges and opportunities. Social Work Research, 24(2), $119-127$.

Berry, M., Charlson, R., \& Dawson, K. (2003). Promising practices in understanding and treating child neglect. Child and Family Social Work, 8, 13 - 24.

Besharov, D. (1981). Toward a better research on child abuse and neglect: Making definitional issues an explicit methodological concern. Child Abuse and Neglect, $5,383-390$.

Biegel, D., Johnsen, J., \& Shafran, R. (1997). Overcoming barriers faced by AfricanAmerican families with a family member with mental illness. Family Relations, $46(2), 163-178$.

Bivins, T. (2006). Ethics in public relations: Responsible advocacy. Belmont, CA: SAGE.

Boer, F., \& Spiering, S. (1991). Siblings in foster care: Success and failure. Child Psychiatry and Human Development, 21(4), 291- 300.

Borden, L., Perkins, D., Villarruel, F., Carleton-Hug, A., Stone, M., \& Keith, J. (2007). Challenges and opportunities to Latino youth development. Hispanic Journal of Behavioral Sciences, 28(2), 187 - 208.

Boser, S. (n.d.). Ethics and power in community campus partnerships for research. Retrieved from http://konference.fdvinfo.net/rc33/2004/Data/PDF/stream_0201.pdf.

Bowlby, J. (1969), Attachment and loss, Vol. 1: Attachment. New York: Basic Books.

Bowlby, J. (1973). Separating siblings in placement. Child Welfare, 37, 14 - 20.

Bowlby, J. (1977). The making and breaking of affectional bonds: Aetiology and psychopathology in the light of attachment theory. British Journal of Psychiatry, $130,201-210$.

Bowlby, J. (1980). Loss: Sadness and depression. (2 ${ }^{\text {nd }}$ ed.). New York, NY: Basic Books.

Bowlby, J. (1982). Attachment and loss. Vol. 1: Attachment (2nd Ed.). New York: Basic Books.

Bretherton, I. (1992). The origins of Attachment Theory: John Bowlby and Mary Ainsworth. Developmental Psychology, 28(5), 759 - 775. 
Brigham, G., Winhusen, T., Lewis, D., \& Kropp, F. (2010). Incentives for retention of pregnant substance users: A secondary analysis. Journal of Substance Abuse Treatment, 38, 90-95.

Brown, J. (2008). Foster parents' perceptions of factors needed for successful foster placements. Journal of Child and Family Studies, 17, 538 - 554.

Brown, J., \& Bednar, L. M. (2004). Children with fetal alcohol spectrum disorders: A concept map of parenting children with FASD. Journal of Family Social Work, $8(3), 1-18$.

Brown, J., \& Calder, P. (2000). Concept mapping the needs of foster parents. Child Welfare, 79(6), 729-746.

Brown, J., \& Campbell, M. (2007). Foster parent perceptions of placement success. Children and Youth Services Review, 29, 1010 - 1020.

Brown, W., \& Seita, J. (2009). Growing up in the care of strangers: The experiences, insights, and recommendations of eleven former foster kids. Tallahassee, FL: William Gladden Foundation Press.

Brown, J., St. Arnault, D., George, N., \& Stinzel, J. (2009). Challenges of transcultural placements: Foster parent perspectives. Child Welfare, 88(3), $103-126$.

Bruskas, D. (2008). Children in foster care: A vulnerable population at risk. Journal of Child and Adolescent Psychiatric Nursing, 21(2), 70 - 77.

Buehler, C., Cox, M., \& Cuddeback, G. (2003). Foster parents' perceptions of factors that promote or inhibit successful fostering. Qualitative Social Work, 2(1), $61-83$.

Buehler, C., Orme, J. G., Post, J., \& Patterson, D. (2000). The long-term correlates of family foster care. Children and Youth Services Review, 22 (8), 595-625.

Buehler, C., Rhodes, K. W., Orme, J. G., \& Cuddeback, G. (2006). The potential for successful family foster care: Conceptualizing competency domains for foster parents. Child Welfare, 85, 523-558.

Burke, J., O’Campo, P., Peak, G., Gielen, A., McDonnell, K., \& Trochim, W. (2005). An introduction to concept mapping as a participatory public health research method. Qualitative Health Research, 15(10), 1392 - 1410.

Buscherhof, J. \& Seymour, E. (1990). On my own terms: The redefinition of success in nursing. Journal of Nursing Scholarship, 22(2), $84-88$. 
Cabinet for Health and Family Services. (2011). Kentucky resource parent handbook. Retrieved from: http://chfs.ky.gov/nr/rdonlyres/e5f11e11-7244-41f6-b462f5c2912e7857/0/resourceparenthandbook.pdf

Cancian, F. (1993). Conflicts between activist research and academic success: Participatory research and alternative strategies. The American Sociologist, 24(1), $92-106$.

Capra, F. (1982). The turning point: Science, society, and the rising culture. New York, NY: Bantam Books.

Cash, S., Mathiesen, S., Barbanell, L., Smith, T., \& Graham, P. (2006). Education and partnerships in child welfare: Mapping the implementation of a child welfare certificate program. Journal of Social Work Education, 42(1), 123 - 138.

Carpenter, B., Van Haitsma, K., Ruckdeschel, K., \& Lawton, M. (2000). The psychosocial preferences of older adults: A pilot examination of content and structure. The Gerontologist, 40(3), 335 - 348.

Cashmore, J., \& Paxman, M. (2006). Predicting after-care outcomes: The importance of "felt" security Child and Family Social Work, 11, 232 - 241.

Cassidy, J. (1988). Child-mother attachment and the self in 6-year-olds. Child Development, 59, 121-134.

Centre for Parenting and Research. (2006). The importance of attachment in the lives of foster children. Retrieved from www.community.nsw.gov.au.

Chapman, M., Wall, A., \& Barth, R. (2004). Children's voices: The perception of children in foster care. American Journal of Orthopsychiatry, 74(3), 293 - 304.

Child and Family Service Review. (2006). Statewide assessment instrument. Retrieved from http://www.acf.hhs.gov/programs/cb/cwmonitoring/tools_guide/statewide.pdf

Chipungu, S., \& Bent-Goodley, T. (2004). Meeting the challenges of contemporary foster care. The Future of Children, 14(1), $74-93$.

Christian, C., \& Schwarz, D. (2010). Child maltreatment and the transition to adult-based medical and mental health care. Pediatrics, 127(1), 139-145.

Clark, J. (2009). Why social work practitioners need research ethics knowledge. Social Work, 54(1), 5 - 7 . 
Clarke, H.B., Crosland, K., Geller, D., Cripe, M., Kenney, T., Neff, B., \& Dunlap, G. (2008). A functional approach to reducing runaways and stabilizing placements for adolescents in foster care. Research in Social Work Practice.

Clausen, A., \& Crittenden, P. (1991). Physical and psychological maltreatment: Relations among types of maltreatment. Child Abuse and Neglect, 15, 5- 18.

Clemmons, J., DiLillo, D., Martinez, I., DeGue, S., \& Jeffcott, M. (2003). Co-occurring forms of child maltreatment and adult adjustment reported by Latina college students. Faculty Publications, Department of Psychology. Retrieved from: http://digitalcommons.unl.edu/psychfacpub/134

Clemmons, J., Walsh, K., DiLillo, D., \& Messman-Moore, T. (2007). Unique and combined contributions of multiple child abuse types and abuse severity to adult trauma symptomatology. Faculty Publications, Department of Psychology. Retrieved from http://digitalcommons.unl.edu/psychfacpub/266

Coakley, T. M., Cuddeback, G., Buehler, C., \& Cox, M. E. (2007). Kinship foster parents' perceptions of factors that promote or inhibit successful fostering. Children and Youth Services Review, 29(1), 92-109.

Cole, S., \& Eamon, M. (2007). Self-perceptions of fulfilling the foster caregiver role: A preliminary analysis. Children and Youth Services Review, 29, $655-671$.

Coleman, M. (2000). A chance for change: The role of trust in foster care. Retrieved from http://scholar.lib.vt.edu/theses/available/etd-0628200010320022/unrestricted/Coleman.pdf.

Collins, A., Bronte-Tinkew, J., \& Burkhauser, M. (2008). Using incentives to increase participation in out-of-school time programs. Child Trends, 2008-25. Retrieved from www.childtrends.org.

Collins-Camargo, C. (In Press). Child welfare research and evaluation. In G.P. Mallon and P.M. Hess (Eds). Child Welfare for the $21^{\text {st }}$ Century: A Handbook of Practices, Policies, and Programs ( $2^{\text {nd }}$ ed.). New York: Columbia University Press.

Courtney, M., Needell, B., \& Wulczyn, F. (2004). Unintended consequences of the push for accountability: the case of national welfare performance standards. Children and Youth Services Review, 26, $1141-1154$.

Crea, T., Barth, R., \& Chintapalli, L. (2007). Home study methods for evaluating prospective resource families: History, current challenges, and promising approaches. Child Welfare, 86(2), $141-161$. 
Creswell, J., Klassen, A., Plano-Clark, V., \& Smith, K. (2011). Best practices for mixed methods research in the health sciences. Retrieved from http//.www.obssr.od.nih.gov

Crittenden, P. M., Claussen, A. H., \& Sugarman, D. B. (1994). Physical and psychological maltreatment in middle childhood and adolescence. Development and Psychopathology, 6, 145-164.

Cross-Tower, C. (2010). Understanding child abuse and neglect ( $8^{\text {th }}$ ed.). Boston, MA: Allyn \& Bacon.

Crowe, K. (2007). Using youth expertise at all levels: The essential resource for effective child welfare practice. New Directions for Youth Development, 113, 139 - 149.

Curran, M., \& Pecora, P. (1999). Incorporating the perspectives of youth placed in family foster care: Selected research findings and methodological challenges. In P. Curtis, G. Dale, \& J. Kendall (Eds.), The Foster Care Crisis (pp. 99 - 128). Lincoln, NE: University of Nebraska Press.

Danto, E. (2008). Same words, different meanings: Notes towards a typology of postmodern social work education. Social Work Education, 27(7), 710 - 722.

Daughtry, D., \& Kunkel, M. (1993). Experience of depression in college students: A Concept Map. Journal of Counseling Psychology, 40(3), 316-323.

De Ridder, D., Depla, M., Severens, P., \& Malsch, M. (1997). Beliefs on coping with illness: A consumer's perspective. Social Science and Medicine, 44(5), 553 - 559.

D'cruz, H. (2004). The social construction of child maltreatment: The role of medical practitioners. Journal of Social Work, 4(1), $99-123$.

DePanfilis, D., \& Salus, M. (2003). Child protective services: A guide for caseworkers. Retrieved from: https://www.childwelfare.gov/pubs/usermanuals/cps/cps.pdf

DeVizia, J. (1974). Success in a foster home program for mentally retarded children. Child Welfare, 53(2), $120-125$.

Diehl, D., Howse, R., \& Trivette, C. (2011). Youth in foster care: Developmental assets and attitudes towards adoption and mentoring. Child and Family Social Work, 16, $81-92$.

Diehl, M., \& Stroebe, W. (1991). Productivity loss in idea-generating groups: Tracking down the blocking effect. Journal of Personality and Social Psychology, 61(3), $392-403$. 
Donnelly, J., Huff,, S., Lindsey, M., McMahon, K., \& Schumacher, J. (2005). The needs of children with life-limiting conditions: A healthcare-provider-based model. American Journal of Hospice and Palliative Medicine, 22(4), 259 - 267.

Dozier, M., Albus, K., Fisher, P., \& Sepulveda, S. (2002). Interventions for foster parents. Development and Psychopathology, 14, $843-860$.

Dries, N., Pepermans, R., \& Carlier, O. (2008). Career success. Constructing a multidimensional model. Journal of Vocational Behavior, 73, 254-267.

Dumont, J. (1989). Concept mapping for evaluation and planning. William Trochim, (Ed.). New York, NY: Pergamon Press.

Dunning, D., Leuenberger, A., \& Sherman, D. (1995). A new look at motivated inference: Are self-serving theories of success a product of motivational forces? Journal of Personality and Social Psychology, 69 (1), 58 - 68.

Dupree, D., \& Stephens, S. (2002). Foster care and early development: Implications for child welfare policy and practice. Retrieved from http://www.capd.org/pubfiles/pub-2002-00-01.pdf.

Dyke, L., \& Duxbury, L. (2011). The implications of subjective career success. Journal for Labour Market Research, 43, 219-229.

Dyke, L., \& Murphy, S. (2006). How do we define success: A qualitative study of what matters most to women and men. Sex Roles, 55, 357 - 371.

Ebner, N. C., \& Freund, A. M. (2007). Personality theories of successful aging: The role of goals and goal-related processes for adaptive development. In J. A. Blackburn \& C. N. Dulmus (Eds.), Handbook of gerontology: Evidence-based approaches to theory, practice, andpolicy (pp. 87-116). New York: Wiley \& Sons.

Eccles, J., Midgley, C., Wigfield, A., Buchanan, C., Reuman, D., Flanagan, C., \& Iver, D. (1993). Development during adolescence: The impact of stage environment fit on young adolescents' experiences in schools and in families. American Psychologist, 48(2), 90 - 101.

Elliot, W., Choi, E., \& Friedline, T. (2013). Online statistics lab in MSW research methods courses: Reducing reluctance toward statistics. Journal of Social Work Education, 49, 81 - 95 .

Ennew, J., \& Plateau, D. (2004). How to research the physical and emotional punishment of children. Bangkok: Save the Children.

Erikson, E. (1959). Identify and the life cycle. New York, NY: International Universities Press. 
Erikson, E. (1968). Identity: Youth and crisis. New York, NY: Norton and Company.

Fahlberg, V. (1991). A child's journey through placement. Indianapolis, IN: Perspectives Press.

Falk-Krzesinski, H. J., Contractor, N., Fiore, S. M., Hall, K. L., Kane, C., Keyton, J., \& Trochim, W. (2011). Mapping a research agenda for the science of team science. Research Evaluation, 20(2), 145-158.

Fargas-Malet, M., McSherry, D., Larkin, E., \& Robinson, C. (2010). Research with children: Methodological issues and innovative techniques. Journal of Early Childhood Research, 8, $175-192$.

Farmer, E. (2010). What factors relate to good placement outcomes in kinship care? British Journal of Social Work, 40, 426-444.

Fenton, Z. (2002). Foster care: The border of family identity maintaining, (re)creating, destroying. New England Law Review, 36(1), 59 - 69.

Fernandez, E. (2006) Growing Up In Care: Resilience and Care Outcomes in R. Flynn, P. Dudding and J. Barber (Eds). Promoting Resilient Development in Children and Families, (pp. 131 - 156). Ottawa University Press.

Fernandez, E. (2007). How children experiences fostering outcomes: Participatory research with children. Child and Family Social Work, 12, 349 - 359.

Festinger, T. (1983). No one ever ask us: A post script to foster care. New York, NY: Columbia University Press.

Finkelhor, D., Turner, H., Hamby, S., \& Ormrod, R. (2011). Polyvictimization: Children's exposure to multiple types of violence, crime, and abuse. National Survey of Children's Exposure to Violence. Retrieved from: https://www.ncjrs.gov/pdffiles1/ojjdp/235504.pdf

Fisher C., \& Wallace S. (2000). Through the community looking glass: reevaluating the ethical and policy implications of research on adolescent risk and psychopathology. Ethics and Behavior 10(2), 99-118.

Fleming, C. (1963). Adolescence: Its social psychology. London: Routledge \& Kegan Paul.

Fleming, J. (2010). Young people's involvement in research: Still a long way to go? Qualitative Social Work, 10(207), 207 - 223. 
Foster, L. (2001). Foster care fundamentals: An overview of California's foster care system. Retrieved from www.library.ca.gov/crb/01/08/01-008.pdf

Fox, A., \& Berrick, J. (2007). A response to no one ever asked us: A review of children's experiences in out-of-home care. Child and Adolescent Social Work Journal, $24(1), 23-51$.

Fowler, P., Toro, P., \& Miles, B. (2009). Pathways to and from homelessness and associated psychosocial outcomes among adolescents leaving the foster care system. American Journal of Public Health, 99(8), 1453 - 1458.

Fraley, R., Niedenthal, P., Marks, M., Brumbaugh, C., \& Vicary, A. (2006). Adult attachment and the perception of emotional expressions: Probing the hyperactivating strategies underlying anxious attachment. Journal of Personality, 74, 1163-1190.

Freundlich, M., \& Avery, A. (2005). Planning for youth in congregate care. Children and Youth services Review, 27, 115 - 34.

Fry, C., Ritter, A., Baldwin, S., Bowen, K., Gardiner, P., Holt, T., Jenkinson, R., \& Johnston, J. (2005). Paying research participants: a study of current practices in Australia. Journal of Medical Ethics, 31, 542-547.

Gallagher, M. (2008). Power is not an evil: Rethinking power in participatory methods. Children's Geographies, 6(2), 137 - 150.

Galvin, P. (1989). Concept mapping for planning and evaluation of a Big Brothers/Big Sisters program. Evaluation and Program Planning, 12, 53 - 57.

Garland, A., Landsverk, J., Hough, R., \& Ellis-MacLeod, E. (1996). Type of maltreatment as a predictor of mental health service for children in foster care. Child Abuse and Neglect, 20(8), 675-688

George, C., Kaplan, N., \& Main, M. (1984) Adult attachment interview protocol.

Gil, E., \& Bogart, K. (1982). An exploratory study of self-esteem and quality of care of 100 children in foster care. Children and Youth Services Review, 4, 351-363.

Gilbertson, R., \& Barber, J. (2002). Breakdown of foster care placement: Carer perspectives and system factors. Australian Social Work, 56(4), 329 - 339.

Gilligan, R. (2000). The importance of listening to the child in foster care. In G. Kelly \& R. Gilligan (Eds.), Issues in foster care (pp. 40 - 58). London: Jessica Kingsley Publishers. 
Giorgi, A. (1985). Sketch of a psychological phenomenological method. In A. Giorgi (Ed.), Phenomenology and psychological research (pp. 12 -28). Pittsburgh, PA: Duquesne University.

Glassman, L., Weierich, M., Hooley, J., Deliberto, T., \& Nock, M. (2007). Child maltreatment, non-suicidal self-injury, and the mediating role of self-criticism. Behaviour Research and Therapy, 45, 2483-2490.

Goerge, R., Wulczyn, F., \& Fanshel, D. (1994). A foster care research agenda for the 90's. Child Welfare, 73(5), 525 - 549.

Gol, A., \& Cook, S. (2004). Exploring the underlying dimensions of coping: A Concept Mapping approach. Journal of Social and Clinical Psychology, 23(2), 155 - 171.

Goldsmith, D., Oppenheim, D., \& Wanlass, J. (2004). Separation and reunification: Using Attachment theory and research to inform decisions affecting the placements of children in foster care. Juvenile and Family Court Journal, 1 - 14.

Gonzalez-Block, M., Rouvier, M., Becerril, V., \& Sesia, P. (2011). Mapping of health system functions to strengthen priority programs: The case of maternal health in Mexico. BioMed Public Health, 11, 164 - 173.

Goodyer, A. (2011). Child-centered foster care. Philadelphia, PA: Jessica Kingsley Publishers.

Graf, B. (2002). Foster care independence act - 1999. Retrieved from http://www.hunter.cuny.edu/socwork/nrcfcpp/downloads/information_packets/fos ter_care_independence_act-pkt.pdf

Graham, A., \& Fitzgerald, R. (2010). Children's participation in research: Some possibilities and constraints in the current Australian research environment. Journal of Sociology, 46(2), $133-147$.

Graham, A., Kerner, J., Quinlan, K., Vinson, C., \& Best, A. (2008). Translating cancer control research into primary care practice: A conceptual framework. American Journal of Lifestyle Medicine, 2(3) 241 - 249.

Grant, R., \& Sugarman, J. (2004). Ethics in human subjects research: Do incentives matter. Journal of Medicine and Philosophy, 29(6), 717-738.

Green, R., Braley, D., \& Kisor, A. (1996). Matching adolescents with foster mothers and fathers: An evaluation of role temperament. Journal of Child and Family Studies, $5(3), 267-283$. 
Groenewoud, A., van Exel, N., Berg, M., \& Huijsman, R. (2008). Building quality report cards for geriatric are in The Netherlands: Using Concept mapping to identify the appropriate building blocks from the consumers' perspective. The Gerontologist, $48(1), 79-92$.

Groothues, C., Beckett, C., \& O’Connor, T. (2001). Successful outcomes: A follow-up study of children adopted from Romania into the UK. Adoption Quarterly, 5(1), 5 -22 .

Gunz, H., \& Heslin, P. (2005). Reconceptualizing career success. Journal of Organizational Behavior, 26, 105-111.

Hahm, H., Lee, Y., Ozonoff, A., \& Van Wert, M. (2010). The impact of multiple types of child maltreatment on subsequent risk behaviors among women during the transition from adolescence to young adulthood. Journal of Youth Adolescence, $39,528-540$.

Haight, W. (2010). The multiple roles of applied social science research evidenceinformed practice. Social Work, 55(2), $101-103$.

Haight, W., Kagle, J., \& Black, J. (2003). Understanding and supporting parent-child relationships during foster care visits: Attachment theory and research. Social Work, 48(2), $195-207$.

Hall, G. (1904). Adolescence. New York, NY: Appleton.

Haque, N., \& Rosas, S. (2010). Concept Mapping of photovoices: Sequencing and integrating methods to understanding immigrants' perceptions of neighborhood influences on health. Family Community Health, 33(3), 193 - 206.

Harden, B. (2004). Safety and stability for foster children: A developmental perspective. Children, Families, and Foster Care, 14(1). Retrieved from: http://futureofchildren.org/futureofchildren/publications/journals/article/index.xml ?journalid $=40 \&$ articleid $=133 \&$ sectionid $=874$.

Hass, M., \& Graydon, K. (2009). Sources of resiliency among successful foster youth. Children and Youth Services Review, 31, 457 - 463.

Henderson, D., \& Scannapieco, M. (2006). Ecological correlates of effective foster care. Journal of Family Social Work, 10(1), 43 - 60.

Herrenkohl, R.C. \& Herrenkohl, T.I. (2009). Assessing a child's experience of multiple maltreatment types: Some unfinished business. Journal of Family Violence, 24, 485-496. 
Heslin, P. (2005). Conceptualizing and evaluating career success. Journal of Organizational Behavior, 26, 113-136.

Hildyard, K., \& Wolfe, D. (2002). Child neglect: developmental issues and outcomes. Child Abuse and Neglect, 26, 679-695.

Hill, K. (2009). Individuals with Disabilities Act of 2004 and the John H. Chafee Foster Care Independence Act of 1999: What are the policy implications for youth with disabilities transitioning from foster care? Child Welfare: Journal of Policy, Practice, and Program, 88(2), 5-23.

Hill, M. (1997). Participatory research with children. Child and Family Social Work, 2, $171-183$.

Hill, R. (2008). Gaps in research and public policies. Child Welfare, 87(2), 359- 367.

Hines, A., Merdinger, J., \& Wyatt, P. (2005). Former foster youth attending college: Resilience and the transition to young adulthood. American Journal of Orthopsychiatry, 75(3), $381-394$.

Holland, P., \& Gorey, K. (2004). Historical, developmental, and behavioral factors associated with foster care challenges. Child and Adolescent Social Work Journal, 21(2), 117-135.

Howe, D. (1994). Modernity, post modernity, and social work. British Journal of Social Work, 24, $513-532$.

Howe, D. (2006). Developmental attachment psychotherapy with fostered and adopted children. Child and Adolescent Mental Health, 11(3), 128 - 134.

Howe, D. (2009). A brief introduction to social work theory. New York, NY: Palgrave Macmillan.

Hughes, E. C. (1937). Institutional office and the person. American Journal of Sociology, 43, 404-413.

Hurt, L., Wiener, R., Russell, B., \& Mannen, R. (1999). Gender differences in evaluating social-sexual conduct in the workplace. Behavioral Sciences and the Law, 17, 413 -433 .

Hutchison, E. (2008). Dimensions of human behavior: The changing life course. ( $3^{\text {rd }}$ ed.). Los Angeles, CA: SAGE.

Iris, M., Ridings, J., \& Conrad, K. (2010). The development of a conceptual model for understanding elder self-neglect. The Gerentologist, 50(3), 303-315. 
Jackson, K., \& Trochim, W. (2002). Concept mapping as an alternative approach for the analysis of open-ended survey responses. Organizational Research Methods, 5(4), 307-336.

Jenkins, R. (1965). The needs of foster parents. Case Conference, 11(7), $211-219$.

Johnsen, J., \& Biegel, D., \& Shafran, R. (2000). Concept mapping in mental health: Uses and adaptations. Evaluation and Program Planning, 23, 67-75.

Jonson-Reid, M., Drake, B., Chung, S., \& Way, I. (2003). Cross-type recidivism among child maltreatment victims and perpetrators. Child Abuse and Neglect, 27, 899917.

Jugdev, K. \& Muller, R. (2005). A retrospective look at our evolving understanding of project success Project Management Journal, 36(4), 19 - 31.

Kagan, J., Kane, M., Quinlan, K., Rosas, S., \& Trochim, W. (2009). Developing a conceptual framework for an evaluation system for the NIAID HIV/AIDS clinical trials networks. Health Research and Policy Systems, 7(12), 1 - 16.

Kalish, R., Voigt, B., Rahimian, A., DiCara, J., \& Sheehan, K. (2010). Listening to youth: Reflections on the effect of a youth development program. Health Promotion Practice, 11, 387 - 393.

Kane, M., \& Trochim, W. (2007). Concept mapping for planning and evaluation. Thousand Oaks, CA: Sage.

Kaplan, S., Skolnik, L., \& Turnbull, A. (2009). Enhancing the empowerment of youth in foster care: supportive services. Child Welfare, 88(1), 133-61.

Katz, L. (1999). Concurrent planning: Benefits and pitfalls. Child Welfare, 78(1), 71 87.

Keith, D. (1989) Refining concept maps: Methodological issues and an example. Evaluation and Program Planning, 12, 75 - 80.

Kelly, G. (2002). The survival of long-term foster care. In G. Kelly \& R. Gilligan (Eds.), Issues in Foster Care (pp. 40 - 58). London: Jessica Kingsley Publishers.

Kemmis, S., \& McTaggart, R. (2005). Participatory action research: Communicative action and the public sphere. In N. Denzin \& Y. Lincoln (Eds.), Handbook of Qualitative Research ( $2^{\text {nd }}$ ed.). Thousand Oaks, CA: Sage.

Kentucky Revised Statute. (2013). 600.020(19). Retrieved from krs.gov. 
Kerman, B., Wildfire, J., \& Barth, R. (2002). Outcomes for young adults who experienced foster care. Children and Youth Services Review, 24(5), 319 - 344.

Khinduka, S. (2001) Keynote address presented at the Annual Meeting of GADE (Group for the Advancement of Doctoral Education), October 12, 2001, Minneapolis, Minnesota.

Kinard, E. (2004). Methodological issues in assessing the effects of maltreatment Characteristics on behavioral adjustment in maltreated children. Journal of Family Violence, 19(5), $303-318$.

Kolb, D., \& Shepherd, D. (1997). Concept mapping organizational cultures. Journal of Management Inquiry, 6(4), $282-295$.

Kuhn, T. S. (1996). The structure of scientific revolutions ( $3^{\text {rd }}$ ed.). Chicago, IL: The University of Chicago Press.

Kunkel, M., Cook, S., Meshel, D., Daughtry, D., \& Hauenstein, A. (1999). God images: A concept map. Journal of Scientific Study of Religion, 38, 193 - 203.

Larabee, D. (2003). The peculiar problems of preparing educational researchers. Educational Researcher,32(4), 13 - 22.

Lee H., \& Zerai, A. (2010). Everyone deserves services no matter what: Defining success in harm-reduction-based substance user treatment. Substance Misuse, 45, 24112427.

Lichter, D., \& Jayakody, R. (2002). Welfare reform: How do we measure success. Annual Review of Sociology, 28, 117 - 141.

Litrownik, A., Laub, A., English, D., Briggs, E., Newton, R., Romney, S., \& Dubowitz, H. (2005). Measuring the severity of child maltreatment. Child Abuse and Neglect, 29, 553-573.

Lobbestael, J., Arntz, A., \& Bernstein, D. (2010). Disentangling the relationship between different types of childhood maltreatment and personality disorders. Journal of Personality Disorders, 24(3), 285-295.

Lourenco, O., \& Machado, A. (1996). In defense of Piaget's theory: A reply to 10 common criticisms. Psychological Review, 103(1), $143-164$.

Magura, S. \& Moses, B. (1986). Outcome measures for child welfare services: Theory and applications. Washington, D.C.: Child Welfare League of America.

Mandell, B. (1973). Where are the children: A class analysis of foster care and adoption. Lexington, MA: DC Heath and Company. 
Manly, J. T., Cicchetti, D., \& Barnett, D. (1994). The impact of subtype, frequency, chronicity, and severity of child maltreatment on social competence and behavior problems. Development and Psychopathology, 6, 121-143.

Mann, J., \& Kretchmar, M. (2006). A disorganized toddler in foster care: Healing and change from an Attachment Theory perspective. Zero to Three. Retrieved from zerotothree.com.

Marin, S., Martineztorres, R., Garcia, F., Vazquez, S., Vargas, E., \& Ayala, V. (2006). Planning a master's level curriculum according to career space recommendations using Concept mapping techniques. International Journal of Technology and Design Education, 16, 237 - 252.

Marquis, R., Leschied, A., Chiodo, D., \& O’Neill, A. (2008). The relationship of child neglect and Physical maltreatment to placement outcomes and behavioral adjustment in children in foster care: A Canadian perspective. Child Welfare, $87(5), 5-25$.

McAuly, C. (1996). Children in long-term foster care. Aldershot: Avebury.

McCutcheon, J. (2010). Historical analysis and contemporary of foster care in Texas: Perceptions of social workers in a private, non-profit foster care agency. Applied Research Projects, Texas State University. Retrieved from http://ecommons.txstate.edu/arp/332.

McDonald, T., Allen, R., Westerfelt, A., \& Pivilian, I. (1996). Assessing the long-term effects of foster care: A research synthesis. Retrieved from www.eric.ed.gov/ERICWebPortal/recordDetail?accno=ED408036.

McFadden, E. (1989). Empowering children and youth in foster care: A forum. Retrieved from eric.gov.

McGuinness, T., \& Schneider, K. (2007). Poverty, child maltreatment, and foster care. Journal of the American Psychiatric Nurses Association, 13, 296 - 303.

McKelvey, C., \& Stevens, J. (1994). Adoption crisis: The truth behind adoption and foster care. Golden, CO: Fulcrum.

McWey, L. (2000). I promise to act better if you let me see my family: Attachment theory and foster care visitation. Journal of Family Social Work, 5(1), 91 - 105.

McWey, L. (2004). Predictors of attachment styles of children in foster care: An Attachment Theory model for working with families. Journal of Marital and Family Therapy, 30(4), 439 - 452.

Merriam-Webster. (2012). Success. Retrieved from ww.merriam-webster.com. 
Mikulincer, M., Shaver, P., \& Pereg, D. (2003). Attachment Theory and affect regulation. The dynamics, development, and cognitive consequences of attachment related strategies. Motivation and Emotion, 27(2), 77 - 102.

Miles, P., Bruns, E.J., Osher, T.W., \& Walker, J.S. (2006). The wraparound process user's guide: A handbook for families. National Wraparound Initiative, Research and Training Center on Family Support and Children's Mental Health. Portland State University.

Miller, J., Rhema , S., Faul, A., D'Ambrosio, J., Yankeelov, P., Amer, R., \& Clark, R. (2012). Strength in process: Using concept mapping to inform community coalition development. Journal of Community Practice, 20(4), 432 - 456.

Miniely, J. \& Desgagne, D. (1983). Success of failure: A case study. Child Welfare, $62(2), 129-139$.

Moran, P., Vuchinich, S., \& Hall, N. (2004). Associations between types of maltreatment and substance use during adolescence. Child Abuse and Neglect, 28, 565-574.

Morris, R. (2007). Voices of foster youth: Problems and ideas for change. Urologic Nursing, 27, $419-427$.

Mpofu, E., Lawrence, F., Ngoma, M. S., Siziya, S., \& Malungo, J. R. S. (2008). Mapping an HIV/STD prevention curriculum for Zambian in-school settings International Journal of Psychology 43(2), 97-106.

Napier, H. (1972). Success and failure in foster care. British Journal of Social Work, 2(2), $187-204$

National Association for the Counsel for Children. (2012). Youth involvement. Retrieved from www.nacchildlaw.org/

National Campaign to Prevent Teen Pregnancy. (2010). Teen pregnancy and child welfare. Retrieved from http://www.thenationalcampaign.org/why-itmatters/pdf/child_welfare.pdf

National Foster Care Youth Advisory Council. (2012). Forming a youth advisory council. Retrieved from www.ytfg.org/documents/Council.pdf.

National Resource Center for Youth Development. (2013). Engaging youth in in permanency planning. Retrieved from http://www.nrcyd.ou.edu/youthengagement/engaging-youth-in-permanency-planning. 
Northern California Training Academy. (2008). A literature review of placement stability in child welfare services: Issues, concerns, outcomes and future directions. Retrieved from http://humanservices.ucdavis.edu/Academy/pdf/FINAL2LitReviewPlacementStab ility.pdf

Nosich, G. (2009). Learning to think things through: A guide to critical thinking across the curriculum. ( ${ }^{\text {rd }}$ ed.). Upper Saddle River, NJ: Pearson/Prentice Hall.

Ocasio, J. \& Knight, J. 2003. Rediscovery of trust: Erickson, kaplan \& the myth of foster care. Opinion Papers. Retrieved from www.eric.ed.gov.

Oosterman, M., Schuengel, C., Slot, N., Bullens, R., \& Doreleijers, T. (2006). Disruptions in foster care: A review and meta-analysis. Children and Youth Services Review, 29, $53-76$.

Pain, R., \& Frances, P. (2003). Reflections on participatory research. Area, 35(1), 46 54.

Paulson, B., Truscott, D., \& Stuart, J. (1999). Clients' perceptions of helpful experiences in counseling Journal of Counseling Psychology, 46(3), 317 - 324.

Paulson, B., \& Worth, M. (2002). Counseling for suicide: Client perspectives. Journal of Counseling and Development, 80, 86-93.

Pearce, J., \& Pezzot-Pearce, T. (2001). Psychotherapeutic approaches to children in foster care: Guidance from attachment theory. Child Psychiatry and Human Development, 32(1), 19 - 44 .

Pecora, P., Kessler, R., Williams, J., Downs, A., English, D., White, J., \& O’Brien, K. (2010). What works in foster care. New York, NY: Oxford.

Pecora, P., Whittaker, J., Maluccio, A., Barth, R., \& Plotnick, R. (1992). The child welfare challenge: Policy, practice, and research. New York: Walter de Gruyter, Inc.

Perkins, R. (2001). What constitutes success: The relative priority of service user's and clinician's views of mental health services. The British Journal of Psychiatry, $179,9-10$.

Permuth-Wey, J., \& Borenstein, A. (2009). Financial remuneration for clinical and behavioral research participation: Ethical and practical considerations. Annals of Epidemiology, 19(4), 280-285.

Peters, C., \& Myrick, S. (2011). Juvenile recidivism: Measuring success or failure. Corrections Today, 32 - 43. 
Petersen A., \& Leffert, N. (1995). Developmental issues influencing guidelines for adolescent health research: a review. Journal of Adolescent Health 17(5), 298305 .

Piaget, J. (1936). Origins of intelligence in the child. London: Routledge \& Kegan Paul.

Piaget, J. (1945). Play, dreams and imitation in childhood. London: Heinemann.

Piaget, J. (1952). The origins of intelligence in children. New York: International Universities Press.

Piaget, J. (1957). Construction of reality in the child. London: Routledge \& Kegan Paul.

Poulin, J. (1992). Kin visiting and the biological attachment of long-term foster children. Journal of Social Service Research, 15, 65 - 79.

Redding, R., Fried, C., \& Britner, P. (2000). Predictors of placement outcomes in treatment foster care: Implications for foster parent selection and service delivery. Journal of Child and Family Studies, 9(4), 425 - 447.

Pugach, M., \& Johnson, L. (2002). Collaborative practitioners, collaborative schools. Denver, CO: Love Publishing.

Rappaport, J. (1977). Community psychology: Values, research, and action. New York, NY: Rhinehart and Winston.

Reddy, L., \& Pfeiffer, S. (1997). Effectiveness of treatment foster care with children and adolescents: A review of outcome studies. Journal of American Academy of Child and Adolescent Psychiatry, 36(5), 581 - 588.

Reifsteck, J. (2005). Failure and success in foster care programs. North American Journal of Psychology, 7(2), $313-326$.

Ridde, V. (2008). Equity and health policy in Africa: Using concept mapping in Moore (BurkinaFaso). BMC Health Services Research 8(90), 1-12.

Ridings, J., Piedra, L., Capeles, J., Rodriguez, R., Freire, F., \& Byoun, S. (2011). Building a latino youth program: Using Concept mapping to identify communitybased strategies for success. Journal of Social Service Research, 37, 34 - 49.

Ridings, J., Powell, D., Johnson, J., Pullie, C., Jones, C., Jones, C., \& Terrell, K. (2008). Using Concept Mapping to promote community building: The African-American initiative at Roseland. Journal of Community Practice, 16(1), 39 - 63.

Riggs, D., Augoustinos, M., \& Delfabbro, P. (2009). Role of foster family belonging in recovery from child maltreatment. Australian Psychologist, 44(3), 166 - 173. 
Robbins, S., Chatterjee, P., \& Canda, E. (2006). Contemporary human behavior theory: A critical perspective for social work. ( $3^{\text {rd }}$ ed.). New York, NY: Allyn \& Bacon.

Rodgers, C., Langa, A., Laffaye, C., Satz, L., Dresselhaus, T., \& Stein, M. (2004). The impact of individual forms of childhood maltreatment on health behavior. Child Abuse and Neglect, 28, 575-586.

Rogers, A. (2010). Human behavior and the social environment. ( $2^{\text {nd }}$ ed.). New York, NY: Routledge.

Rogers, A. (2013). Human behavior and the social environment. ( $3^{\text {rd }}$ ed.). New York, NY: Routledge.

Rogers, R. (2011). I remember thinking why isn't there someone to help me? Why isn't there someone who can help me make sense of what I am going through?: Instant adulthood and the transition of young people out of state care. Journal of Sociology, 47, $411-426$.

Romesburg, H. C. 2004. Cluster analysis for researchers. Morrisville, NC: Lulu Press, Inc.

Rosas, S. (2005). Concept mapping as a technique for program theory development. American Journal of Evaluation, 26, 389- 401.

Rosas, S., \& Camphausen, L. (2007). The use of concept mapping for scale development and validation in evaluation. Evaluation and Program Planning, 30(2), 125 - 135.

Rosas, S., \& Kane, M. (2012). Quality and rigor or the concept mapping methodology. A pooled study analysis. Evaluation and Program Planning, 35, 236 - 245.

Rowe, D. (1976). Attitudes, social class, and the quality of foster care. Social Service Review, 50(3), $506-514$.

Rutter, M. (1987). Psychosocial resilience and protective mechanisms. American Journal of Orthopsychiatry, 57, $316-331$.

Samuels, G. (2009). Ambiguous loss of home: the experience of familial (im)permanence among young adults with foster care backgrounds. Children and Youth Services Review, 31, $1229-1239$.

Samuels, G., \& Pryce, J. (2008). What doesn't kill you makes you stronger: Survivalist self-reliance as resilience and risk among young adults aging out of foster care. Children and Youth Services Review, 30, 1198 - 1210.

Sanchez, R. (2004). Youth perspectives of permanency. California Permanency for Youth Project. Retrieved from www.calyouthconn.org. 
Schofield, G., \& Beek, M. (2005). Providing a secure base: Parenting children in longterm foster family care. Attachment and Human Development, 7(1), 3 - 25.

Schweitzer, M., S. Carnes, E. Peelle, A. K. Wolfe, and J. F. Munro, 1996. Measuring the success of public participation efforts associated with the U.S. Department of Energy's environmental management activities. Practical Environmental Directions: A Changing Agenda. NAEP $21^{\text {st }}$ Annual Conference Proceedings, National Association of Environmental Professionals, pp. 593600.

Sharkey, J., \& Layzer, C. (2000). Whose definition of success? Identifying factors that affect english language learners' access to academic success and resources. TESOL Quarterly, 34(2).

Sherman, E., Neuman, R., \& Shyne, A. (1973). Service to children in their own homes. New York, NY: Child Welfare League of America.

Shireman, J. (n.d.). Improving children's experiences in foster care: Foster parent ideas. Forum on Public Policy. Retrieved from orumonpublicpolicy.com/spring09papers/archivespr09/shireman.pdf

Sime, D. (2008). Ethical and methodological issues in engaging young people in poverty and participatory research methods. Children's Geographies, 6(1), $63-78$.

Sinclair, I., \& Wilson, K. (2003). Matches and mismatches. British Journal of Social Work, 33, $871-884$.

Smith, C. (2009). Foster care and families apart: Poverty, placement, and potential. In C. Broussard \& A. Joseph (Eds.), Family Poverty in Diverse Contexts (pp. 121 137). New York: Routledge.

Springer, K., Sheridan, J., Kuo, D., \& Carnes, M. (2007). Long-term physical and mental health consequences of childhood physical abuse: Results from a large population-based sample of men and women. Child Abuse and Neglect: The International Journal, 31(5), 2007, 517 - 530.

Steep, L. (2002, February 5). Are we giving teens a bad rap? Washington Post, e version. Retrieved from www.washingtonpost.com/

Stein, M. (2006). Young people aging out of care: The poverty of theory. Child and Youth Services Review, 28, $422-434$.

Steinberg, L., Cauffman, E., Woolard, J., Graham, S., \& Banich, M. (2009). Are adolescents less mature than adults? Minors' access to abortion, the juvenile death penalty, and the alleged APA "flip-flop". American Psychologist, 64(7), 583594. 
Stone, N., \& Stone, S. (1983). The prediction of successful foster placement. Social Casework, 64, 11-17.

Stovall-McClough, K., \& Dozier, M. (2004). Forming attachments in foster care: Infant attachment behaviors during the first 2 months of placement. Development and Psychopathology, 16, $253-271$.

Stoyanov, S., \& Kirschner, P. (2004). Expert Concept Mapping method for defining the characteristics of adaptive e-learning: ALFANET project case. ETR\&D, 52(2), 41 -56 .

Street, E., \& Davies, M. (1999). Assessing and matching foster care relationships: An international framework. Adoption and Fostering, 23(2), $31-41$.

Striker, J. (2010). Typologies and outcomes for foster children. Child \& YouthCare Forum, 34(1), 43-55.

Strijker, J., Zandberg, T., \& van der Meulen, B. (2002). Indicators for placement in foster care. British Journal of Social Work, 32(2), 217 - 232.

Strolin-Goltzman, J., Kollar, S., \& Trinkle, J. (2010). Listening to the voices of children in foster care: Youths speak out about child welfare workforce turnover and selection. Social Work, 55(1), 47 - 53.

Szilagyi, M. (1998). The pediatrician and the child in foster care. Pediatrics in Review, $19(2), 39-50$.

Thomas, G., \& Fernandez, W. (2008). Success in IT projects: A matter of definition. International Journal of Project Management, 26, 733 - 742.

Tolman, D., \& Brydon-Miller, M. (2001). Interpretive and participatory research methods: Moving towards subjectivities. In D. Tolman \& M Brydon-Miller (Eds.), From Subjects to Subjectivities: A Handbook of Interpretive and Participatory Methods (pp. 3 -11). New York, NY: New York University.

Trickett, P., \& McBride-Chang, C. (1995).The developmental impact of different forms of child abuse and neglect. Developmental Review, 15, 311 - 337.

Trochim, W. (1989a). Concept mapping: Soft science or hard art? In W. Trochim (Ed.) A Special Issue of Evaluation and Program Planning, 12, 87-110.

Trochim, W. (1989b). Outcome pattern matching and program theory. In W. Trochim (Ed.) A Special Issue of Evaluation and Program Planning, 12, 87-110.

Trochim, W. (1993). Reliability of concept mapping. Paper presented at the Annual Conference of the American Evaluation Association, Dallas, Texas. 
Trochim, W. \& Linton, R. (1986). Conceptualization for evaluation and planning. Evaluation and Program Planning, 9, 289-308.

Truscott, D., Paulson, B., \& Everall, R. (1999). Studying participants' experiences using Concept Mapping. The Alberta Journal of Educational Research, 3, 320 - 323.

Ungar, M. (2004). Surviving as a postmodern social worker: Two ps and three rs of direct practice. Social Work, 49(3), $488-496$.

Ungar, M., \& Teram, E. (2000). Drifting toward mental health: High risk adolescents and the process of empowerment. Youth \& Society, 33(2), $228-252$.

United States Department for Health and Human Services. (2013). Ethics and confidentiality. Retrieved from www.childwelfare.gov.

United States Department of Health and Human Services, Adoption and Foster Care Analysis And Reporting System. (2013). Kentucky. Retrieved from www.childwelfare.gov.

Urek, M. (2005). Making a case in social work: The construction of an unsuitable mother. Qualitative Social Work, 4, 451 - 467.

Van Wormer, K. (2011). Human behavior and the social environment: Individuals and families. ( $2^{\text {nd }}$ ed.). New York, NY: Oxford University Press.

Vosniadou, S., \& Brewer, W. (1987). Theories of knowledge restructuring in development. Review of Educational Research, 57(1), 51 - 67.

Wakefield, J. (1995). When an irresistible epistemology meets an immovable ontology. Social Work Research, 19(1), 9 - 17.

Ward, H. (1971). A psychiatric foster care success story. Medical Annals of the District of Columbia, 40(12), $745-748$.

Ward, J. (1963). Hierarchical grouping to optimize an objective function. Journal of American Statistical Association, 58(301), 236-244.

Whelan, D. (2003). Using attachment theory when placing siblings in foster care. Child and Adolescent Social Work Journal, 20(1), 21 - 36.

White, K., \& Farrell, A. (2001). Structure of anxiety symptoms in urban children: Competing factor models of the revised children's manifest anxiety scale. Journal of Counseling and Clinical Psychology, 69(2), 333 - 337.

Whiting, J. (2000). The view from down here: Foster children's stories. Child \& Youth Care Forum, 29. 79-95. 
Whiting, J., \& Lee, R. (2003). Voices from the system: A qualitative study of foster children's stories. Family Relations, 52, 288 - 295.

Wilson, K., Petrie, S., \& Sinclair, I. (2003). A kind of loving: A model for effective foster care. British Journal of Social Work, 33, 991 - 1003.

Wilson, S., Norris, A., Shi, X., \& Rack, J. (2010). Comparing physically abused, neglected, and non-maltreated children during interactions with their parents: A meta-analysis of observational studies. Communication Monographs, 77(4), 540 575.

Winters, N., \& Metz, W. (2009). The wraparound approach in systems of care. Psychiatric Clinician of North America, 32, 135 - 151.

Woolf, G. (1990). An outlook for foster care in the United States. Child Welfare, 69(1), $75-81$.

Wylie, M., \& Turner, L. (2011). The attuned therapist. Psychotherapy Networker, 19 27.

Zastrow, C., \& Kirst-Ashman, K. (2010). Understanding human behavior and the social environment. ( $9^{\text {th }}$ ed.). Belmont, CA: Brooks/Cole. 
Appendix 1

\title{
interested in sharing your ideas about foster care...
}

\author{
and getting \\ paid for it?! \\ If so, this is for you! \\ You are invited to be a \\ participant in the \\ "Success in Foster care" \\ Research Project!
}

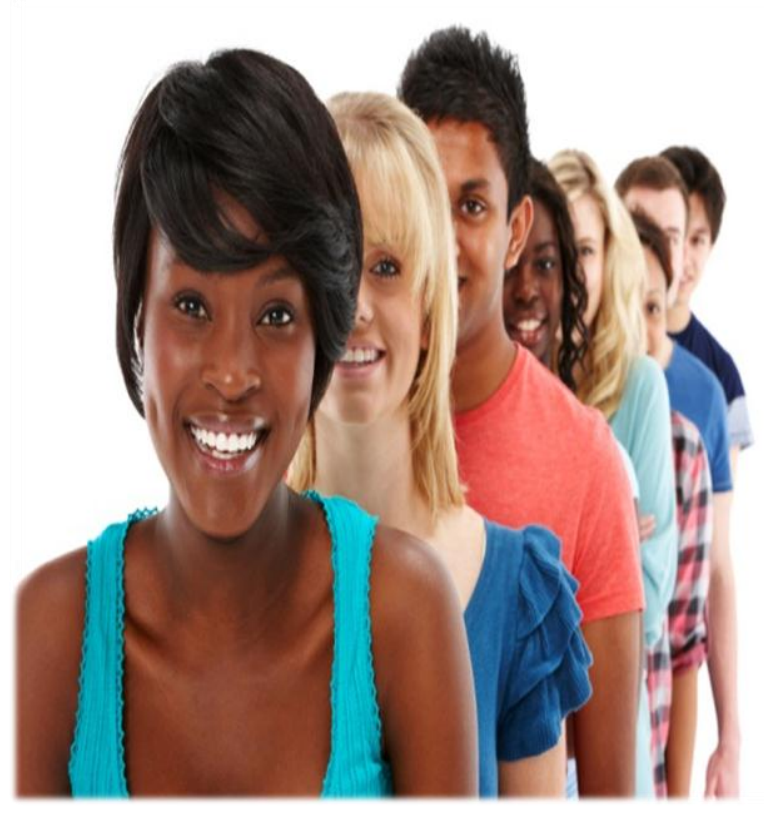

What: This research study aims to gather the perspectives of foster youth about what it means to be successful in foster care.

How: $\quad$ Teens who are in this study will be asked to participate in two focus group meetings. After the first meeting, teens will get a \$10 cash gift card. After the second meeting, teens will get a $\$ 40$ cash gift card. That's a total of $\$ 50$ !

Who: If you are between the ages of $14-18$, currently in foster care, and have permission from your social worker, you can participate!

When: Location/Date TBD

If you have any questions or concerns about this study, you can call 270-779-2699. This study is being conducted by the university of Louisville, Kent School of Social Work

Dr. Crystal collins-camargo, Principal investigator, 502-852-3174 


\section{Appendix 2}

\section{Success On Their Own Terms:}

\section{Youths' Perspectives On What It Means To Be Successful in Foster Care}

Demographic \& Information Questionnaire

1. What is your name (first and last)?

2. What county do you currently live in?

3. What county are you from?

4. What is your age?

5. How would you describe your gender? Male Female Transgender

6. Who is your state social worker?

7. About how long have you been in foster care? (Please tell whether you are answering in days, months, or years.)

8. What is your race?

_ African American/Black Hispanic/Latino/Latina

Caucasian

American Indian/Native American

Asian

Other (please specify)

9. Do you have children? Yes No

8a. If you do have children, how many children do you have?

10. Are you currently attending school? Yes No 10a. If you do attend school, what grade are you in?

10b. If you do not attend school, did you: _ Graduate _ Get Your GED _ Quit/Dropout

11. Are you currently employed? Yes No

12. Are you currently involved in any foster care groups/organizations? Yes No

12a. If yes, what is the name of the group or organization you are involved with? 
13. Some kids come in and out of foster care more than once but others enters only once. For the most recent time, why were you placed in foster care?

14. In your life, about how many different foster homes have you been placed in?

15. Overall, how would you rate your foster care experience (circle one of the numbers below)?

1

Bad
2

$\stackrel{3}{\text { Neither Good or Bad }}$
4 5 Good 


\title{
CURRICULUM VITAE
}

\author{
Justin "Jay" Miller, MSW, CSW (ABD) \\ 11822 Duane Point Circle \#203 \\ Louisville, KY 40243 \\ Home: 270-779-2699 \\ Email: justin.miller@louisville.edu
}

\section{EDUCATION}

- Doctoral Candidate, University of Louisville Kent School of Social Work

- Doris Duke Fellow (Doris Duke Foundation \& University of ChicagoChapin Hall)

- Dissertation Title: Success on Their Own Terms: Youth Perspectives on What It Means to Be Successful In Foster Care (Expected Completion October, 2013)

- Master of Social Work, Spalding University, 2007

○ Honors Graduate, 4.0 GPA

- Bachelor of Science, Social Work, Western Kentucky University, 2003

\section{SUPPLEMENTAL EDUCATION}

- Enhancing Safety and Permanency of Children in Child Welfare, University of Kentucky, 2008

- Assessing Child Sexual Abuse, Western Kentucky University, 2006

- Protection and Permanency Child Welfare Academy, University of Kentucky, 2004

\section{SPECIALIZED TRAINING}

- Federal Emergency Management Agency Crisis Training- 2009

- Suicide Prevention - 2009

- Forensic Interviewing of Children- Child Protective Services- 2006

- Meeting the Needs of Families and Children in Domestic Violence- 2004

- Health Insurance and Portability and Accountability Act- 2004

- Assessment and Case Management of Child Sexual Abuse- 2004

- Dynamics and Indicators of Families In Need of Services- 2004

- Medical Indicators of Child Maltreatment- 2004

\section{LICENSE}


- Certified Social Worker- Licensed at the Graduate Level (Licensed by State of Kentucky- \#5250)

\section{RESEARCH EXPERIENCE (including Grant \& Contract Projects)}

\section{Current Projects}

- Principal Researcher - Success on Their Own Terms: Youth Perspectives on What It Means to Be Successful In Foster Care (funded dissertation) Utilizing a mixed-methodology, this study seeks to delineate a conceptual domain for what it means to be "successful" in foster care, from the perspectives of current foster youth (Doris Duke Fellowship Grant - \$50,000).

- Co-Principal Researcher - Peer-Learning Networks in Social Work Doctoral Education: An Interdisciplinary Model

This study utilizes a structured questionnaire with scaled survey items, as well as open-ended questions, to examine the use, benefits of, and challenges to participating in a doctoral Peer Learning Network (PLN).

\section{Past Projects}

- Principal Researcher - Leveraging The Experiences of Foster Care Alumni: A Mixed-Method Model for Organizing

This study utilized a mixed-method approach to inform the planning and organizational formation of a newly formed, state-wide foster care alumni group.

- Program Evaluation Consultant - Kentucky Department for Behavioral Health, Developmental and Intellectual Disabilities (Contract)

Served as consultant in the development of a specific program evaluation protocol for a grant proposal to expand Sobriety Treatment and Recovery Teams in Kentucky. (2012)

- Investigator - Lincoln Trail Health Department (Contract)

Conducted a three county assessment to identify health care needs in three rural counties. Methods included developing and analyzing survey and survey data, interviewing key stakeholders, and conducting focus groups. (2012)

- Community Research Consultant - Kentuckiana Regional Planning and Development Agency (KIPDA)(Contract) Conducted participatory research, to include data collection, analyses, and dissemination for KIPDA Rural Diabetes Coalition. Research conducted as part of federally administered grant. (2011) 
- Research Assistant (Independent Study) - Project MATCH

Developed database and analyzed data related to foster parent and social worker perceptions of state foster care. Managed survey data via BLUE software systems. (2010)

- Investigator - Fostering Peer Support: A Pilot Process Evaluation - Cabinet for Health and Family Services \& Spalding University (Funded Master's Culminating Project)

Conducted survey analysis related to youth participation in the Jefferson County Peer Support Group. (\$500 - in-kind supports)(2007)

\section{TEACHING EXPERIENCE}

- Assistant Professor - Spalding University - Louisville, KY

July 2012 - Current

AY - 2011-12 (Rank: Full-time Instructor)

AY - 2010-11 (Rank: Proportionate-Time Instructor)

Responsible for 24.0 hours of instruction across undergraduate and graduate social work curriculum. Courses taught in current position include:

- SW 600 (Introduction to the Profession)

- SW 604 (Foundations of Social Work Practice)

- SW 612 (Human Development in the Social Context - Micro/Mezzo)

- SW 613 (Human Development in the Social Context - Macro)

- SW 620 \& 622 (MSW Field Seminars)

- SW 626 \& 627 (Advanced MSW Field Seminars)

- SW 630 (Integrative Practice I)

- SW 631 (Integrative Practice II)

- SW 346 (HBSE I)

- SW 347 (HBSE II)

○ SW 350/SW 450 (Research)

- SW 473/474 (BSSW Field Seminars)

- SW 280 (Child Maltreatment) *Developed *On-line course

- Developed/taught Social Work Licensure Preparatory CEU Courses at LSW, CSW, and LCSW levels (quarterly since 2008).

○ Developed, implemented, and facilitated academic training program for university track and field team (2010-2011)

- Developed, implemented, and facilitated BSSW to MSW Initiative

- Currently serve on University Faculty Development Committee (On-line Learning), School Evaluation, Field, MSW Curriculum, and Learning Community Committees

- $\quad$ Lecturer - University of Louisville - Louisville, KY Summer 2011 
Responsible for lecturing (emphasis on research design) and developing SPSS/PASW lab series for:

○ SW 766 (Doctoral Preparation)

- Adjunct Instructor - Spalding University - Louisville, KY

August 2009 - June 2010

Courses taught:

- SW 630 (Practice I)

- SW 631 (Practice II)

\section{PROFESSIONAL EXPERIENCE}

- Pediatric Social Worker - United States Government, Ireland Hospital - Ft. Knox, KY

May 2009 - August 2010

Designed and developed comprehensive case management/care coordination plans for patients seen in the pediatric clinic, on both an in and out-patient basis. Conducted psycho-social evaluation and counseling to individuals, groups, and families to facilitate care and optimize care management. Evaluated diagnoses, and unexplained chronic symptoms, and identified areas of need and resources to assist with treatment. Trained medical personnel on child maltreatment indicators, assessment measures, and appropriate steps to deal with child abuse/neglect.

- Social Service Clinician - Cabinet for Health and Family Services- Crimes Against Children Unit - Louisville, KY

May 2007 - April 2009

Worked directly with Louisville Metro Police Detectives in investigating serious cases of child abuse/neglect including, but not limited to, extreme physical abuse and child fatalities/near fatalities. Coordinated service interventions and worked directly with families to develop and evaluate case plans and progress of said plans. Initiated court action in Jefferson County Family Court and provided written and oral testimony in both Family and Circuit courts. Routinely covered supervisory duties in the absence of supervisor.

- Social Service Worker - Cabinet for Health and Family Services - Louisville, KY August 2004 - May 2007

Provided family/community based services, which included child protective services. Investigated complaints of abuse/neglect of children, spouses, and other adults. Made home visits, assessed the need for services, and provided initial intervention to families in need. Ensured unified service provision among paraprofessionals, developed service objectives and case plans, and placed children in adoptive/foster/family care homes or juvenile facilities.

- Behavior Health Specialist - Lifeskills, Inc. - Bowling Green, KY 
January - July 2004

Worked with primary therapist in creating, implementing, and presenting individual treatment/behavior programs in order to strengthen the clients' overall well-being. Administered comprehensive psychological, emotional, cognitive, and behavioral interventions under the supervision of primary therapist. Assisted in the development and continuation of parent support groups.

- Emergency Night Assessor - Cabinet for Health and Family Services Louisville, KY August 2006 - April 2009 (PRN)

Completed emergency (imminent risk) assessments of allegations of abuse and/or neglect taken from the Kentucky State Child Abuse Hotline. Provided crisis intervention and referred services to families in need.

- Medical Social Worker - Rescare, Inc. - Louisville, KY August 2007 - August 2009 (Part Timel 15-20 hours weekly) Provide in-home social work services to clients under the federal Medicaid HCB Waiver Program. Conduct psycho-social assessments, Medicaid initial/renewal assessments, and monthly contacts for MR/MMR/Autistic/DD client population.

\section{FIELD PRACTICUM \& INTERNSHIPS}

- Field Practicum Intern (Graduate Level) - Foster Home Recruitment and Certification - Louisville, KY

July 2006 - May 2007

Reviewed licensed foster homes for compliance of policy requirements. Conducted reviews of foster homes, monitored expenditures, and completed foster parent adoption memos and packets. Assessed, completed, and submitted home evaluations for potential foster resource homes. Authored, developed, and facilitated the Jefferson County Peer Support Group for adolescent foster children.

- Social Work Intern - Department for Community Based Services Munfordville, KY

June 2002 - September 2003

Assisted social workers with daily case management duties. Supervised court ordered visitation and documented status, nature, and outcomes of these visits. Routinely researched family case history and provided written reports to various parties within the county family court system.

\section{AWARDS}

- Featured Research Fellow, Chapin Hall Brief - April 2013

- Featured Social Worker, NASW - KY - March 2013

- Spalding University Teaching Initiative Grant Award - 2013

- Doris Duke Fellowship Award (\$50,000 in funded support for research) - 2012 
- Metroversity Faculty Adult Learner Award Nominee - 2012

- International Graduate Scholar Award, Global Sustainability Conference, University of Waikato, Hamilton, New Zealand - 2011

- United States Army Commander's Coin for Excellence in Civilian Service, Ft. Knox MEDAC- 2010

- Cabinet for Health and Family Services- Paul T. Grannis Award- 2007 (Statewide Award)

- Cabinet for Health and Family Services- ACE Award- 2007 (Regional Award)

- Kentuckiana Metroversity Outstanding Graduate Student Award- 2007

- Spalding University Egan Graduate Student Award- 2007

- Spalding University School of Social Work Outstanding Learner as Teacher Award- 2007

- Cabinet for Health and Family Services Commendation- 2007

\section{PUBLICATIONS}

Owens, L., Miller, J., \& Grise-Owens, E. (in press). Activating a teaching philosophy in social Work education: Articulation, implementation, and evaluation. Journal of Teaching in Social Work.

Grise-Owens, E., Miller, J., \& Owens, L. (in press). Responding to global shifts: MetaPractice as a relevant social work practice paradigm. Journal of Teaching in Social Work.

Miller, J., Rhema, S., Faul, A., D’Ambrosio, J., Yankeelov, P., Amer, R., \& Clark, R. (2013). Strength in process: Using concept mapping to inform community coalition development. Journal of Community Practice, 20(4), 432-456.

Miller, J. (2009). I was in foster care too: From promise to practice. Inside Out: Reflections on Personal and Professional Intersections, 15(2), 90-94.

\section{Manuscripts in Review}

Grise-Owens, E., Miller, J., Eaves, M., \& Mays-Burton, M. (in review). Exploring implicit curriculum: Accessing student voice through autoethnography. Journal of Teaching in Social Work.

Miller, J., Owens, L., \& Faul, A. (in review). Leveraging the experiences of foster care alumni: A mixed-method approach to organizing. Child and Youth Services Review.

\section{$\underline{\text { Non-juried Publications \& Reports }}$}

Platt, P., Miller, J., Szigray, S., \& Nelson, L. (2012). Community health needs 
assessment report. Bullitt County Health Department and Lincoln Trail Health District.

Miller, J. (2008). Protecting the protectors: Am I really safe? New Social Worker Magazine, (8) Winter Edition.

Miller, J. (2007). Fostering peer support: A pilot process evaluation. Louisville, KY: Spalding University.

\section{PRESENTATIONS}

\section{Featured/Keynote Presentations \& Trainings}

Miller, J. (2013). Leveraging the experiences of foster care alumni. Invited presentation for the Kentucky Citizen Review Panel, Lexington, KY.

Miller, J. (2012). Stabilizing foster care placements: Pragmatic tips for foster parents. Invited training conducted for NECCO Therapeutic Foster Care Services, Louisville, KY.

Miller, J. (2012). From Promise to Practice: Meeting the Needs of Foster Youth. Keynote/Invited presentation presented at the New Beginnings Foster Agency, Louisville, KY.

Miller, J. (2012). My journey in foster care. Keynote address presented at the Red Carpet Thanksgiving Foster Care Celebration, Louisville, KY.

Miller, J. (2011). Diversity: The first three steps. Keynote address presented at the United States Census Bureau's Diversity Fair, Jeffersonville, Indiana.

Miller, J. (2009). Child abuse ABCs. Featured presentation to the United States Army MEDDAC Command, Ft. Knox, KY.

Miller, J. (2007). Child abuse investigations in Kentucky. Invited training for the Professional Child Welfare Training Program.

\section{Presented Papers}

Faul, A.C., Gordon, B., D'Ambrosio, J.G., Ferrell, G., Tucker, M., Schapmire, T.J., Morgan, F., Thompson, J., Rhema, S., Miller, J., Boamah, D.A., Brown, L., Boes, R.C., Zheng, Y., Lawson, T.R. (2013, July). Academia and the Aging Network. Paper presented at the 38th Annual N4A Conference and Tradeshow, Louisville, KY.

Owens, L., Miller, J., \& Grise-Owens, E. (2013, March). Meta-practice: A new paradigm 
in social work practice. Paper presented at the 2013 conference of the Association of Baccalaureate Social Work Program Directors, Myrtle Beach, South Carolina.

Lewis, J., \& Miller, J. (2012, August). Examining social workers' attitudes towards sex offenders: A social justice imperative. Paper presented at the 2012 Society for the Study of Social Problems Annual Meeting, Denver, Colorado.

Owens, L., Miller, J., \& Grise-Owens, E. (2012, July). Meta-practice: Incorporating sustainability into the social work curriculum. Paper accepted for presentation at the Social Work Social Development - International Social Work Conference, in Stockholm, Sweden. (Unable to present)

Faul, A., D'Ambrosio, J., Yankeelov, P., Collins, L., Miller, J., \& Rhema, S. (2012, July). The use of Concept Mapping to create a coalition logic model and evaluation tool. Presented at the Concept Mapping Colloquium, Chicago, IL.

D'Ambrosio, J., Faul, A., Yankeelov, P., Amer, R., Miller, J., Rhema, S., \& Clark, R. (2012, February). Moving from theory to practice: A participatory action concept mapping exercise. Paper presented at the AGHE Annual Meeting and Educational Leadership Conference, Arlington, VA.

Faul, A., Yankeelov, P., D’Ambrosio, J., Miller, J., Amer, R., Rhema, S., \& Clark, R. (2012, January). The use of concept mapping to create a coalition logic model and evaluation tool. Paper presented at the Society for Social Work Research Annual Conference, Washington, DC.

Grise-Owens, E., Owens, L., \& Miller, J. (2011, January). Sustainability through "meta"-practice. Paper presented at the Global Sustainability Conference, University of Waikato, Hamilton, New Zealand.

Miller, J. \& Grise-Owens, E. (2010, October). What would the wombat do: Sustainability through meta-practice." Paper presented at the Council on Social Work Education- APM, Portland, Oregon.

Miller, J., \& Grise-Owens, E. (2009, November). The impact of consumerism on learning: Education or entitlement? Paper presented at the Lilly International Conference on College Teaching. Miami University, Oxford, OH.

Miller, J., \& Grise-Owens, E. (2008, November). Teaching - Learning empowerment in a consumerist culture. Paper presented at the Council on Social Work EducationAPM, Philadelphia, PA.

Grise-Owens, E., Platt, P., Miller, J., Owens, L., (2008, October). Meta-Practice: Toward a new dimension of social work practice and policy. Paper presented at the Council on Social Work Education- APM, Philadelphia, PA. 
Grise-Owens, E., \& Miller, J. (2008, March). Let them eat pie: Just cutting up about democracy. Paper presented at the The Rouge Forum - Education: Reform or Revolution National Conference, Louisville, KY.

Miller, J., Grise-Owens, E., \& White, J. (2008, March). Toward a democratic classroom: A liberatory approach. Paper presented at The Rouge Forum - Education: Reform or Revolution National Conference, Louisville, KY.

Grise-Owens, E., Miller, J., \& White, J. (2007, November). Liberatory pedagogy: A blue-print for teacher-student learning. Paper presented at the Lilly International Conference on College Teaching. Miami University, Oxford, OH.

Grise-Owens, E., Miller, J., \& White, J. (2007, October). Choppin' it up about liberatory learning: Next generation's pedagogical possibilities. Paper presented at the Council on Social Work Education- APM, San Francisco, CA.

Miller, J. (2007, September). Child abuse investigations in Kentucky. Presented to the PCWCP Program, Louisville, KY.

Miller, J. (2007, May). Fostering peer support. Paper presented at the Spalding University Culminating Project Symposium, Louisville, KY.

Grise-Owens, E., Miller, J., \& White, J. (2007, April). Liberatory learning: Give p's a chance. Paper presented at the Kentucky Association of Social Work Educators Spring Conference, Murray, KY.

\section{$\underline{\text { Poster Sessions }}$}

Lewis, J., \& Miller, J. (2012, November). Examining social workers' attitudes towards sex offenders: A social justice imperative. Poster session presented at the 2012 Council on Social Work Education APM, Washington, DC.

Miller, J., Rhema, S., Faul, A., \& D'Ambrosio, J. (2012, November). The promise of social work in coalition development: A pragmatic approach. Poster session presented at the 2012 Council on Social Work Education APM, Washington, DC.

Grise-Owens, E., Owens, L., \& Miller, J. (2011, October). Using a Teaching Philosophy Statement to Promote Practice Competencies for Social Work Educators. Poster session presented at the Council on Social Work Education - APM, Atlanta, GA.

Grise-Owens, E., Platt, P., Miller, J., Owens, L., (2009, April). A new dimension of social work: "Meta-Practice." Poster session presented at the Spalding University Scholarship and Service Learning Day, Louisville, KY.

Miller, J., \& Grise-Owens, E. (2009, April). Teaching learning in a culture of 
consumerism: Perspectives and possibilities. Poster session presented at the Spalding University Scholarship and Service Learning Day, Louisville, KY.

Miller, J., White, J., \& Grise-Owens, E. (2008, April). Liberatory teaching - learning: Student-Teacher perspectives. Poster session presented at the Spalding University Scholarship and Service Learning Day, Louisville, KY.

\section{PROFESSIONAL SERVICE}

- Foster Care Alumni of America - Kentucky (President) - Current

- Kentucky Children's Justice Task Force (Appointed by the Commissioner of the Department for Community Based Services) - Current

- Emerging Workforce Initiative Board Member - Current

- Jefferson County Citizen's Review Panel - Current

- Project Hope Planning Committee - Current

- Jefferson County Foster Care Peer Support Group- (Founder \& Facilitator) 2007-2008

- Louisville Association of Black Social Workers- (Co-Founder, Past President) 2004-2008

- Kappa Alpha Psi Fraternity, Inc. (Community Service Chairperson) - 2004

- Big Brothers/Big Sisters, Inc.- (Community Mentor) - 2008-2009

\section{ORGANIZATION MEMBERSHIPS}

- Foster Care Alumni of America - Kentucky - Current President

- National Association of Social Workers - Current

- Kentucky Association of Social Work Educators - Current

- Council on Social Work Education - Current

- Society for Social Work and Research - Current

- Association of Baccalaureate Social Work Program Directors - Current

- American Academy of Case Management - Current

- Foster Care Alumni of America- Current

\section{MEDIA INTERVIEWS}

- "The Plight of Youth Aging Out of Foster Care" - WAVE 3 News (NBC Affiliate) - Feature Story - March, 2012

- "Training for Foster Parents" - An instructional video produced by the Eastern Kentucky University Training Consortium - February, 2011

- "Supporting Youth in Foster Care" - Kentuckiana Sunrise Morning Show December, 2007 